\title{
Regulating music for a change: \\ Lessons learned from history using an analytic framework
}

by

\author{
Catherine Mary Allison, B.A., B. Music
}

A thesis submitted to the Faculty of Graduate Studies and Research in partial fulfillment of the requirements for the degree of

Master of Arts

School of Journalism and Communication

\author{
Carleton University \\ Ottawa, Ontario \\ September 2008
}

(C) 2008, Catherine M. Allison 


$\begin{array}{ll}\begin{array}{l}\text { Library and } \\ \text { Archives Canada }\end{array} & \begin{array}{l}\text { Bibliothèque et } \\ \text { Archives Canada }\end{array} \\ \begin{array}{l}\text { Published Heritage } \\ \text { Branch }\end{array} & \begin{array}{l}\text { Direction du } \\ \text { Patrimoine de l'édition }\end{array} \\ \begin{array}{l}\text { 395 Wellington Street } \\ \text { Ottawa ON K1A 0N4 } \\ \text { Canada }\end{array} & \begin{array}{l}\text { 395, rue Wellington } \\ \text { Ottawa ON K1A 0N4 } \\ \text { Canada }\end{array}\end{array}$

Your file Votre référence ISBN: 978-0-494-43443-7

Our file Notre référence

ISBN: 978-0-494-43443-7

NOTICE:

The author has granted a nonexclusive license allowing Library and Archives Canada to reproduce, publish, archive, preserve, conserve, communicate to the public by telecommunication or on the Internet, loan, distribute and sell theses worldwide, for commercial or noncommercial purposes, in microform, paper, electronic and/or any other formats.

The author retains copyright ownership and moral rights in this thesis. Neither the thesis nor substantial extracts from it may be printed or otherwise reproduced without the author's permission.
AVIS:

L'auteur a accordé une licence non exclusive permettant à la Bibliothèque et Archives Canada de reproduire, publier, archiver, sauvegarder, conserver, transmettre au public par télécommunication ou par l'Internet, prêter, distribuer et vendre des thèses partout dans le monde, à des fins commerciales ou autres, sur support microforme, papier, électronique et/ou autres formats.

L'auteur conserve la propriété du droit d'auteur et des droits moraux qui protège cette thèse. $\mathrm{Ni}$ la thèse ni des extraits substantiels de celle-ci ne doivent être imprimés ou autrement reproduits sans son autorisation.
In compliance with the Canadian Privacy Act some supporting forms may have been removed from this thesis.

While these forms may be included in the document page count, their removal does not represent any loss of content from the thesis.
Conformément à la loi canadienne sur la protection de la vie privée, quelques formulaires secondaires ont été enlevés de cette thèse.

Bien que ces formulaires aient inclus dans la pagination, il n'y aura aucun contenu manquant.

\section{Canada}




\begin{abstract}
Partly inspired by Attali's notion of the political economy of music and by Foucault's concept of governmentality, the objective of this thesis is to argue that while music is a site of regulatory power, rather than having a repressive or "chilling" effect, regulation is often a catalyst for change. I analyze two examples of music regulation through the use of an analytic framework that helps to classify various forms of control of music. The first study considers the regulation of church music during the Council of Trent in the $16^{\text {th }}$ century. The second study examines the regulation of jazz music in New York City beginning with the 1920 s cabaret laws. The productive effects of intense moments of regulation on musical forms, on musical creators or on methods of distribution or consumption, result in the emergence of new forms of music, new creators and/or new audiences.
\end{abstract}




\section{Acknowledgements}

First, to the Carleton gang: many thanks to my thesis advisor, Professor Sheryl Hamilton, for pulling and pushing my thought processes in many new directions, and for ensuring that what I wrote was a thesis, not a rambling tome. Also thanks to my other committee members, Professor Paul Théberge, for offering his always helpful comments and challenging observations, and Professor Peter Swan, for asking provocative questions at my defense. I am grateful for the laughter and stimulating conversations with my terrific Carleton friends, so a shout-out goes to Sara, Melissa, Lee-Anne, Angela, Kathleen, Tyler and Sheehan. Thank you to Professor Michael Geist at Ottawa U., who, after giving one of his compelling talks on copyright, unwittingly suggested that "something about music and regulation" might be appropriate to pursue as a thesis topic.

My friends Allyson, Alexandra, Janet, Andrie, Nancy, Jo and Marian have been so supportive and helpful as I struggled to deal with the "work-school" balance. Bruce, you got me into this mess in the first place ... thanks a lot! I appreciate Sharon and Michael's constant reminders to follow my dreams. Moishe (RIP), Miss Adelaide and Maxwell, bless you for being non-judgmental, and for always purring on cue. Thanks to you all.

I owe a huge debt to my family for supporting my lifelong learning plan: Laurie, Terry, Allison, and especially my Mom, Carol. The good news is that this part is now over and I know I couldn't have done it without you. Thank you from the bottom of my heart for everything. The bad news, I am sorry to say, is that the lifelong learning plan will continue. I think Dad would have approved.

I am very fortunate to have had two wonderful mentors who influenced this project. They were:

David Neil (1949-2007), a former Gartner Group colleague, who taught me some important lessons about regulation, and encouraged me to keep asking questions until I was satisfied I had found the truth, or something close to it; and

Dr. Patrick Cardy (1953-2005), my composition professor, who taught me to write polyphonic music in the stile antico so that the words could be understood, and encouraged me to continue my academic studies.

I am so grateful for having an opportunity to learn from them. I will always treasure their intellect, wit, insight and candour. Sadly, the time they spent making this world a better place was far too short. Often while working on this project, I yearned to talk with them about my jumbled ideas and scattered thoughts, but their untimely deaths prevented that. I only hope that they have met up and are enjoying a pint together somewhere in the Celestial City, chuckling over my struggles to get this thesis done.

I am dedicating this work to the memory of them both. 


\section{Table of Contents}

\section{Chapter One}

Framing Music Regulation: Actors, Processes and Outcomes

Introduction

Research Questions

Conceptualizing regulation

Theoretical Framework

Literature Review

Political economy of music

Censorship by governments or institutions

Moral regulation of music

Artistic regulation of music

Regulation of music as noise

Economic regulation of music through technology or legislation - or both Research Methodology

Constructing an analytic framework for music regulation

Chapter Review

Conclusion

\section{Chapter Two}

\section{Regulating 16th century church music: The Tridentine KISS principle}

Historical Context

The Council of Trent begins

The Decision is rendered $\quad 44$

Testing the New Policy 48

The Conduct of conduct $\quad 50$

What about Trent "Regulatees"?

External influences on musicians related to the Council 52

Nice work - if you can get it $\quad 53$

Global rules, local execution $\quad 54$

Palestrina: an enterprising composer $\quad 55$

The Band of Brothers $\quad 57$

Summary: the role of various actors as key elements in the process of regulation 59

Musical Outcomes from Tridentine regulation $\quad 61$

Focus on the words $\quad 62$

Decentralized execution of regulation in local jurisdictions by the clergy 63

The care and feeding of musicians: training and education in the "new style" 65

The Venetian/Northern Italian influence on sacred music 67

$\begin{array}{ll}\text { Re-writing the music books } & 68\end{array}$

From polyphony to monody; from spiritual madrigal to concert mass $\quad 69$

$\begin{array}{ll}\text { Instrumental music is heard in church } & 70\end{array}$ 
The sound of music changes: harmony and the standardization of modes $\quad 72$

$\begin{array}{ll}\text { Technological advancements in light of new harmonies } & 73\end{array}$

Productive outcomes of regulation on musical forms $\quad 73$

$\begin{array}{ll}\text { Conclusion: Guidelines for Change } & 74\end{array}$

\section{Chapter Three}

"Putting the Sin in Syncopation": New York City Cabaret Laws, 1926-1986 77

$\begin{array}{ll}\text { Historical Context } & 78\end{array}$

The Actors and their techniques $\quad 80$

Moral regulation of jazz through the lens of the press 83

Moral panic in New York City: jazz as a "folk devil"

Economic regulation of jazz begins, while moral regulation continues $\quad 89$

$\begin{array}{ll}\text { Institutional regulation of jazz venues } & 92\end{array}$

Heaping on the regulations: carding and zoning $\quad 94$

The Musicians' Union: hurtful, not helpful $\quad 98$

$\begin{array}{lr}\text { The dissolution of institutional regulation } & 102\end{array}$

Outcomes: The Effects of New York City Cabaret Laws on Jazz Music 104

Harlem Renaissance and the diversification of jazz: effects of regulating $\begin{array}{ll}\text { the place of jazz } & 105\end{array}$

$\begin{array}{ll}\text { The benefits of economic regulation } & 107\end{array}$

Productive outcomes of regulation on musicians, formats, and musical venues

108

Outcome of the Union's regulatory actions on jazz 110

Conclusion: Regulation transformed jazz, and jazz transformed society 113

\section{Chapter Four}

Observations and Lessons Learned from Policing Music 117

$\begin{array}{ll}\text { Music is not just content } & 119\end{array}$

Conclusion: Has regulation had a productive effect on musical creativity? $\quad 127$

\section{Endnotes}

\section{List of Appendices}

1. An analytic framework for music regulation 138

2. Situating the Council of Trent case study in the framework 139

3. Situating the New York City cabaret laws case study in the framework $\quad 140$

4. Situating other music examples in the framework 142 


\section{Chapter One}

\section{Framing Music Regulation: Actors, Processes and Outcomes}

"In noise can be read the codes of life, the relations among men. Clamor, Melody, Dissonance, Harmony; when it is fashioned by man with specific tools ... when it becomes sound, noise is the source of purpose and power, of the dream-Music. It is at the heart of ... aesthetics; ... it is a means of power and a form of entertainment."

-- Jacques Attali, Noise: The Political Economy of Music $(1977,6)$.

\section{Introduction}

Piracy. Downloading. MP3. Digital locks. DCMA. Peer-to-peer. Copyright. Anticircumvention. WIPO. The Labels. Bill C-61. Shifting. Napster. Streaming. Lawsuits. Mash-ups. DRM. Online business models. BitTorrent. Sampling. The indies. The Long Tail. Digitalization. Social networking. Sony Rootkit. Paradigm shift. CRIA. Digital media. iPod. Filesharing. These are terms used when the subject of music comes up today. Most did not exist ten years ago. They do not describe music in any way. They speak of the regulatory pandemonium now taking place in the music industry. In the panic to make sense of this uproar, we have forgotten to consider the music. This thesis is not about the buzz words, but about the historicism of music regulation.

Since Napster appeared on the music scene in 1999, there have been relentless debates about how, and to what end, outdated copyright regimes have led to the development of technological protection measures that restrict the production, distribution and consumption of music. In board rooms, chat rooms and class rooms, the abundance of rhetoric about copyright in music has been overwhelming (Hemmungs Wirtén, 2006). The above neologisms relate to the control of music through copyright, creating a mighty buzz about restrictions, blocking and ownership. This noisy discourse has obscured discussions about music itself. Moreover, little analysis exists that describes 
the constraints placed on or exerted by music itself over a wider history of the regulation of this art form.

Since the beginning of recorded history, music has existed as a key mode of communication. Because of music's ability to influence individual and group behaviour, and because it can create social structure as well as conflict, throughout history, many have sought to control it. The combination of technological constraints, copyright (read as a legal form of control) and music have enjoyed major attention in current academic and popular discourse, becoming the "hot topic of the moment" (Frith 2004a, 209). However, I argue that attempts to control the production, distribution or consumption of music by applying copyright regimes through the use of technology are modern examples of control located in a larger regulatory framework that has existed since ancient societies first placed value on music. ${ }^{1}$ Early philosophies of music upheld the view that music possessed value in a form that Pierre Bourdieu has termed "cultural capital" $(1984,114)$. Music has therefore long wielded power which societies have attempted to harness, leading to tension between music's use value and mass behavioural control.

My argument is partly inspired by Jacques Attali, a French philosopher, scholar, economist and advisor to the French government. ${ }^{2}$ His book, Noise: The Political Economy of Music (1977/1985 Eng. translation) provides a prophetic observation about the relationship between music and regulation. Although Noise was written well before Napster's appearance, Attali notes that "[music] has remained a tool of regulatory power, a fundamental form of the code of power functioning through new channels" $(1977,36)$. With respect to the economic value placed on music, Attali writes, "Music has 
maintained a strange, ambiguous and prophetic relationship with money" $(2000),{ }^{3}$ but like Bourdieu, Attali also notes the essential value of music in terms of cultural capital:

Music, as a mirror of society, calls this truism to our attention: society is much more than economistic categories, Marxist or otherwise, would have us believe. Music is more than an object of study: it is a way of perceiving the world [and is] a tool of understanding $(1977,4)$.

I suggest that the relentless discourse about the effects of the Internet, digitalization and unresolved copyright reform on music today have overshadowed the productive results of regulatory measures imposed on music. This criticism has suppressed discussion of the unintended consequences and by-products resulting from the influence of regulation. We fail to see these effects as inevitable outcomes of regulation, or we view them as surprising results, because we have neglected to consider that humankind has systematically controlled music since ancient times. Recent technological advances that have been able to restrict music are new, but Attali suggests that music has been consistently regulated for at least twenty-five centuries (1977, 3). After considering musical events occurring in the distant and more recent past, the similarities and differences suggest to me the ability to form an overall structure through which music regulation can be more systematically approached. Analyzing two significant historical examples using this framework provides further insight into the nature and effects of regulation. Today's hotly debated digital copyright regime falls neatly into the overall structure of control - but it is not the only system of regulation that exists, and it is certainly not a unique instance of regulation in the history of music.

The objective of this thesis is to argue that while music has become a site of regulatory power, rather than having a necessarily repressive or "chilling" effect, regulation is often a catalyst for producing creative results. Specifically, I suggest that the 
effects of specific moments of regulation on musical genres, on musicians or on methods of distribution or consumption, often result in the emergence of new styles, new creators and new audiences via new distribution channels. Using an analytic framework to examine music regulation provides a lens through which to explore how previous instances of legal, economic, political and social restrictions have had a productive effect on music. These lessons from history can help to re-contextualize and re-evaluate current regimes of control over music, such as technological restrictions that impose forms of digital copyright. Using this mechanism to interpret specific moments of musical history, I will show that there are unintended consequences and unforeseen outcomes in rethinking the relationships amongst music, creativity, power and control.

\section{Research Questions}

The main question that frames my thesis is, "In what ways does regulation act as a productive force or otherwise exert influence on music itself?" Other questions that help to clarify my argument include:

- Of the actors involved in regulating music, how does one entity or group rather than another position itself to develop and then impose regulations?

- What do the similarities between these actors tell us in terms of their motivations and strategies, as well as their success or failure to maintain regulatory power?

- What has been the response towards regulation (for example, resistance, compliance, adaptation, or innovation) in other historical events, and how do these reactions compare to recent forms of music regulation?

\section{Conceptualizing regulation}

On a prima facie basis, "regulation" tends to have a negative connotation. According to the $\mathrm{OED},{ }^{4}$ to regulate means "to control, decree, govern, restrict, guide or 
direct by rules, or to adapt to circumstances or surroundings", but can also mean "to bring or reduce something or someone to order; to correct by control; or to adjust, through time, quantity, or force, with reference to some standard or purpose". In familiar speech, regulation is thought of as the imposition of rules by a group or entity, on some other group or entity, to return order to a situation or to control behaviour. The existence of a regulator presupposes that there will be enforcement or "policy-ing" of the rules, guiding principles, or beliefs, to ensure the desired result. In other words, by imposing regulation, there are consequences - either expected or unintended - that we might otherwise describe as productive outcomes. Kenneth Thompson notes that while regulation can imply "government", or "a policy", it can also signify "struggles over meanings, values, forms of subjectivity and identity" $(1997,3)$.

A familiar form of regulation is the economic sort occurring in various industries including telecommunications, broadcasting, electricity, transportation and finance, as a reaction to either a scarcity or an overabundance of a resource or commodity. Methods of regulation also exist in the cultural industries, for example in publishing, theatre, radio, television and film. It is more difficult to imagine how music - an amorphous, invisible, ubiquitous cultural art form, able to be momentarily present or absent, which communicates expression, enjoyment, entertainment, leisure, and pleasure, that is universally recognizable and accessible to anyone who can hear - can be controlled. ${ }^{5}$ However, we know that it is controlled, and its intrinsic value requires safeguarding today, it has become a household object of cultural regulation.

Thompson has noted that early sociologists placed cultural forms on an equal footing with economic and other structures. An early modern view of cultural regulation 
was the political economy of culture provided by Karl Marx, who observed that there was a relationship between economy and culture in every historical period, stating that "unless material production itself is understood in its specific historical form, it is impossible to grasp the characteristics of the intellectual production which corresponds to it, or the reciprocal action between the two" (Marx 1859/1973, 67). Following Marx, in his late 1920s essay, "Americanism and Fordism" (1929/1971), Antonio Gramsci theorized that economic production was linked to cultural consumption, using the example that mass production allowed the Ford Motor Company to pay higher wages, thus permitting the working class to enjoy the consumption of culture. Gramsci's theory of hegemony suggested that cultural regulation was promoted through ideological leadership $(1971,410)$. Beyond Marx and Gramsci, several theories of regulation evolved that can be applied to culture and thus to music. Those most pertinent to my thesis follow.

\section{Theoretical Framework}

There are three sources on which I draw for my analysis of music regulation. They are Foucault's theory of governmentality and his challenge of the belief that power resides with government, sovereignty and discipline, along with his theory of carceral networks, read as systems of power (institutional, economic and subjective); Attali's theory of the political economy of music; and the French Regulation School's theories of "Regimes of Accumulation" (ROA) and "Modes of Regulation" (MOR), which I will describe later in the discussion of the methodology used to develop an analytic framework for music regulation.

Foucault's theoretical contribution to my thesis is two-fold. First, his theory of government explains that there are systems of power in society - webs of control that 
empower and regulate behaviour - of which there are three types: state government, or institutional; economic; and self-government, or moral $(1991,91)$. These three categories are in lockstep with the framework I have envisioned for music regulation, serving as the main types, or "modes" of regulation. Foucault challenges a particular notion of power (power-as-sovereignty, or "absolute" power), suggesting that since the concept of power has changed throughout history, instead it should be viewed as a system of surveillance and discipline (1977). I read this view of power as a form of regulation, since it "presupposes a tightly knit grid of material coercions rather than the physical existence of a sovereign ... This non-sovereign power, which lies outside the form of sovereignty, is disciplinary power" (Foucault 1980,78). This view is a "challenge to the belief that power begins and ends with the state" (Boyle 1997, 205). Foucault's theory therefore suggests that there are other forms of regulation than those imposed by the state, institutions, or governments.

Foucault also contributes to my project with his notion of "governmentality" (the connection of government and thought, a contraction of the words government and rationality) as the "conduct of conduct" $(1991,87){ }^{6}$ Similar to his view of power, this notion is not necessarily related to a nation-state, nor is Foucault's view of regulation always about hard-nosed enforcement. Instead, governmentality provides an opportunity for those who hold institutional power to merely issue a reprimand, act in an advisory capacity, or simply to provide guidance. Foucault suggests that there is an evolution from strong to weak regulation and thus a traceable course of development from institutional and economic power towards self-regulation and self-discipline $(1991,102)$. 
Foucault's writing on governmentality has initiated rich discussions related to the development of policies on cultural regulation, read as a form of governance, enacted through surveillance and guidance $(1991,89)$. While this extensive body of literature does not specifically address music, it does provide a backdrop for larger debates involving culture and governmental policies. Commentators including Tony Bennett, Jack Bratich, Mitchell Dean, Ian Hunter and Jonathan Sterne have acknowledged that Foucault's influences on cultural studies have been numerous and far-reaching (Bratich 2003, 3-4). Bratich suggests that Bennett's 1992 essay, "Putting Policy into Cultural Studies" spawned early debates around the issues of culture and governance as seen through Foucault's lens, while Hunter (1991) framed culture and Foucault's notion of governing by problematizing cultural studies' critique of aesthetics. Michael Dorland discusses the "policing" of culture by calling to mind Foucauldian theories of governmentality and invoking cultural policy in society through regulation:

As Foucault puts it, 'police [a form of governmentality] oversees everything that regulates society ... It is life itself that is the object of police: in whatever is indispensable, useful, and superfluous" . .. and, in an orderly "police state, the realm of the cultural [is] inherently a seminal dimension of the ... technologies of 'good government' ... the nature of regulation [is] prescriptive, not legalistic (Dorland 2000, 146).

Dorland's interpretation of Foucault's governmentality, achieved by policing ("policy"-ing) culture, is echoed by Kevin Dowler's use of Foucault to discuss techniques of governmental administration of culture, suggesting that Foucault's ideas form the basis of policy $(1996,336)$ and that these tactics are used by semi-autonomous cultural agencies to establish a form of governmentality that creates "conditions of self-regulation ... operating as forms of both discipline and surveillance" $(1996,339)$. My reading of Dorland suggests a vision of regulator-actors as the "music police", although this group 
may not always conduct itself in as strictly forbidding a manner as the name might imply. Yet another commentator interprets Foucault's notion of governmentality as the “"conduct of conduct' [which] entails the idea that the one governed is ... in some rudimentary sense, an actor, and therefore a locus of freedom" (Dean 1999, 13). Dean suggests that in Foucault's concept of governmentality, the actor-regulators take on paramount importance in understanding and acting on concepts of power and control: "The notion of government as the 'conduct of conduct' presupposes the primary freedom of those who are governed [through] ... acting and thinking. It also presupposes this freedom and these capacities on the part of those who govern" $(1999,15)$. Analyzing the actors' conduct within a specific mode of music regulation, whether institutional, economic or social, and studying the techniques and processes they use, will help to shape my project and uncover possible answers to my thesis question.

Finally, Attali's work is invaluable to my project, for while he does not offer a specific theory or a framework for music regulation, he suggests that music signifies power and social change by supporting the value of observing historical cycles of music, and articulates the need to develop a structure that anticipates what may come next. Reading Attali is reminiscent of how Foucault might interpret music and this made me think that developing a framework for music regulation could be useful in putting recent events in the music industry into perspective. In the "Foreword" to Noise, Frederic Jameson notes that the significance and originality of Attali's work is its contribution to "a general revival of history, and of a renewed appetite for historiography" and its suggestion of "the possibility of a superstructure to anticipate historical developments, to foreshadow new social formations in a prophetic and annunciatory way" (1985, xi). Attali 
suggests that music exhibits a "prophetic" quality, in that within any particular time period, music has the power to predict and enact social transformation $(1985,11)$. At first glance, this may seem hyperbolic, and some critics such as Douglas Collins doubt this claim, suggesting that Attali's work is too dependent on Theodor Adorno's view of the political economy of culture, too imitative of Foucault's epistemés, and reeks of French “intellocrat-ism" (Collins 1985, 16). Despite Attali's detractors, his observation is an intriguing idea that I wish to explore further, since it suggests there is more we can learn about regulation and resistance in music than simply taking today's "hot topics" downloading, mash-ups, piracy, digital rights management, shifting, shuffling, sampling, copyright - at face value.

\section{Literature Review}

A review of the literature specifically dealing with music and regulation is rich but relatively compartmentalized. There are contributions from the fields of music history, communications, sociology, economy, law, politics and technology. Some analysis is combinatory (the "political economy" of music). There is abundant analysis of music censorship by governments or religious institutions. There are studies about how music is controlled via self-regulation or through moral regulation. Literature exists that explains how music is regulated artistically. Another aspect of the discussion describes how music, interpreted as a noise disturbance, is regulated. More recently, there has been a profusion of literature about music regulation related to how access is technologically controlled using copyright to defend various forms of ownership. My analysis of music regulation differs from these previous studies by studying the relationships between compartments of a holistic system, rather than analyzing one aspect of music regulation 
at a time. Instead, I view the compartments as part of a grid that provides a regulatory framework for music. I will describe the grid later in this chapter, but first I will briefly review the existing literature for each of the major compartments.

\section{Political economy of music}

Early awareness of controls over music through commercial means can be found in Theodor Adorno's writing on music in the 1930s. Adorno was specifically concerned about the commodification of music (particularly popular music, which at the time was mainly jazz), and raised issues with respect to the effects of economic control on music's cultural quality. Adorno was not opposed to popular music, but rather to its ruthless exploitation by the burgeoning commercial music industry. At the heart of his critique was a condemnation of what he termed the "pseudo-individualism" of music: the dangerous direction that popular music was taking towards banality, with its easy-toconsume standardization through rationalized production, promotion and distribution (1941, 444-445) and the obligatory "hook", or unique musical gimmick distinguishable in each hit song $(1941,447)$. These concerns were reconfirmed in Adorno and Max Horkheimer's writings about "The Culture Industry", in The Dialectics of Enlightenment (1944). Their famous essay focused on culture as an economic entity, acknowledging that there were (and, prophetically, there still are) hegemonic forces of control over cultural forms, and discussed the negative effects that hegemonic corporations had on the production of culture. Adorno's account of the political importance of music thus represents a view of "the disruptive power of sound itself" (Street 2007, 329) and provides a way of explaining how music functions in systems of adherence and resistance (Street, 330). 
Attali also discusses the problems with mass-cultural production of music in a manner reminiscent of Adorno's views of "mass-deception" of the culture industry. However, Attali studies music by "tracing the political economy of music as a succession of orders" $(1977,19)$ in terms of four historical stages. Reminiscent of Foucault's epistemés, these stages evolve, develop and morph from one to the next. First is "sacrifice" (Middle Ages to the end of $17^{\text {th }}$ century); next, "representation" (which lasted all of the $18^{\text {th }}$ and most of the $19^{\text {th }}$ century); then "repetition" (from the end of the $19^{\text {th }}$ century to just before the present); and finally, "composition" (which is the current stage - music as a free, autonomous activity, decentralized and uncensored). In Noise, Attali predicts that this last stage highlights music's ability to transform societal power.

Besides Attali, others have noted the relationship between music and order, often viewed as a form of governmentality. An early observation made in the $6^{\text {th }}$ century $\mathrm{BC}$ by Confucius connected physical laws governing music with government: "the music of a peaceful and prosperous country is quiet and joyous, and the government is orderly; the music of a country in turmoil shows dissatisfaction and anger, and the government is chaotic" (Confucius, in Berg, 5). Two hundred years later in his Republic, Plato credits the philosopher Damon with the statement that "music was so important to the governing of society that musical styles could not be changed without changes also occurring in the laws of the state" (Plato, 360 BC, Book 4). The composer Igor Stravinsky observed that order and discipline are necessary elements of music, and that music is "the contrary of chaos. It never gives itself up to chaos without immediately finding ... its very existence threatened." (Stravinsky 1947, 21). More recent notions of governmentality discussed in the academic literature include the role that government agencies such as the $\mathrm{CRTC}^{7}$ play 
with respect to preserving a nationalistic perspective of culture by regulating content (Raboy, 2006), for example, by specifying the minimum percentage of music that must include Canadian content broadcast over radio. ${ }^{8}$ Will Straw (1996), Simon Frith (1996, 1993), Martin Breen (1992), and Dick Hebdige (1987) have suggested that governmental regulation of this sort is needed to protect a nation's cultural capital and to help maintain regional identities, especially in performances of popular music and indigenous folk music. Jody Berland takes a less complimentary view of Canadian content quotas, suggesting that while "government agencies defend 'Canadian culture' by means of protective regulation such as quotas for broadcasters, ... the bond between music and listeners is metonymically linked to government cultural policy ... attitudes toward this bond cannot escape association with such intervention" (1998, 136-7).

The theories and views describing the cultural-economic debates in the music industry that are frequently called forth today centre on the technological control of music by large commercial conglomerates and the effect on both creators and audience. However, there are other means of regulating music that have been used in the past which remain in use today. These should also be considered, both separately and as interdependent elements, in the discussion of a system of music regulation.

\section{Censorship by governments or institutions}

A large body of literature covers this aspect of musical control, owing to the fact that music has become a site for social commentary and a mechanism to easily communicate social causes. An emerging centre of concentration for music censorship debates is the Freemuse ${ }^{9}$ organization. Founder Martin Cloonan suggests that while censorship is definitely a form of regulation, the relationship between the two is "a more 
complex matter than might immediately be thought ... [with] some grey areas" $(2004,3)$. He argues that censorship can be further sub-divided into levels that include "the silencing of free expression before publication; ... restriction; ... and suppression" (2004, 5), and that within these levels, there are many different actors and situations at play. Cloonan distinguishes between "agencies of censorship", actors that include governments, private corporations and pressure groups.

Forms of politicized music censorship have attracted considerable scholarly attention. The ability of certain styles of music (for example, atonal music, or jazz) to hold meaning and thus signify calls to society for rebellion or anarchy has generated much discussion about how (and whether) governments have intervened in restricting or prohibiting specific aesthetic styles. For example, John Street (2003) submits that "from attempts by the Stalinist regime to ban the saxophone from the Soviet Union in the 1920s, to the persecution of 'swing youth' in Nazi Germany, music and its fans have incurred political persecution", including those under the Taliban regime, where all forms of music were banned throughout Afghanistan $(2003,117)$. Frederick Starr notes that in both the USSR and Germany, jazz music was dismissed as the 'whining instruments so insulting to the soul', and those who danced to the prohibited "decadent Jewish" and "degenerate" music of jazz giants such as Benny Goodman and Louis Armstrong were viewed with scorn $(1983,175-6)$. Michael Kater's comprehensive study of jazz in the culture of Nazi Germany describes how jazz was completely banned in Nazi Germany from 1933 until the fall of the Third Reich (Kater, 1992). Erik Levi notes that "although censorship of the arts was outlawed during the Weimar Republic, modernist composers were subjected to a constant stream of vitriolic criticism from reactionary sections of the 
German music establishment" $(2004,63)$. An explanation of how and why the music of Shostakovich in Stalinist Russia was censored and the outcome of that censorship is particularly well-studied (Brooke, 2002; Fay, 2000; Ho, 1998; Krebs, 1970; Mitchell, 2004, Norris, 1982; Wilson, 1994).

Literature exists that addresses both political and aesthetic motivation for censorship, in that music has been censored either because it was associated with rebellion, or it was composed in a style so noticeably different from previous traditions that it became a form of rebellion against a government or a regime. Muff Andersson provides an example of music censorship based on the words used in popular songs by studying the South African Broadcasting Corporation, which, under apartheid, operated a system of censorship that involved scratching records to ruin them, ensuring they could never be played on the radio again (1981). In addition to numerous studies of political censorship of South African music, there are countless stories of popular and folk music censorship occurring in countries including Burma, Lebanon, Palestine, Mexico and America, as detailed by Marie Korpe (2004). Eric Nuzum notes that in the U.S., the popular country and western group, the Dixie Chicks, provides an interesting object of censorship study, not because of the lyrics in their songs or musical styles, but due to a particularly sensitive political comment uttered at a strategic moment in U.S. history by one of its members. ${ }^{10}$ As a result, the Chicks faced censorship by radio stations and were ghettoized by the music industry, but eventually turned much of the American public into adoring fans (Nuzum 2004, 156). ${ }^{11}$ As Street notes, "The potential of music to promote approved causes is linked to its potential to fuel rebellion" $(2003,117)$. 
In summary, censorship achieves control by suppressing information, including messages carried through music, in order to influence the amount of available knowledge, which in turn affects the way an individual thinks or acts. While some examples of music censorship can be viewed as a form of behavioural regulation, they are not indicative of controls imposed by social norms but rather are forms of constraint imposed on the public, usually by authoritarian governments or dictatorial political leaders. State regulation, on the other hand, achieves control by rules, principles or exertion of authority in democratic societies, in order to meet its main objective of protection.

\section{Moral regulation of music}

The imposition of a regulatory regime is not always legislatively based. Another body of literature that informs my project consists of debates around the moral regulation of music, enforced through social norms. For example, Stanley Cohen's study of moral panics based on 1960 s gang fighting and his theories about what constitutes deviant behaviour $(1972,28)$, help to explain the reasons behind the moral regulation of music by concerned parents over violent or lewd lyrics in rock music. After Cohen, there is a body of work (Binder 1993; Dotter 1994; Freeman, 2006; Frith 1981; Jones 1991; McDonald 1988) that provides analysis of the moral regulation of music which focuses mainly on the content of, and on audience reaction to the lyrics of popular music, instead of the actual music itself. Conversely, of the latter, Dick Hebdige (1987) has suggested that social ideas can be coded into musical aesthetic information, and thus can take on meanings (regardless of the lyrics) that might then be open to censorship or regulation. John Lynxweiler (2000) provides examples of the moral regulation of "deviant" music by social movement organizations and "moral entrepreneurs" (organizations representing 
parental, conservative religious, and feminist concerns for child-victims) who advocate and continue to encourage the control of access to heavy metal and rap music $(2000,63)$. Ulla Carlsson notes that some messages in music lyrics are considered offensive (they can promote violence, or are homophobic, or promote drug or alcohol use, or encourage sexuality in young people) and are considered particularly damaging for children and ethnic minority audiences $(2006,14)$. These examples show that music regulation is not always imposed by government via legal sanctions, but can be enforced by a community of like-minded individuals possessing a collective belief of what is proper or correct.

\section{Artistic regulation of music}

A belief system around music that is considered morally correct is different than one that is concerned with aesthetics. Literature describing artistic regulation is often based on perceptions of taste: either that certain types of music are "better" than others and therefore ought to be heard or shared, or that music should simply be rejected because it is considered just plain "bad"; that is, some music is considered to be so unpleasant, inauthentic, inappropriate, ridiculous, or overused, that it is dismissed as not worthy of listening to. Plato was the first to comment on "good" or "bad" musical modes, suggesting that music performed in a particular mode would cause the listeners to exhibit specific behaviours associated with that mode. ${ }^{12}$ Studies exist detailing the nuances of "bad" musicians (Washburne, 2004), "tasteless" musical genres (Fox, 2004; Adorno, 1941/2002) and "trivial" music (Hanslick 1891/1986; Dahlhaus, 1967/2004).

Whether music is judged to be "bad", or whether it is believed to have merit, Frith (2004b) believes that this form of regulation is an "egocentric aesthetic (' $\mathrm{I}$ ' is the most common word in all forms of music criticism), driven by a passionate desire to make 
other people listen differently" (2004b, 34). The operative word here is "make": Frith notes that regulation is enacted through (usually) friendly persuasion, and is thus a form of social regulation. Whether music is in good taste or not is a theoretical notion explained by Bourdieu (1984) who submits that musical preferences are organized using a complex web of social and institutional relations called "habitus", where musical taste represents characteristics that are inbred in a social class, rather than taste being a form of personal choice. Mike McGuire (2005) suggests that social networking websites which offer recommendation tools are increasingly used to persuade others to try out music they favour, even arguing that taste-sharing is essentially driving the online music business. To be sure, the aesthetic regulation of music today is subjective and rarely results in an indictment, but it can have a profound effect on a musician's popularity, sense of pride and future career prospects. Likewise, the literature on this aspect of regulation suggests that listeners' musical choices can be judged by others, demonstrating that audiences can also be controlled through artistic means.

\section{Regulation of music as noise}

There is a niche of academic discussion that deals with music regulation from the standpoint of noise regulation, including where music should and should not be performed. Attali notes that before the industrial revolution, no laws existed to suppress noise or commotion and that "the right to make noise was a natural right" $(1985,123)$. Emily Cockayne (2002) notes that societies through the ages have taken part in creating and upholding music-as-noise regulation, for example, in communities or neighbourhoods that request quiet after a certain hour. ${ }^{13}$ Her analysis shows that early music regulation from the mid- $16^{\text {th }}$ century stemmed not from a desire to prevent noise or 
bad music, but to enforce crowd control: "Where they existed, civic regulations to limit poor music were motivated not by a desire to preserve the reputation of music; the preeminent concern amongst the authorities was to limit the assembly of crowds by such ad hoc performances," but later, "the focus was more upon a lack or loss of talent, the use of poor quality instruments, or music performed at an inappropriate time" $(2002,36)$.

Cockayne suggests that music regulation of this sort grew from noise regulation to ... unfavourable reactions to particular musicians -- music that was out of place, time or tune. 'Noise' was used to describe sounds that were musical or unmusical, pleasant or unpleasant, and could also be applied to quarrelling, strife or the spreading of rumours. Indeed, 'noise' was often regarded as being synonymous with 'sound' $(2002,36)$.

Cockayne suggests a migration from one system of regulation (noise as it relates to the place of performance) to another (aesthetic). In terms of regulation of the "place of music", Andrew Leyshon notes that music is central to festivals, fairs, raves and protests, but through "spatial politics ... police and state seek to monitor and regulate" the music that permeates throughout these spaces: music "forms part of environment's 'moral geography', whereby certain forms of conduct belong and others do not" $(1998,23)$.

We find from these discussions that regulation of the place or practice of music is commonly connected to the control of noise. Today that control is generally linked to official enforcement by the state, although this form of regulation can be tempered or even lifted during certain rituals, when even artistic regulation of music is disregarded: consider whistles and noisemakers heard on New Year's Eve, horns sounding at a hockey game when a goal is scored, or bells that announce an event or warn of danger. 
Economic regulation of music through technology or legislation - or both

Commercial control of music has attracted an abundance of literature which focuses on highlighting problems caused by the impact of new technologies or by the imposition of copyright, or a combination of these two regimes. These studies often address the tension between new technologies and outdated copyright regimes and how that interplay has caused music to become very difficult for consumers to access.

Literature exists that discusses the complications of technology in arguments of authorship in music (Coombe 1998; McLeod 2001; Frith 2002; Hemmungs Wirtén 2004). Comprehensive studies detail the impacts of technology on musical creativity (Théberge 1997 and 2004; Katz, 2004; Demers 2006). There are many impassioned debates on the difficulties of distribution and/or consumption of music through technology, often mentioning restrictive copyright legislation (Taylor 2002; Jones 2002; Lessig 2004; Leyshon 2005). There are also many views on the political economy of the Internet as a form of technology used to distribute music, and on how the Internet itself is regulated (Boyle 1997; Lessig 1999; Kretschmer 2001; Meisel 2002; Murray and Scott 2002).

Since the appearance of Napster in 1999, much has been written on forms of economic or corporate control as a site of regulation for music, mainly due to the Internet's ability to bypass copyright (Bettig 1996 and 2003; Litman 2001; Vaidhyanathan 2001 and 2004; Lessig 2006). These authors argue that less stringent copyright is needed, while John Lovering suggests that "the music industry is profoundly dependent on public systems of regulation" $(1998,34)$ and analyzes the deficiencies in legal forms of regulation, specifically copyright laws, which are responsible for producing much of the income the music industry depends on via royalties. Other 
commentators also empathize with the music industry, claiming their revenue sources are slowly eroding due to downloading, and warn of the resultant impending market failure. Samuel Trosow (2003) explains the need for regulatory controls when there has been some form of market failure. He notes that certain types of market failure or imperfections arise that often require governmental action (which the music industry has been pleading for more of), though the scope and degree of the role of government varies considerably from country to country. Trosow suggests the need for a high level of government involvement especially in the music copyright debates, yet notes the inefficiency of this intervention to date for the large music industry actors, particularly in Canada. Conversely, Martin Scherzinger suggests that economic regulation of music through corporate control must be continually questioned:

While consumption involves a degree of subjective agency (liberated from the dictates of church, state, and so on), a focus on consumption alone as the site of agency must be contested lest the increasing centralization of control in the arena of production triumphantly compels consumers to hear the "right" messages (2005, 63-64).

Gilbert Rodman and Cheyanne Vanderdonkt (2006) agree that the filesharing debates have become "too" economic, insofar as they reduce a complex phenomenon to a single issue: financial loss to the labels resulting from the theft of intellectual property by filesharers who can bypass copyright restrictions. They counter-argue that filesharing debates are frequently not economic enough, since they evade the financial complexities of the music business in favor of an overly simplistic equation: downloaded music equals lost sales revenues. Their analysis shows that the industry has been unsuccessful in making either economic claims about the negative effects of filesharing on sales or moral claims about protecting helpless musicians from the downloading pirates. 
Keith Acheson and Christopher Maule (1999) provide an analysis of regulation through entities that impose copyright regulations on music through collecting tariffs, such as music performing rights societies (for example, $\operatorname{SOCAN}^{14}$ in Canada). They also note the actions of telecommunications service providers and their ISP businesses, which transport music (sometimes offering it as a packaged service), and control music access through the imposition of fees for that carriage. Acheson and Maule point out yet another form of regulation: that of denial of access due to copyright, through international copyright standards-setting activities for music distribution, requiring adherence to treaties set out by world trade organizations. David Johnson (1996) notes that in the early Internet years, actors such as government policy developers believed that cyberspace was unregulatable, due to transnational issues of jurisdiction. However, since music can now resides in cyberspace with a virtual border that is activated whenever a computer boots up and connects to the Internet, Johnson notes that the chain of legal events which is triggered is now governed by international communications bodies through copyright regulations. While Johnson suggests that cyberspace needs to be regulated by some international body, Boyle offers the view that this may prove to be difficult, stating that "if we are to have some alternatives to the jurisprudence of digital libertarianism, we will have to offer a richer picture of Internet politics than that of the coercive (but impotent) state and the neutral and facilitative technology" $(1997,205)$.

In researching regulation theories, I have discovered that the balance of the analysis focuses on economic scenarios rather than cultural ones. After 1999, there is an explosion of discussion around regulatory mechanisms affecting music, thanks to the emergence of Napster, which provided a backdrop for legal and social commentary for 
and against the economic regulation of musical formats using intellectual property regimes. Much of the literature addresses technology protection measures and the negative impact that the music industry's desire for restricting the consumption of music has had on the music industry, creators, and consumers. Musicology texts frequently identify moments throughout Western music history where there has been a marked change in aesthetic style, but these are rarely identified as productive outcomes of regulation. If mentioned at all in these events, regulation is but one of many pressures brought to bear, and is usually raised as an afterthought, with references to forms of state censorship or nationalism, or openly associated with political interference. Moreover, frequently it is not the music itself, but the accompanying words which are the subject of scrutiny. Numerous blogs, podcasts, and frequent industry and academic conferences have fed the discussion around technological and governmental regulation, and serve as jumping-off points for current popular press, media and news reports about regulation, censorship and control in the music industry.

\section{Research Methodology}

After analyzing these sources, I found little research that drew comparisons between the difficulties experienced by today's music industry and earlier historical accounts of similar attempts to limit or control production, distribution or consumption of music. As a result, there is incomplete analysis around what possible guiding principles could be drawn from past regulatory events involving music. This could shed new light on current issues, and might allow us to peer, albeit fleetingly, into the future of the music industry. It seems possible that by analyzing certain disruptive moments in music history, some patterns and similarities might be uncovered. Unquestionably, disruptive 
forces to music cannot always be linked to regulatory events. However, where regulation has played a prominent role, there are discernible changes in music. Comparing the findings from some historical moments against more recent regulatory events may help to answer my thesis questions. Organizing these moments using an analytic framework could assist in clarifying the structure of past and present regulatory controls on music, based on theories suggested by the French Regulation School involving modes and regimes of regulation, as well as theories proposed by Foucault, Attali, Lawrence Lessig, and others.

The French Regulation School's theories provide a sound basis for building a framework that describes the structure of music regulation. ${ }^{15}$ This body of thought ${ }^{16}$ was inspired by the "Marxian tradition of critiquing neo-classical economics and Fordism" (Mosco 1996, 58). Its theoretical construct closely parallels Marx's characterization of historical change, driven by contradictions between the forces and relations of production. The French School's focus is on economic regulatory issues driven by consumption and involves two inter-related concepts: Regimes of Accumulation (ROA) and Modes of Regulation (MOR). ROAs are particular approaches or sites whereby capital organizes and expands for a period of time with some degree of stability. ${ }^{17}$ MORs are constructs of law, customs, policies or institutional practices that put context around ROAs. The intersection of MORs with ROAs constitutes a network of relationships. The structure of French regulation theory provides a useful model to describe commodified forms of capital accumulation, its various crises, and the social arrangements that allow regulation to continue (Steinmetz 1994, 202). The fact that French regulation theory has "also been seen to generate new social movements" (Steinmetz 1994,186) echoes Attali, 
convincing me that a framework based on "modes" and "regimes" is a workable starting point.

Why a framework? Foucault has shown the benefits of constructing a framework in The Order of Things ("Classifying", 1970). The values affecting and determining a given object - in this case, music - help to give that object its structure. Foucault explains that structure "makes possible the description of what one sees ... in ways which are neither contradictory nor mutually exclusive" $(1970,147)$. Music has long been analyzed in terms of both harmonic and in larger musical formulaic structures. Music can be situated in a regulatory structure conceived as a form of economic control; however, I suggest that a framework for music regulation can also include other forms beyond financial/commercial control. Foucault explains that "to attempt to improve one's power of observation by looking through a lens ... has more value with correlations between the various kinds of evidence that may be provided by one's impressions, one's reading, or learned compilations." Therefore, by "seeing a few things systematically" $(1970,146)$, I hope to offer a perspective on what regulation has done, not so much to music, but for music. As Foucault explains, by "selecting a finite and relatively limited group of characteristics, its variations and constants may be studied" $(1970,152)$.

The use of grids or frames to analyze regulation occurs in other scholarly studies. For example, Andrew Murray and Colin Scott use a grid to explain and classify modes of regulation in their research on mechanisms for regulation and control of new media (Murray and Scott 2002, 504). These were developed as a direct response to a modified version of Lessig's earlier examination of four distinct "modalities of regulation" for the Internet and digital technology, which Lessig considers to be law, markets, norms, and 
architecture (1999, 235-239). Murray and Scott describe institutional regulation as "hierarchical control"; economic power is named "competition-based control"; and social regulation is termed "community-based control". These "bases of regulation", plus a fourth, "design-based control" (492), are used to depict the range of regulatory problems posed by new media. Johannes Jaeger and Werner Raza use a regulatory framework to apply the French Regulation School ROA and MOR concept to land-use theory $(2001,8)$. All of these scholars use a framework approach to organize and classify the large number of regulatory examples they are analyzing in order to establish connections and thus draw conclusions about how regulation affects the object of their study.

\section{Constructing an analytic framework for music regulation}

It is possible to classify various modes (or types) and regimes (or systems) of music regulation into an analytic framework where these modes and regimes intersect by identifying and locating examples of music regulation. First, music regulation can be categorized by the individuals or groups that impose controls:

- Governmental, political or legislative regulation - This institutional mode of music regulation range from influence exerted by religious or state institutions or leaders, using decrees, orders, legal statutes such as copyright law (recently, the U.S. $\mathrm{DMCA}^{18}$ or Canada's proposed Bill C- $61^{19}$ ), or treaties such as WIPO. ${ }^{20}$

- Commercial, corporate or financial regulation - Economic regulation imposed to harness the use-value of music for financial purposes (classic scarcity/overabundance regulation found in other industries). This mode is used in the music industry by rightsholders such as record labels, publishers or music rights collectives (e.g., SOCAN, ASCAP ${ }^{21}$ or $\mathrm{BMI}^{22}$ ) which collect royalties on behalf of creators.

- Social/moral/subjective regulation - Regulation imposed for social or moral purposes, ranging from very restrictive to quite permissive (Thompson and Sharma 1996, 446447), frequently tied to legitimating religious or ethical beliefs. For example, in Orthodox Judaism, parents are encouraged to limit children's exposure to nonOrthodox music to prevent influence from external beliefs. Compliance with regulation is through individual choice. For example, a creator can choose to compose 
music that is deemed socially acceptable rather than music with lyrics that could be censored. This self-regulation often stems from a desire to regulate oneself before the "strong arm" of government steps in to impose sanctions.

Music is also regulated by systems (or regimes) through instruments of regulation:

- Artistic regulation, the promotion or imposition of an aesthetic standard to control mass behaviour. One example is nationalism, where a government adopts an ethnocentric stance, directly imposing musical regulations, or uses agencies to maintain or preserve a certain culture, national style or heritage.

- Performance/spatial regulation, control imposed by altering the site, place or manner of music-making or consumption, for example, imposing noise by-laws that restrict where music can be performed. This regime works by affecting certain listening practices such as time- or format-shifting, or shuffling.

- Access regulation which allows or prevents the right to use or create music through mechanical means, such as limiting production of sheet music or piano rolls by music publishers, or by limiting production of LPs by record companies. More recently, this has been enacted through technological protection measures (TPMs) using digital locks or filters in consumer entertainment equipment, or using gate-keeping technologies such as digital rights management (DRM) systems. Access is not only via to mechanical or technological means. Techniques can also involve setting up barriers (such as walling up convents in the 1500s, preventing nuns' singing to be heard by outsiders), or establishing a royalty system that collects fees, which are then distributed as remunerative payments for the use of that music.

This grid thus classifies "who" or "what" regulates and "how" regulation is imposed. The basic framework is shown in Appendix 1. Organizing examples of music regulation in this way underscores two key components of music regulation: the specific Actors involved in a regulatory event, and Outcomes, or by-products, of regulation. Rules are imposed by an entity possessing the ability to control. Those at whom the regulation is directed either conform or resist these efforts. Regulation results in adherence or resistance by establishing or restoring order, or inciting reactions that defy attempts to control. Regulation can also produce unintended consequences in music resulting in 
changes to styles, composition techniques, consumption methods, patterns of access, and new forms, creators, audiences, creation or access tools and uses of music.

Actors fall into two camps: those who impose control (such as religious leaders, heads of state, dictators, corporations with economic interests, cultural organizations and institutions), and those affected by regulation (such as composers, performers, music educators, parents, audiences, consumers, and social movement activists and groups). As power bases change, the regulator can sometimes become the regulated.

Outcomes are the result of productive effects and consequences of regulation, such as changes to or emergence of existing musical styles; outright rebellion; the invention of new forms of production; the evolution of new means of distribution; music recommendation systems; the development of new economic models for the use of music that provide compensation to creators; or the defeat of regulation.

Besides actors and outcomes, another component of analysis includes the process or techniques used in a musical regulatory event, that is, the manner in which the rules are policed, implemented or executed. Before rules are set out, negotiation, mediation or mitigation involving both the regulator and the regulated frequently occurs. This involves disagreement, conflict, debate, consultation, consensus-building and conciliation.

Some regulations become generally accepted societal practices. For example, many of us refrain from playing music at high volumes so as not to disturb others. The belief that regulations exist invokes a panopticon of surveillance. Adherence to them can lead to the establishment of new social mores, far-reaching cultural changes, and widely accepted principles. In contrast, consequences of resistance can include the imposition of penalties or financial fines, ostracism from society, performance bans, imprisonment or 
banishment from one's country. The treatment of Russian composer Dmitri Shostakovich is an example. His music was denounced by Stalin and criticized as being formalist $\mathrm{t}^{23}$ to the point where all performances of his music were banned, he was threatened with arrest and forced to publicly repent. Eventually some regulations become obsolete, their intentions forgotten as they fade into obscurity due to changing tastes, customs, cultural practices or governing systems.

At times a regulation's original intent becomes misconstrued or purposely manipulated in order to affect some financial or competitive gain. We see this today with the major record labels' relentless attempts to restrict the reproduction of digital forms of music through the enforcement of intellectual property laws, regardless of the fact that copyright law was originally conceived as a protective measure for creators. The act of challenging these attempts demonstrates that resistance can lead to obstinacy, a challenge to authority, defiance, persistence, and sometimes the overturning of a regulation.

Using the framework assists in the analysis of specific examples of disruptive moments in music history by locating them in the grid. Examining a regulatory event using the framework involves reviewing the context and scenarios in which the regulator and the parties or entities that are regulated, find themselves before, during and after regulations are applied. Studying these examples helps to describe the nature of adaptive or resistant behaviour, and reveals the productive changes achieved by regulation throughout a variety of historical timeframes. This analysis is borne out of Foucault's notion of the governmentality of "logics" - that the "how" of power is as important as "who" has power (Dowler 1996, 336; Sterne 2003, 111-112; both commenting on Foucault 1991, 102). This exercise helps to detect patterns, compare similarities or 
differences in terms of actors, outcomes and techniques, and ultimately allows me to make some observations about music, power, control and regulation that may provide further insight into some of the current troubles in today's music industry.

\section{Chapter Review}

Of the numerous examples from which to choose, I have selected two specific case studies that illustrate the major modes and regimes of regulation at work in very different ways. They are entirely unrelated and signify events occurring during significantly disparate historical periods, or as Foucault would say, in different epistemés, when music was utilized and valued in entirely different ways. Chapter Two analyzes the Roman Catholic Church's Council of Trent, held in Italy in the mid-1500s. This regulatory event is an example of a single-mode, single-regime form of control, demonstrating artistic regulation by an institutional actor. Amongst other effects, regulation played a role in the development of new harmonic and melodic forms which in turn led to new musical styles, gave rise to the establishment of productive relationships between musicians and their community, their employers, and each other, and enabled the introduction of new methods of notating and transcribing music. Chapter Three analyzes the cabaret laws in New York City beginning in the late 1920s. This example illustrates all three modes and three regimes of regulation at work on music, sometimes even occurring simultaneously. The combined regulatory pressures contributed to the complex evolution of jazz in that city through inter-racial influences, by applying controls to sites of music production and on musicians using political manipulation (exerted even by their own union), and via new technologies that increased the popularity of jazz, minimizing the regulatory effect. 
I describe these case studies from a number of discursive areas. Some of the discussion centres on the three modes of regulation. Are there techniques used in one mode that make it more successful than another? Are processes inflexible and dictatorial, or consultative and negotiated? Do modes transition from one to another over time, or are they distinct and static? Can all three modes co-exist together in the same example? How does the locus of control affect the success of regulation, in terms of being tight or loose? How long did it take for regulation to achieve compliance, or meet with resistance?

I also explore questions about the actors involved in various aspects of music regulation. Why is one actor rather than another in a position to impose regulations? Have musicians' reactions to regulation changed over time? How do their reactions affect the acceptance of regulation by other actor groups? My analysis also looks at effects and outcomes. Does one regime of regulation have a stronger impact on music creation, distribution or consumption than another? How do other influences such as moral panics, reigning tastemakers, or philosophies characterizing an era affect music creation?

Chapter Four summarizes the key points observed from the case studies and offers some reflection on the lessons learned from analyzing music regulation using the framework. I suggest that there are conclusions to be drawn regarding the nature of music regulation as a catalyst for change in both historical and current situations. These have to do with, for example, creative innovation as a response to resistance; a re-examination of the value of music because of regulation; and unique reactions from both musicians and audiences to regulatory processes, amongst others. Finally, I will offer a few answers to some philosophical questions raised by the notion of music regulation. Why has music continually faced regulation through time? Can regulation have a productive effect on 
musical creativity? Perhaps there is something new to learn about music by viewing it through the lens of regulation. Is it possible to verify Attali's contention that music possesses transformative power - that it acts as a beacon for impending social change?

\section{Conclusion}

Through regulation, control is exerted over music by those who create, distribute or consume it. Attali also presents the notion that music itself wields power, that "[music] has remained a tool of regulatory power, a fundamental form of the code of power [forever] functioning through new channels" $(1977,36)$. This power exists in three forms: ... music is a tool of power; of ritual power when it is a question of making people forget the fear of violence; of representative power when it is a question of making them believe in order and harmony; and of bureaucratic power when it is a question of silencing those who oppose it (Attali 1977, 19; my emphasis).

The following two case studies demonstrate Attali's notions of the representative, ritual and bureaucratic power of music, individually and in combination, through the perspectives of actors involved in, the techniques used, and the productive outcomes of various regulatory events. They illustrate institutional, economic and social regulations imposed on music through artistic, performance and technological regulation, in different historical time periods, and in different nation-states. My goal is to show that attempts to regulate music, both historically and during the current disputes, are productive, beneficial and useful in keeping the art form vital, flourishing and continually renewed. 


\section{Chapter Two}

Regulating $16^{\text {th }}$ century church music: The Tridentine KISS $^{24}$ principle

"In our times [composers] have put all their industry and effort into the writing of imitative passages, so that while one voice says "Sanctus", still another says "Gloria tua", with howling, bellowing, and stammering, so that they more nearly resemble cats in January than flowers in May."

-- Bishop Bernardino Cirillo, 1549, in Lockwood 1975, 14)

Twenty years after Martin Luther ignited the Protestant Reformation by nailing his ninety-five Latin theses to the door of Wittenberg Cathedral in 1517, the Roman Catholic Church was in a state of crisis. In response to the perceived threat of the increase in ecumenical and political power of the Reform movement, Pope Paul III (1534-49) issued a bull in 1536 to convene the Council of Trent. ${ }^{25}$ Amongst many problems with Church ceremony, religious authorities felt that sacred music had fallen into disarray and threatened to tarnish the dignity and sanctity of upholding holy doctrines. There were two pressing issues that required resolution: the debates for and against polyphony, ${ }^{26} \mathrm{a}$ musical style which was nearing its stylistic pinnacle but was obscuring the intelligibility of words, and the search for appropriate sacred music, disassociated from secular songs which had strayed into coarse and vulgar territory. In other words, the Church had had enough of hearing music in the sanctuary that sounded like cats in heat.

The Church's call for reformation of musical styles was included as part of decrees issued at the Council of Trent. These new regulations, and the musicians' response to them, provide a solid historical example of music regulation: institutional power (the mode) exerting artistic control (the regime) over music. This example is represented in the regulatory framework chart shown in Appendix 2.

Three major actor-groups were involved in this event. The main actor was the Roman Catholic Church, which for this event was represented by a complex political 
hierarchy that included a succession of five Popes, committees of papal advisors, bishops, cardinals, and a collection of other clerics and ecclesiastical experts chosen from throughout Christendom. ${ }^{27}$ Next, I consider the process by which a new set of governing policies was negotiated - the actual mechanism of the Council itself - as an actor, and a complex one at that. Between 1545 and 1563, the Council of Trent met during three periods (1545-47, 1551-52, and 1562-63) over a span of eighteen years, with two major interruptions, ${ }^{28}$ resulting in numerous directional changes and a tremendous amount of document revision. Much of the text dealing specifically with music was aggressively changed and then condensed.

Indeed, the concise and simple wording used to address revised musical practices that remained in the final Council of Trent decrees was rather ambiguous for those left to interpret, oversee and implement the new rules. These were chiefly the cardinals designated by the Pope to ensure that directives were followed, and the musicians involved in creating music from that point onward. Recent evidence, rigorously and painstakingly gathered by Craig Monson, shows that the abbreviated wording related to music in the Council's decrees was far less restrictive than what many musicologists have previously understood. ${ }^{29}$ In fact, it appears that the telling of this particular moment in musical history has been somewhat distorted over time by musicologists who have misinterpreted and over-simplified the regulations that the Church imposed on music.

The third group of actors, consisting of church musicians including singers, organists and other instrumentalists, and composers, were those at whom the regulations were mainly directed. The Italian composer Giovanni Pierluigi da Palestrina (1525-1594), frequently singled out as the leading composer of sacred music of the time, best 
demonstrated the desired style under the new regulatory regime. He is often identified as the "saviour" of polyphonic music; however, claims that Palestrina's music alone complied with the requirements set out in Trent are not entirely true. ${ }^{30}$ There were other notable composers of the time such as Giovanni Animuccia, Orlando di Lassus, Vincenzo Ruffo and Jacobus de Kerle, who also created accepted styles of church music (Leichententritt 1944, 324-325). While it is debatable that Palestrina should claim this legendary title solely as his own, he did play a multi-faceted role in this regulatory event. The productive outcome of the Council's music regulations contributed to a radical though gradual change in Western music in terms of texture, rhythm, harmony and the connection between words and music.

\section{Historical Context}

After lengthy politico-religious negotiations including where deliberations would be held, the Council finally began in 1545 in the northern Italian town of Trent, ${ }^{31}$ symbolically initiating what is now known as the Counter-Reformation. Trent was three hundred miles north-east of Rome, and nowhere near where anyone wanted the Council to be. However, it was the only place it could be held in terms of being minimally acceptable to the majority of participants, as it was a more central location within Europe to Germany, France, Austria, and more easily accessible by land to Spain than was Rome. Already, then, there existed an atmosphere of compromise.

While the primary motivation for the Council may have been to stem the rising tide of Protestantism brought on by Luther, Monson notes that "the Council is no longer perceived as an ultimately decisive event, which ... effectively turned Catholicism aside from centuries of corruption, but as a primary episode in several hundred years of 
reform" $(2002,1)$. Although it was a major regulatory event in the history of church music, it was informed by a pre-existing and ancient regulatory context.

Attali has suggested that music has power to transform society, and certainly early spiritual beliefs were influenced by an awareness of music's power to mold, and thus regulate, character and society. Christianity had inherited beliefs about the moral effects of various harmonies and modes from ancient philosophers. Pythagoras's discoveries of the numerical basis of acoustics based on the concept of the "circle of fifths" 32 contributed to beliefs that certain modes and harmonies could either calm or agitate the listener (Lawrence 1987, 285). ${ }^{33}$ Plato suggested that music's importance in society was such that musical modes could not be changed without also changing the laws of the state. The early Christian philosopher, Anicius Boethius (c. 480-524) observed that because music had the power to incite good or evil, there was a direct relation between the harmony of music - the "regulation and ordering of sound" - and the minds of listeners (Boethius 505/1989, 7). "Since the human race has become lascivious and impressionable, it is taken up totally by representational modes", he wrote $(505,3)$. The discipline that was required for singing in unison and for producing harmonious sounds introduced a regimen for participants while enacting their religious rituals. Thus, in the medieval church, musical expression provided control, obedience and conformity.

Until the $14^{\text {th }}$ century, church music consisted of singing monophonic Gregorian chants, also known as plainsong or plainchant, and served as the basis for the early stages of polyphonic composition (Lawrence 1987, 281). Plainchant melodies were based on one of twelve medieval modes, each with a specific sequence of whole tones and semitones. Polyphonic lines were centred around the three "perfect" harmonic intervals 
(octaves, fourths and fifths) but throughout the $15^{\text {th }}$ century intervals such as thirds and sixths appeared in melodies. The Church discouraged these new sounds, feeling they had "sensuous appeal" and were not conducive to holy thoughts (Lawrence 1987, 285). They also created harmonic dissonance, diverting attention from the words of the Mass. ${ }^{34}$

By the late $15^{\text {th }}$ century another musical problem troubled the Church: music's association with word meaning. Sacred music composers began using secular material to produce parody or "imitation" masses where a single voice, motive, or an entire structure from a familiar tune was borrowed for use as its main theme. Music from madrigals and bawdy songs offered a change from Gregorian chant melodies, and as well, the use of contrafactum (the setting of liturgical words to secular songs) affected the sanctity of worship, as music from the street found its way inside the sanctuary (Grout 1988, 227).

During the Renaissance period ${ }^{35}$ there was no concern about copyright protection or composers' rights, and no preoccupation with the need for absolute originality. Composers often borrowed other composers' tunes. This ethos of appropriation corresponded with the religious belief that music was a servant of the Church, divinely inspired, meant to focus a worshiper's mind on heavenly things, and not considered an object on which to make proprietary claims. While some Church authorities rejected all music except unaccompanied congregational plainchant sung in unison, others saw the value of enriching sacred music by adding organ or other instrumental accompaniment, incorporating secular works to develop a new repertoire, and using the local vernacular.

To deal with these issues, numerous music regulations emerged from ecclesiastical synods ${ }^{36}$ and councils which pre-dated Trent. The Avignon Council (13241325) decreed the use of simple monophony over polyphony in church music, free of 
devices that could detract from the clarity of the words (Society of St. Gregory 1928, 3). A papal decree condemned the substitution of new secular tunes for simpler plainchant, and permitted only perfect intervals to be used in tunes and harmony (Lawrence 1987, 285). A recommendation was also made to avoid use of the "tritone" interval (known as the diabolus in musica, or "the devil in music") ${ }^{37}$ in compositions wherever possible, since hearing it was thought to produce instability in the listener.

Condemnation of the use of secular songs in the sanctuary continued for two centuries after Avignon. During the Synod of Schwerin (1492), concerns emerged over the unintelligibility of words in church music. At the Council of Basel (1503), concern over the use of non-liturgical songs was voiced once again. The Council of Senonense (1528) decreed that only organ was to be used to accompany hymns and spiritual chants. The Synods of Cologne (1536 and 1550) ruled that the organ was to "produce no lascivious or secular sound, but should be religious and pious. It is better for the whole [song] to be sung than for part to be left to the organ, as is the custom in certain places, with great abuse" (in Fellerer 1953, 578).

Church organists were frequently blamed for the degradation of church music in the early $16^{\text {th }}$ century as they flaunted their skills by playing exuberant dance music and popular tunes even during divine moments of the service, which sometimes added an hour or more to the normal duration of the Mass. The same complaints were made of other instrumentalists, often brought in by the organists to embellish music performed for special occasions. This was not appreciated by clerics trying to maintain a serene atmosphere, so at the Council of Paris (1528), church musicians were formally requested to perform appropriate religious music (Fellerer 1953, 579-580). Composers (who were 
usually also church organists) were held accountable for the general unruliness in church music, especially since they often used secular songs as the themes of the parody masses they composed. ${ }^{38}$ The Church warned that

The Mass should proceed with dignity and with more devotion than lasciviousness. Some will compose a Mass upon a madrigal or a French song or upon a battle, and when such compositions are heard in the Church they induce everyone to laugh, whereby the temple of God becomes a place to recite lascivious and ludicrous things, as if it were a stage where it is permissible to render every sort of music of ridiculous buffoonery and lasciviousness (in Fellerer $1953,582)$.

By the early $16^{\text {th }}$ century, then, the Church was determined to abolish unorthodox musical practices and improve the ability for liturgical texts to be understood, a problem thought to be caused by increasingly complex polyphonic techniques used by composers. The authorities believed it was time to reign in church musicians who indulged in artistic license and were basically upstaging clerics during worship services. What better forum through which to deal with these issues than during the upcoming Council?

The Council of Trent's purpose was not focused solely on reforming musical practices but to respond to the overarching threats posed by Protestantism. ${ }^{39}$ These threats came from Martin Luther and John Calvin who protested against the perceived corruption and abuse of power by the Catholic Church. These Reformers demanded changes to Catholic worship including permitting more meaningful participation by the congregation. Opposition to the Mass was not confined to theological issues, but extended to its being sung in Latin, a language spoken and understood only by the clergy and educated church-goers. This created an ethos of elitism between the commoners and those in higher religious strata, imposing a further form of control over the congregation by maintaining a measure of distance and mystery. ${ }^{40}$ 
Luther's recommendation was to reform the Mass ${ }^{41}$ and his ideas were widely encouraged by monarchs in other countries such as Germany and Bavaria. However, the separation of church and state was such a radical idea at the time that even mild tolerance towards a reform movement signified to Catholics that there was major disruption afoot in the order of society. The Church realized it was in deep trouble.

\section{The Council of Trent begins}

Realizing that the threat of a Protestant Reformation was no longer confined to an insignificant clerical faction and that it had the potential of winning over some powerful detractors, Pope Paul III (1534-49) decided to hold a general council for both Catholics and Protestants to help smooth things out. However, when he proposed the concept to his cardinals, it was unanimously opposed, and it took nine years to finally convince them otherwise. ${ }^{42}$ Luther prepared articles for presentation to the Council designed to offer possible compromises amongst his followers, but he died in 1546, just as the Council was convened. Other Reformers were invited, but none attended.

When the Council of Trent began in 1545, its two key objectives were to condemn the principles of Protestantism that threatened Catholic doctrines, and to set out clear guidelines for disciplined administration that addressed the corruption in the Church -- one of the chief provocations of the Reformation. Twenty-five formal sessions were held over three distinct periods of time to thoroughly address all aspects of Catholic doctrine. ${ }^{43}$ While the Pope did not take part in daily meetings, the Council was attended by papal legates, cardinals, archbishops, bishops and other papal advisors which varied in number, increasing towards the end when the final decrees were signed by 255 members. 
The actual development of the regulations by the Council was a complicated, bureaucratic process of negotiation between bishops, papal advisors and other experts. Most of the work took place in informal, private gatherings which culminated in daylong public sessions where decrees were approved and read. Formal sessions were separated by weeks or months of preliminary debate. Eight of the sessions were ceremonial openings and closings of the convocations. Issues of doctrine and reform were considered simultaneously by subcommittees so that each doctrinal decree was accompanied by a relevant reform decree. Initially, bishops heard debates on issues argued by specialists. Papal legates who managed the Council presided over the bishops' private discussions of these matters. Finally, the resulting canons and decrees were publicly presented, voted upon, and documented for that session (Monson 2002, 3).

That the Council concerned itself with music amongst all the other important issues indicates an acknowledgement that music played an important role in liturgical reform by conveying a spiritual message and creating a mood of meditation. There was definite agreement that something had to be done about the abuses suffered by music in the church, and the issue was brought up repeatedly. Notably, there were few musicians directly involved in these discussions. ${ }^{44}$ Near the end of the Council at the twenty-second session in 1562 , church music was formally identified as a specific abuse of the Mass.

A preliminary committee of seven bishops was struck to decide on an appropriate clean-up strategy. After several meetings, documents were prepared to record the issues to be discussed at the general session. Only one committee member, Cardinal Gabriele Paleotti, credited as the primary author of canons on Mass abuses, had a long-standing 
interest in music (Monson 2003, 4). Some of the direct submissions to the committee

have survived from his files, for example:

Abuses, with regard to ceremonies and solemn rites. ... Around the moment of the elevation of the most holy sacrament, when ... a lofty silence ought to be observed by everyone, ... organs make a great noise and musicians sing, and some other things intrude which, apart from the fact that they are untimely, also frequently appear to recall something licentious and to distract souls from spiritual inclinations. In the singing [during] the sacrament, there [is] much licentiousness, against the custom of the ancient church.... The Creed is not recited complete ... and the Lord's Prayer, too, is suppressed, for the sake of music made together by singers, musicians, and instruments. By a novel and remarkable contrivance, ... in some churches this great mystery [is] completed without much labour of singing, praying, meditating, and they rush to the end, as if concern in the church were with the belly, not with piety, and with the world, not with Christ (observations of Bishop Stanislaus Hosius, one of the papal legates; trans. Monson 2002, 6-7).

There was also a problem concerning bad singers. Without proper training, choirs

could turn religious services into cacophonous spectacles. Concern over the poor quality

of singing and the use of unrevised texts was expressed by the Bishop of Vienna:

The first abuse of these singers arises from the fact that many of them do not even know one note from another ... and are in fact unskilled in any phase of music. Therefore they teach through substitute assistants, a course of action not without its derision and mockery from the people. The second abuse ... is that [they have] no care in them as to whether they are [using] either corrected or uncorrected musical books ... But since even one vowel, incorrectly written, is able to make the sense of the words perverse and heretical, therefore those most important books [Missals and Breviaries] which are accustomed to be used ... ought to be most carefully written and edited. ... Let them take care that they use in Choir only corrected books, and let them not use any other chants than those which are taken from Scripture or at least are not contrary to it (Bishop Blancicampianus, trans. Hayburn 1979, 26-27).

Yet another Bishop complained to the Pope that

Nowadays they sing these things in any way at all, mixing them in an indifferent and uncertain manner ... I should like, when a Mass is to be sung in church, [that] the music [is] to be framed to the fundamental meaning of the words, in certain intervals and numbers apt to move our affections to religion and piety, and likewise in psalms, hymns and other praises that are offered to the Lord (Bishop Bernardino Cirillo, 1549, trans. Lockwood 1975, 11-14). 
After considering these and many other long-suffering complaints, the first formal reference made about reforms to music in Council documents was finally presented in August 1562 . This was proposed only as a subject for discussion, and was neither voted on at the general conference, nor published in the final decrees:

It must also be considered whether the kind of music that has now become established in polyphony, which refreshes the ear more than the mind, and which seems to incite lasciviousness rather than religion, should be abolished from the Masses, in which things are often sung, such as della caccia and la battaglia ${ }^{45}$ (Trent, Canon 8:918, 1562; trans. Monson 2002, 8).

The committee's aim was to present proposals at the general session in a way that could be readily accepted without provoking unnecessary discussion by individual bishops who might otherwise repeat similar instances of abuses in their own dioceses. A re-submitted version thus substantially reduced the reference to music:

Let the manner of music in divine services be restored to the standard which John XXII prescribed in the Extravagantes on the lifestyle and decency of clerics, or else let the singing be such that the words are understood rather than the music (Trent, Canon 8:922, 1562; trans. Monson 2002, 8-9).

While this version omitted concerns about the infiltration of secular music, it did mention the problem of intelligibility of words by referring to concerns expressed at Avignon two hundred years before, suggesting that Trent participants were aware of the connection between their efforts and musical reforms that had been previously attempted.

The final draft of the proposal did not deal with stylistic musical details, but instead focused on fundamental concepts. This revision was prepared by the legates for discussion at the general session in September 1562 and provided a longer statement about music than in the previous version. However, this was still not the final decree:

Since the sacred mysteries should be celebrated with utmost reverence, with both deepest feeling toward God alone, and with external worship that is truly suitable and becoming, so that others may be filled with devotion and called 
to religion ... Everything should be regulated so that the Masses, whether they be celebrated with the plain voice or in song, with everything clearly and quickly executed, may reach the ears of the hearers and quietly penetrate their hearts. In those Masses where measured music and organ are customary, nothing profane should be intermingled, but only hymns and divine praises. If something from the divine service is sung with the organ while the service proceeds, let it first be recited in a simple, clear voice, lest the reading of the sacred words be imperceptible. The entire manner of singing in musical modes should be calculated, not to afford vain delight to the ear, but so that the words may be comprehensible to all; and thus may the hearts of the listeners be caught up into the desire for celestial harmonies and contemplation of the joys of the blessed. (Trent, Canon 8:927, 1562, trans. Monson 2002, 9).

\section{The Decision is rendered}

During the general session that followed, certain bishops suggested condensing the long list of canons on abuses of the Mass into a single general decree. After considerable debate, the idea was supported by other prelates, whereupon a mere fifteen Latin words ${ }^{46}$ remained concerning aspects of music to be observed and avoided in the celebration of the Mass: "Let them keep away from the churches compositions in which there is an intermingling of the lascivious or impure, whether by instrument or voice" (Trent, Canon 8:963, 1562 trans. Monson 2002, 11). This scant phrase represented the final and only musical pronouncement actually approved in the final vote after the lengthy negotiations. On the topic of music abuses, then, the delegates said very little. One short sentence about music was all that was published in the final Canons and Decrees of the Council's twenty-second session. ${ }^{47}$

The deliberations addressing church music resulted from an editorial process that left little detail about the implementation of the rules. This is notable as to the process used in this regulatory event. At the Council of Trent, what was thought of as an important area of regulation was eventually reduced to a rather vague directive in terms of how musicians were now supposed to "behave". On the other hand, the process of 
communicating the rules in this way permitted a more liberal interpretation. A more accurate portrayal of the rules suggests that these were musical guidelines (in a Foucauldian sense) rather than regulations, in that they cautioned against, but never prohibited, the use of complicated polyphonic styles. Setting out a musical policy rather than imposing a detailed order affected the way composers adapted and conformed to the standards deemed acceptable by the Church.

Besides textual intelligibility, there had been considerable discussion and divided opinion over whether polyphony should be eliminated. Earlier in the Council, more extreme proposals had been put forward by two participants, Cardinals Giovanni Morone and Bernardo Navagero, who advocated complete abolishment of polyphony (Lockwood 1957, 343). However, there was a more urgent call to reject any association with "lascivious or impure" secular melodies, which over the years had crept insidiously into church music and were felt to be obscuring comprehension of the liturgy. Besides specifically prohibiting secular elements, the implication from the official version of the final reworded regulation placed few restrictions on music. It said nothing about limiting or discontinuing the use of polyphony, made no comment about minimizing rambunctious organ playing, and it never touched on the intelligibility issue. My interest in this case is therefore not how restrictive the regulations were in placing limitations on music, but rather how open the regulations were to interpretation and execution.

The twenty-second session was neither the end of the Council nor the end of the discussion over church music regulation. Many of the original "abuses of the Mass" committee members including Cardinal Paleotti recognized that a single canon on Mass reform would be too general to be effective once the decrees were executed. During the 
Council's twenty-fourth session in May 1563, Cardinals Morone and Navagero were appointed to institute a far-reaching program of reform, and they had not forgotten about music, especially polyphony. Because Morone and Navagero had previously banned polyphonic styles in their respective jurisdictions, it has been suggested that the two Cardinals headed up a faction to oppose using polyphony in the Mass (Lockwood 1966, 41). However, Paleotti, the music-loving Archbishop of Bologna who was responsible for documenting the proceedings, would not have forgotten about music either, so the two dissidents would have faced considerable opposition from him. It seems unlikely that during the last stages of the Council, none of the participants would have wanted to impose a total ban on polyphony. ${ }^{48}$ This would have provoked delays, judging by all the revisions that had led to the final wording agreed upon from the previous year. Preparing the new reform package required a series of meetings, informal consultations with numerous sources, the incorporation of numerous changes, and the receipt of petitions from various representatives of other nations - a process not unlike any modern bureaucratic process of negotiated legislation. ${ }^{49}$

As a result of these further discussions, an additional reference to music was accepted and published in the twenty-fourth session. The instructions were as follows:

Let them all be required to attend divine services ... and to praise the name of God reverently, clearly, and devoutly in hymns and canticles in the choir established for psalmody...Concerning the proper manner of singing or playing therein, the precise regulation for assembling and remaining in choir, together with everything necessary for the ministers of the church, and so on: the provincial synod shall prescribe an established form for the benefit of, and in accordance with the customs of each province. In the interim, the bishop, with no less than two canons, one chosen by himself; the other by the chapter, may rule in these matters as seems expedient (Trent, Canon 12, 1563; trans. Monson 2002, 18). 
This decree treated music even more generally than had been done in previous sessions. The opportunity to re-visit the issue of textual intelligibility which had been de-tabled in deliberations from the previous year was again ignored, but this rule specifically stipulated that musical directives were to be implemented at the local level, ensured that post-Tridentine church music would be anything but uniform and monolithic - certainly, that styles would not be dictated and prescribed by "head office".

The twenty-fifth and final session of Trent included the only instance in which polyphony was truly threatened in the way suggested by musicologists' tales of Tridentine attacks on music, and its last-minute "salvation". It also represented the only instance where severe musical restrictions actually survived all the way to the debates by the general assembly. In late 1562, the legates instructed Paleotti to begin work on a decree to reform convents and monasteries, so he developed a draft to address the cloistering of nuns. Wording was proposed to the delegates that included specific musical restrictions regarding convents:

Let the divine services be accomplished by them with voices raised, and not by professionals hired for that purpose; and in the sacrifice of the Mass let them make the responses that the choir usually makes; but let them not usurp the role of the deacon and subdeacon of reciting the Lessons, Epistles, and Gospels. Let them abstain from modulating and inflecting the voice or from other artifice of singing, which is called "figured" or "instrumental", as much in choir as elsewhere (November 20, 1563; trans. Monson 2002, 20).

There was no room for interpretation here: this was a severe restriction on music. The draft directed that no external musicians could sing in convents, and that polyphony (i.e., "inflecting the voice", etc.) was to be banished. Paleotti's document suggested that he was extremely critical of music in convents. Fortunately, the Sisters and their music had a few supporters in the general congregation at Trent. Several delegates opposed the 
prohibition of singing in convents; some suggested that the matter should be left up to the discretion of the Mothers Superior. Others took the position that such matters should be left to provincial and local councils (Monson 2002, 21). The summary of criticisms for this draft decree came out in favour of music: "As for the nuns. Let the entire matter be referred back to the heads of their orders; or let these canons be combined with those above. ... Musical songs are not to be prohibited" (in Monson 2002, 22). All references to styles of music heard in convents were dropped in the documents from the twenty-fifth and last session of the Council. Fortunately, polyphonic music in convents was saved. ${ }^{50}$

In terms of a regulatory process, then, the Council did not develop enforced legislation to deal with the reform of church music, but simply communicated a broad policy and left the implementation to local and provincial jurisdictions. While the Council closed with the words Anathema sit, ${ }^{51}$ communicating an ominous warning to all who considered disobeying the regulations that had been so meticulously developed, the new decrees allowed any local or provincial religious order or diocese that had its own distinctive liturgical tradition to propose revisions and submit them to the Holy See for approval. In this way, responsibility for the implementation and interpretation of specific regulations concerning musical matters was given to provincial synods and local bishops (Monson 2002, 19). In all there were seventeen separate provincial synods held after Trent that included discussion of specific regulations for music (Fellerer 1953, 590-592).

\section{Testing the New Policy}

Although the only documented regulation resulting from Trent addressed the type of music that could not be heard in church, the issue of polyphony versus intelligibility was not over. A commission of cardinals was set up in 1564 to oversee the reform of both 
musical forms and the musical activities of the papal chapel. Commission members included Cardinals Carlo Borromeo, nephew of the reigning Pope, and Vitellozzi Vitelli, both who privately employed musicians (Capes 1847,122 ). Discussion ensued over the various merits and drawbacks of musical styles commonly heard in Church services prior to the Council. Once the new musical policy was agreed upon, the next step was to test it. An entry in the Sistine diary from 28 April 1565 indicates that singers of the papal chapel "were assembled in the home of Cardinal Vitelli to sing some masses and test whether the words could be understood, as their Eminences desire" (Sherr 1984, 75). Who the singers were and what music was sung is not known, but we do know that in 1564, the composer Vincenzo Ruffo was invited by Borromeo to "write a Mass which should be as clear as possible" (Hayburn 1979, 30). It is possible that masses by Palestrina were performed, since he was a prominent musician in Rome and well known in ecclesiastical circles, though at the time not a member of the Chapel. While there is no evidence that Palestrina's Pope Marcellus Mass was selected for the test, records from the Sistine Chapel show that a few months after the meeting at Cardinal Vitelli's house, Palestrina received an increase in his pension "in consideration for various masses which he wrote and for others which he was commissioned to write for the service of the Chapel" (in Lockwood 1975, 8) ${ }^{52}$ However, the music of another composer, Jacob de Kerle, ${ }^{53}$ may also have been heard at the "trial". De Kerle had been commissioned to compose a lengthy work expressly for the Council of Trent, and obliged with the Preces speciales (“Council Prayers", 1561-1562) which were sung frequently during Trent (Leichtentritt 1944, 320). His work also demonstrated to Council delegates that 
polyphony was capable of projecting the words in an intelligible manner. Thus, it may have been de Kerle who was more accurately the first "saviour" of polyphony.

Job stability and musicians' suitability were also items that came under scrutiny by the Commission (Lockwood 1966; Sherr 1994; Atlas 1998). The cardinals evaluated the papal choir and investigated the matter of tenure for its members. Accordingly, Borromeo and Vitelli began their assessment by re-auditioning the swelling numbers in the highly-paid choir (its ideal limit was twenty-four members, but at the time there were nearly forty singers). They found that several members had been appointed merely by a motu proprio, yet their singing skills were lacking. The suitability of all singers was reviewed, resulting in the dismissal of fourteen of the Sistine Chapel choristers either because they were poor singers, or not ordained. ${ }^{54}$ Undoubtedly these tests were a sign for church musicians everywhere that they were now being put "on notice".

\section{The Conduct of conduct}

In observing the regulatory actors in this case study - the individual committee members, the larger voting assembly, and the complex negotiation system - we see the deep dedication to following a process. The "rules for making rules" - what Foucault terms the "conduct of conduct" - was a guiding principle as these actors went about their regulatory business. Whether there was a real or perceived threat to the sanctity of worship by the use of secular ditties as the themes in masses, often sung by untrained choirs, accompanied by grandstanding organists and noisy instrumentalists, the regulators wanted to ensure that the new policies would effectively deter the old ways from reappearing. While the issue of text intelligibility allegedly caused by polyphony was discussed at length, it was dismissed and the strategic focus was now on the decentralized 
execution of the new rules. The regulators must have realized that it was nearly impossible for the long arm of church law to reach out to every performer, composer and into every parish church to enforce the way musicians should behave and music should be heard. Thus, the regulatory process involved establishing policies for music, rather than imposing harsh legislation - a process that neatly characterizes Foucault's notion of governmentality. The test runs conducted by two powerful cardinals of Rome provided incontrovertible evidence that it was quite possible to reconcile the complexity of polyphonic music with the requirement for textual clarity. Whatever music was heard at the "trial", and regardless of who had written it, the strategy of regulation through example-setting was one that communicated the way forward to future composers.

\section{What about Trent "Regulatees"?}

The Council's regulations were aimed mainly at the group of actor-musicians who were affiliated with the Church: composers, instrumentalists and singers. To a great extent before and even after Trent, they controlled what was heard in the sanctuary. While they conferred with their religious employers, they were undoubtedly viewed as subject matter experts, choosing the appropriate style, format and length of musical works that were heard, during regular worship, and for special events and feast days. I have noted some of the problems that were undoubtedly attributable to these musicians prior to Trent. However, it would be incorrect to infer that musicians of the time were a rebellious bunch. Perhaps they did play enthusiastically to the crowd, but they were not intentional troublemakers. Those lucky enough to be employed by the Church enjoyed a modest but steady income (Lockwood 1957, 352), so they busied themselves with remedying previous abuses by producing the style of music their employers would 
approve, ensuring they remained employed. When they failed to impress their ecclesiastical employers, they quickly revised their work or otherwise ensured such missteps would not be repeated in future compositions or performances.

\section{External influences on musicians related to the Council}

There were other pressures linked to the new decrees that musicians were forced to deal with. Even before Trent, musicians were affected by a fundamental technological change, that of production of printed music and its distribution from the composer directly to the public. Hand-copied printed music became necessary due to the number of chants and the impossibility of memorizing them all. The invention of the printing press using movable type in the $15^{\text {th }}$ century and the steady advances of printing throughout the $16^{\text {th }}$ century enabled the efficient dissemination of revised versions of chant texts and music. After the Council concluded, new editions of polyphonic works with improved textual clarity were published with the heading Iuxta Formam Concilii, "according to the form of the Council" (Monson 2002, 26). Commercial music printing flourished in Venice with the production of editions of substantial size. ${ }^{55}$ The abundance of printed music had a substantial effect on music consumption and was responsible for the emergence of a new group of recreational music-makers who performed secular music.

Amateurs who sang madrigals ${ }^{56}$ also sang motets,${ }^{57}$ thus sacred music publication also increased. However, numerous errors, both musical and textual, had crept into these books and remained uncorrected. The problem of poorly revised scores was compounded by the fact that many church singers were amateurs who lacked professional training in music or Latin, so mistakes were continually repeated. The Council addressed these problems by decreeing that music books were to be revised. However, there was no 
compromise on the issue of music sung in Latin since in an earlier session, the Council had officially adopted the Vulgate, an early Latin translation of the Bible, implicitly affirming the use of Latin instead of local language in celebrating the Mass.

Nice work - if you can get it

Having accurate texts and music books would certainly have improved the performers' situation, but being a professional musician during the Renaissance and trying to find a steady, paying job was not easy. For example, when it came to official employment for musicians, until the 1560 s there were simply not many jobs, even at the "head office" in Rome. In addition to the papal chapel which employed twenty-five adult male singers, there were paid institutional posts for only another six choirmasters and forty more singers. The requirement for ordained, and therefore unmarried, musicians posed a further limitation. Even beyond Rome, religious institutions preferred to employ unmarried choirmasters in order to command their undivided attention, although the choice of maintaining this restriction was left to each bishop (O'Regan 1994, 553-4) ${ }^{58}$

Instrumentalists were rarely hired by the church, since during the Middle Ages, the use of instruments other than the organ was generally regarded with disdain due to their association with secular music (Grout 1988, 286). Although instrumental music gained in popularity as the $16^{\text {th }}$ century progressed and these musicians gained respect as composers expanded their repertoire beyond choirs, the most commonly-heard instrument in church was the pipe organ, usually played in alternation with the choir (Grout 1988, 289). ${ }^{59}$ That is not to say that instrumentalists were never employed, but they were rarely heard in Vatican services prior to the late $16^{\text {th }}$ century. 
While singers and choirmasters formed an important part of the institution's personnel and their presence was regarded as essential to worship, absence or lateness was punished by fines. Their lives inside and out of the institution were strictly regulated, as was their conduct. As decreed during the Council, musicians were to "always adopt appropriate attire, both in and out of church, shall abstain from unlawful hunting, bird catching, dancing, taverns, and play, and they shall be so rich in purity of moral character as to be justly called the senate of the church" (Trent, $24^{\text {th }}$ session, 1563 , trans. Monson $2002,18)$. Salaries were set at a level appropriate for celibate men without family commitments, though they received free accommodation. A musician could not expect to earn much from composing sacred music in the period before the conclusion of Trent, since churches relied heavily on the established Franco-Flemish repertory (O'Regan 1994, 554). There was more money to be made as a composer who could also work as a nobleman's privately-employed chapel organist, though there was arguably less security.

For the most part, then, musicians had to seek work wherever it was available, and although there was a certain degree of artistic license and subjectivity inherent in the art form, ecclesiastical patronage represented good job security. While pronouncements from Trent did not specifically banish "bad" singers from all choirs or suggest that all musicians were to be auditioned, the clergy was determined to comply with the new Tridentine way. But were musicians equally as determined to follow the rules?

\section{Global rules, local execution}

After the Council ended, the issue of textual comprehensibility must have been on the minds of reform-minded clergy returning from Trent, who would have communicated details directly to local composers about the deliberations that had taken place, or else 
would have initiated local synods that musicians would have attended. In this way, the Catholic world gradually heard about changes that had been explored over the eighteen years of the Council, including the final regulations for music. It is unlikely that many musicians would have read the official Tridentine pronouncements. Their perception of the Council's decrees on music was more likely influenced by orders from ecclesiastical patrons, by published reforms of provincial synods that interpreted the Tridentine decrees, by what they may have heard informally, or by seeing the most recent musical publications claiming to have been composed "according to the form of the Council of Trent" (Lockwood, 1957, 354). As for the actual policies recorded in the Trent decrees, regardless of local practices, composers and performers were now well aware that lascivious and impure music was offside, at least within the confines of the sanctuary -that is, if they wanted to remain employed. While before, composers frequently used secular songs in a Mass as primary thematic material, they knew that this practice was now banned if the tune was associated with some ill-meaning or non-sacred connotation, so Gregorian chants were back in favour for this purpose. Musicians followed the rules because they were determined to keep their jobs.

Even without a specific reference to textual intelligibility in sacred music, within a few years of the Council's conclusion, ensuring that the words were clear was assumed to be a mandatory requirement of Tridentine reforms. Regardless of local traditions, word clarity was a requirement of which all composers were now distinctly aware.

\section{Palestrina: an enterprising composer}

One master of textual intelligibility in polyphonic works was Palestrina, whose music was held up as a standard for correct post-Tridentine style. After his education in 
the prodigious Franco-Flemish musical tradition, he became an accomplished organist and choirmaster. Based on his excellent musical reputation, he was appointed by Pope Julius III to direct and provide musical training to the choirboys at St. Peter's. For the next 40 years until his death, despite the requirement for musicians to be ordained (he was married), he held prestigious positions in the Vatican including organist and choirmaster in the Giulia Chapel, singer in the Sistine Chapel choir, choirmaster at church of the Pope as Bishop of Rome, and choirmaster at the Roman Seminary where he provided clerics with formal music education, one of the Tridentine edicts.

Throughout his life Palestrina never completely left the church's employ, though he did take on paid work for wealthy patrons and other organizations. He declined lucrative posts in Vienna and Mantua, but accepted commissions from the Duke of Mantua, producing the Mantuan Masses (1578) for the nobleman's private chapel (Atlas 1998, 589). Even for these works, performed well out of earshot from any post-Tridentine regulators, Palestrina was ever-mindful of the importance of textual clarity in his music. In correspondence to the Duke about the score, Palestrina wrote that if the work was not satisfactory, "I beg you to let me know how you prefer it: whether long, or short, or composed so that the words may be understood" (Palestrina, 1568; in Fenlon 1980, 90).

Despite the renown he experienced even in his own lifetime, little is known about Palestrina beyond the basic details of his life, patrons and commissions. It is due to this scarcity of hard evidence that the "legend" of Palestrina arose. First propagated in a biography (1828) by Giuseppe Baini (Bokina 1998, 161), it was suggested that the Missa Papae Marcelli was instrumental in "saving" polyphonic music from its proposed ban 
when it was allegedly heard at the Borromeo-Vitelli "audition". ${ }^{60}$ Baini's thesis was adopted by numerous successors but has not withstood recent musicological research. ${ }^{61}$

\section{The Band of Brothers}

During his career, Palestrina became involved in a group that was external, but directly related to the Church. This institution bears mentioning because it provided alternate employment for musicians, and expanded the role music played in society during and after the Council of Trent. The rise of industry and commerce in $15^{\text {th }}$ century Europe led to the organization of guilds to serve the spiritual and fellowship needs of artisans, tradesmen, professionals and shopkeepers. These were known as confraternities, or "brotherhoods", and were based on a religious tradition that complemented the religious life of their members, using a model of ritual kinship (Terpstra, 2000). These groups ranged in size from a few dozen to a few hundred members and were active throughout Europe. ${ }^{62}$ Membership conferred spiritual, social and charitable benefits, ${ }^{63}$ and individuals often belonged to more than one group according to their needs or preference. Because these groups sought social legitimacy, and the Church wanted to engage citizens in religious activities, the two entities worked together symbiotically.

Throughout the $16^{\text {th }}$ and $17^{\text {th }}$ centuries, lay confraternities were critical for spreading Christianity, combining social activities, religious education, moral discipline, devotional exercises and ceremony (Arnold 1965; Black 2004). After Trent, religious devotion became fashionable amongst all classes in Europe. By the late 1500s, citizens flocked to join confraternities and on holy days would participate enthusiastically in devotional exercises held at confraternity oratories or in elaborate processions. Over time, participation between confraternities became competitive, and elaborate celebrations 
often pushed the actions of these groups to the margins of acceptability in the eyes of the church, who viewed some activities as occasions for disorder, gluttony and drunkenness (Bossy 1985, 59). Confraternities, organized mainly "by lay people, were the most obvious expression of the new post-Tridentine spirituality; their officers became keenly aware of the potential of music for attracting people" (O'Regan 1994, 556). Musicians joined confraternities both as members and as paid performers. Even the Sistine Chapel choir formed its own confraternity in 1585 , with Palestrina likely being its founding member. ${ }^{64}$ This compagnia dei musici was "specifically for musicians, mark[ing] the beginning of unionization in the profession and of a new confidence among its members outside the chapel and, in most cases, outside the clerical state" (O'Regan 1994, 555). The act of organizing such a group signified the beginning of a challenge to the Chapel's, and thus the Church's, dominance over musicians by providing an alternate source of income for musicians, independent from their chapel remuneration. Freelance work for confraternities, albeit part-time, became an annual money-making opportunity during feast days and major ceremonies. As celebrations became more grandiose, full choirs were employed music's value was demonstrated by the progressively higher payments made to musicians over time. Palestrina's talents were in great demand for these events and as a member of several confraternities, he was frequently contracted to compose music, select musicians, and direct performances (O’Regan 1994, 558). Palestrina's lucrative freelance contract work was noticed and emulated by other enterprising chapel masters and church musicians in churches throughout Europe. Although he was not the only church musician making money on the side, someone of his renown who was involved in both the administration and artistic work of confraternities 
was viewed not just as a trailblazer, but also as one who supported the formal organization of musicians. Besides his undisputed renown as a composer of the "right style" of sacred music, he was a well-regarded modern day music leader and impresario.

The role of confraternities changed significantly from the height of their popularity just after Trent ended, to their virtual disappearance by the mid- $17^{\text {th }}$ century due to the decline in status of the regular versus the secular clergy and new patterns in devotional activities of laymen as their activities became less spiritual. Although confraternities provided new composition and performance opportunities for musicians, when their popularity waned, both performers and composers were affected from an employment perspective. Musicians began turning to private employment with noblemen who frequently sponsored individual composers or commissioned specific works.

\section{Summary: the role of various actors as key elements in the process of regulation}

The Church recognized the relationship between the role music played in upholding the sanctity of worship, and of maintaining important beliefs and doctrines of Roman Catholicism. It was deeply motivated to retain order and harmony - both literally and figuratively - through this powerful communicative medium. I interpret the Church's religious power here not as the imposition of moral power, but of institutional power, since at the time it was the dominant governing institution of European society. Besides maintaining control through religious legislation, there was also a strong motivation for economic control - losing worshippers to Protestantism could lead the Catholic church into financial ruin. Using today's language of regulation, in the $16^{\text {th }}$ century, the Roman Catholic Church risked losing market power. 
In order to ensure that the Holy Regulator arrived at reasoned set of laws, an elaborate process of negotiation, analysis and conciliation was used at Trent. In the end, while regulation pertaining to music was designed as more guiding principle than distinct order, and composers were never actually forced to choose textual intelligibility over polyphony, the process provided considerable leeway for individual adaptation of the rule to a particular situation. By articulating the rules for music in general terms, they could be followed more easily without encountering resistance. This provided a productive environment that enabled increasingly diverse musical styles to flourish.

Musicians in $16^{\text {th }}$ century Rome were also financially motivated: they needed employment, and the church was one place that could provide modest, though steady salaries and a potential job for life. Musicians did their best to serve their employers by adapting and conforming to new policies, while still aspiring to create new and interesting music. New employment opportunities were created for musicians outside the Church through confraternities and patronage appointments. Musicians began to gain some career independence by joining or forming confraternities. It is easy to equate this early formation of musician groups with the more formal process of organizing musicians' unions many centuries later though it would be inaccurate to suggest that the emergence of musical confraternities in the $16^{\text {th }}$ century signified resistance to institutionally-dictated regulations. The purpose of these groups was to deal with the operational aspects of performance such as negotiating fees, deciding on repertoire, rehearsing for performances, auditioning new musicians, and gathering for social reasons (drinking beer!). Musicians involved with confraternities became increasingly aware of 
the economic benefits that could be derived from practicing their art, and accordingly were able to negotiate more favourable remuneration for their work.

Palestrina developed his technique while also reacting to the changing priorities of his employers. His music demonstrated new ways of matching words to melodies and rhythm so that the words remained clear. There is evidence that his unique polyphonic style was influenced by discussions held during the Council of Trent. Musicians inspired by Palestrina's example helped to literally "re-form" music by experimenting with new styles, thus returning music to the state of order and harmony desired by the Church.

\section{Musical Outcomes from Tridentine regulation}

In his description of the Renaissance period of music that spanned from 1400-

$1600 \mathrm{AD}$, music historian Lewis Lockwood observes that

... a new era came into being through the exposure of music and musicians to a new set of prevailing aesthetic and philosophical impulses, combined with a new set of social and technological conditions and with steady developments in ... musical technique (Lockwood, Grove Online, "Renaissance").

As a regulatory event, the Council of Trent contributed to changes in Catholic church music that are now identified with what is considered to be the end of the Renaissance era. However, there was no sudden rupture in music style as a result of the Council of Trent's directives. As Lockwood states, "resolutions reached at Trent cannot be regarded ... as a culmination of the Reform trend... [T] he wording ... condemn[ed] unsuitable church music, but omitt[ed] the formulation of specific criteria or suggestions for determining the components of a reformed style" (1957, 342-3). Considering its simplicity and generality, the Trent decrees produced significant, though gradual changes to musical style over the next three decades. "Lascivious or impure" elements were solely 
prohibited, so by exclusion, any secular musical influences were rejected. Contrary to what some historians have read into draft versions, there was no specific emphasis on intelligibility of sacred texts, nor was polyphony endorsed only on the condition that it could not interfere with intelligibility. No suggestion was made to reintroduce ancient plainchant back into the Catholic liturgy, yet there was renewed interest in reviving Gregorian chant, and the use of secular tunes disappeared. The regulation was remarkable not for what it said, but for what it did not say.

In the Renaissance, music was known for its complex multi-voiced polyphony, but there was a distinct difference in the sound of sacred music heard in Church at beginning of the $16^{\text {th }}$ century compared to music after the Council ended. Even before its conclusion, composers such as Palestrina and de Kerle were producing a smooth polyphonic sound with harmonized and well-balanced voice parts, and homophony to emphasize certain important sections of the text. Before the decrees were even published, regulators weighed and balanced the various options and items of importance pertaining to music. The debates about what was acceptable or not created what we would call today a "buzz" around music. Composers close to the action listened carefully to the discussion, communicating to others what they heard. An environment of creativity and experimentation existed for musicians during this time of intense interest in music.

\section{Focus on the words}

The desire for textual intelligibility in church music had been dropped from the Council's final wording, but it was not ignored. Although draft proposals and the ensuing discussion were not made public, the details were widely known to participants and observers at Trent. Because Cardinal Paleotti was charged with drafting the "Acts" while 
the Council proceeded, and revising them in subsequent years, he was partly responsible for keeping the issue of textual clarity in focus, despite the specific wording having been removed from the final, published decrees (Monson 2002, 22). These documents were published shortly after the final canons were printed, and were similar to press releases that simplified the detailed decrees which contained comprehensive technical wording. Paleotti noted that the issue of textual intelligibility had been omitted from the official canons, but he included it in the final version of the Acts:

In the deliberations regarding music in divine service, although some rather condemned [than approved] it in churches, the rest, ... especially the Spanish, gave their vote that it should by all means be retained in accordance with the most ancient usage of the Catholic Church to arouse the faithful to love of God, provided that it should be free of lasciviousness and wantonness, and provided that, so far as possible, the words of the singers should be comprehensible to the hearers (Paleotti, Acts of the Council of Trent, trans. Monson 2002, 23)

In this way, the Tridentine Acts actually restored the requirement for textual intelligibility without overtly stating it. When these shorter documents were then reviewed or consulted by the clergy, especially those who had not attended the proceedings, these details would have given the distinct impression that intelligibility was indeed part of the decree. Prior to Trent, textual intelligibility it had been a matter of grave concern. By the early $17^{\text {th }}$ century, it was an assumed feature of church music.

\section{Decentralized execution of regulation in local jurisdictions by the clergy}

In response to the Council's new decrees, every diocese and religious order either had to accept the Roman rite or to conduct a thorough revision of its own rite in order to retain it. Canon 12 of the $24^{\text {th }}$ session at Trent in 1562 directed provincial synods to establish "a precise rule in light of ... the customs of each province about the appropriate style of singing and chanting, about the determined manner of gathering and remaining in 
choir, and all that is necessary about church ministers" (in Tanner 1990, 767). Some Orders and many older and larger dioceses, proceeded to revise their practices, ensuring that music conformed to the new aesthetic dictated by either the Council or synods charged with implementing its directives. ${ }^{65}$ Regulations were thus executed using a decentralized system of power, always referencing the Trent decrees or the abridged Acts version. Even so, local customs did not always synchronize with head office directives.

For example, we know that once Paleotti became Archbishop of Bologna, he adapted the rules by choosing to severely restrict the singing of nuns. ${ }^{66}$ Likewise, Cardinal Borromeo continued controlling the outcome of music after Trent had adjourned (Fellerer 1953; Leichtentritt 1944; Lockwood 1957; Monson 2002). After being appointed Archbishop of Milan in 1565, he called a provincial council which reaffirmed the Trent decrees and laid down specific requirements for church music, resurrecting the proposals on monastic reform that had been discarded during Trent and implementing a severely regulated environment for convents under his jurisdiction. ${ }^{67}$ His Milan Council echoed the prohibition of "profane and lascivious" singing, calling for "grave, pious, and distinct music, appropriate to the House of God and to divine praises, so that simultaneously the words may be understood and the listeners aroused to piety" (Lockwood 1957, 358). All instruments other than the organ were forbidden in church a rule observed in Milan throughout his lifetime, though nowhere else in northern Italy.

The expectations of the Church as expressed in the decrees of Council of Trent, and local religious practice, were sometimes divergent. The emphasis on the parish as the social and spiritual centre of society was made evident through constant attempts by the Catholic Church to regulate local behaviour with, for example, regular visits made by 
bishops to parishes. Often, despite the increased vigilance of the Catholic clergy, parishioners maintained their local traditions despite the Church's universal reforms. At times these divergent actions were even approved by Rome. ${ }^{68}$ Rome's consent to permit explicit resistance to the decrees signified an inability to change longstanding local traditions and resulted in diverse regulatory responses which were less, or in the case of administrators such as Paleotti and Borromeo, sometimes more restrictive in terms of the effects on music. Unable to maintain control from Vatican central, music was regulated at the diocesan and parish levels, creating the potential for communication breakdowns when oversight of even minimum levels of performance was expected. The presence of both diluted and restrictive regulation reinforces my view that the Tridentine decrees were more policy-based guidelines than heavily-enforced laws. The task of following the guidelines was generally left to musicians, who now operated in self-regulatory mode.

The care and feeding of musicians: training and education in the "new style"

In order to maintain the standards of musical quality demanded by the Council of Trent, legislation now existed requiring clerics to be musically trained so they could learn how to properly sing the required hymns and Gregorian chants (Hayburn, 28). This was done partly to counter the limited number of trained church musicians, since restrictions were imposed based on their matrimonial state. While it would have been impossible to reproduce the high quality of music heard in Rome in small or remote parishes, at least there was now some consistent musical training. For this reason, Borromeo hired the composer Vincenzo Ruffo (1508-1587) as the chief instructor in polyphony and also commissioned him to compose masses and spiritual madrigals following the new style after Trent, writing to Ruffo, "I am much pleased with your plan to make a collection of 
decent madrigals such that every good man can sing them, and if worthy men could be found to compose the music it would be easy to have someone here write the words on spiritual and devout subjects" (Borromeo 1565, in Lockwood 1957, 349). In Ruffo's dedication of the Masses to Borromeo, he presented a clear understanding of what the Cardinal expected in the post-Tridentine music environment:

According to the decree of ... Council of Trent, I was to compose some Masses which should avoid everything of a profane and idle manner in worship, and that the powerful and sweet sound of the voices should soothe and caress the ears of the listeners in a pious, religious, and holy way ... Accordingly, I composed one Mass in this way: so that the numbers of the syllables and the voices and tones together should be clearly and distinctly understood and perceived by the pious listeners. Thus it was that later imitating that example I more readily and easily composed other Masses of the same type (Ruffo 1570, in Lockwood 1957, 354).

Borromeo's sincere desire to reform music was reflected in his liberal attitude towards the madrigal form, and in his understanding that newly revised church music depended on assurances of proper training and adequate salaries and living conditions for church musicians. As a representative of the church's efforts to regulate music, his genuine interest in promoting the new musical style and his empathy for musicians (other than those in convents) encouraged an environment of compliance through rigorous oversight. His efforts at renewing and revitalizing Catholic Church liturgy made him an example of the "living refutation of Protestantism" (Lockwood 1957, 358), despite obstacles from many sides (including an attempt on his life) and the difficulties of supervising a highly decentralized reform program. Just as Palestrina, Ruffo and de Kerle were instrumental in demonstrating the correct music style, Borromeo became a symbol of regulatory enforcement in the reform movement. For his work, he was canonized by the Church in 1610 (Lockwood 1957, 368). 
The Venetian/Northern Italian influence on sacred music

Once there was a greater openness to developing church music that focused on clarity of the text, in the aftermath of Trent, composers got to work, often re-writing entire sections of the Mass in a modified chordal style. This style was quickly adopted by northern Italian composers including Ruffo in Milan, and by Adrien Willaert (14901562), his pupil Cipriano de Rore (1515-1565), and Gioseffo Zarlino (1570-1590) in Venice. Next to Rome, Venice had become the most important city in Italy for music, and by the end of the $16^{\text {th }}$ century it had developed its own distinct musical character, with the Church of St. Mark as the musical centre. ${ }^{69}$ Organists there were amongst the best in Italy, and instrumentalists were allowed to accompany singers in the church (Grout, 338). Spiritual madrigals became popular, as did polychoral motets using divided choirs. Both forms exhibited a more homophonic style of choral writing, where compositions emphasized chordal harmonies rather than polyphonic lines. As musicians circulated between the northern cities of Venice and Milan and throughout neighbouring countries, their local styles gained renown, providing opportunities to cross-pollinate their music with styles developing in Rome (O'Regan 1994, 555). ${ }^{70}$

Thus as a result of inference from the Tridentine regulatory process that text intelligibility was of great importance in the new style, future generations of post-Trent composers either devoted themselves to the more contemporary sacred monody or polychoral styles, or imitated the Palestrina's style, whose technique became known as stile antico ("ancient style"), the standard for $16^{\text {th }}$ century church music. In his role as an instructor at the Roman Seminary (1566-1571), like Ruffo in Milan, Palestrina fostered the growth of Italian composers through his teaching. Influenced by his northern 
counterparts, he continued to broaden his repertoire of musical styles, perfecting the spiritual madrigal style which he composed from 1575 onwards (Phillips 1994, 581).

Re-writing the music books

While composers were newly concerned with textual clarity in polyphonic works, there were also important implications for post-Tridentine reform of ancient Gregorian chant repertoire, including proper declamation and correct accentuation techniques. Plainchants used as melodic themes for Masses were a safe choice for composers who now understood that secular songs were strictly off-limits. A chant reform movement emerged that included reviving these traditional melodies and reconfiguring them where necessary to enhance the relationship between text and music. A precipitating event for the substantial reform of plainchant was the Council's requirement to revise liturgical books that aligned with the new standards. The order of service (the Breviary) and the words that were read or sung during the Mass (the Missal) were edited, reprinted and then distributed to dioceses so the revised Roman rite could be adopted (Atlas, 604).

That task completed, Pope Gregory XIII then wrote to Palestrina in 1577, stating that it was "most necessary that the music be cleaned up and regulated" according to the Trent rules, in order to "prune away" from these books their "superfluities ... barbarisms and obscurities. ...[C]hanting of sacred texts should not lead to any loss in clarity of the words, but that they should be declaimed as if they were not being chanted" (in Sherr 1984, 76). Palestrina and fellow composer (and former student) Annibale Zoilo were thus entrusted with the important job of revising the plainchants for the Gradual ${ }^{71}$ and Antiphonary ${ }^{72}$ aspects of the worship service. However, it was a lengthy process, and they eventually gave up the project. After Palestrina's death, the task was assigned to two 
other composers, Felice Anerio and Francesco Soriano, who completed the work twenty years later (Atlas, 605). ${ }^{73}$ The new edition of chant books led to production of an instruction manual designed to train singers in the correct performance of the revised versions of plainsong, which were now sung rhythmically rather than in free form.

From polyphony to monody; from spiritual madrigal to concert mass

The renewed emphasis on words sung to music influenced the emergence of the spiritual madrigal, a form of sacred musical that was a specific productive outcome of the Council of Trent. While music containing secular text was prohibited anywhere near or in the Church, the use of religious texts beyond the words of the basic Mass offered new opportunities for musical expressiveness by providing additional lyrics that could instill devotion in the listeners. Encouraged by powerful clerics like Borromeo, words of the psalms and prayers set to music were performed in both religious circles and in courts of the nobility.

Influenced by the growing popularity of secular madrigals and French chansons, sacred madrigals were widely published throughout Italy, allowing the genre to become popular in middle-class circles as well. ${ }^{74}$ Although madrigals began as polyphonic works, this new form of Italian solo song began using monody, which focused on one main voice proclaiming the text with the other voices or instrumental accompaniment aligning to it. Monody emerged partly due to a change in the way music was notated, with the melodic line and the accompanying harmonic progressions recorded on paper for the first time, and partly as the result of elevating songs to a higher level of artistry, with music adapted to the words of dramatic religious poetry. The overlapping of polyphonic and monodic 
styles around 1600 signaled the beginning of the Baroque era and the close of the Renaissance period (Lockwood, "Renaissance”, Grove Online).

In effect, Monteverdi became the bridge between these two periods by composing works he termed prima pratica ("first practice"), the style used by Palestrina that combined traditional polyphony with textual emphasis. He also composed in a new style he called secunda pratica that introduced instrumental accompaniment. Monteverdi's spiritual madrigals evolved to longer works and then to early forms of opera using sacred subjects. This produced a secularized musical form that directly influenced sacred music after Trent. The general nature of the Council's music regulations never precluded liturgical texts from being set to approved music, so professionally trained singers frequently performed operatic music using Catholic texts. The technically challenging and emotionally dramatic characteristics of arias and duets in opera found their way into Mass settings, giving these works popular appeal. Composers wrote sections of the Mass as separate movements, similar to separate scenes or acts as parts of an opera. This began an approved trend to mix features of both sacred and secular music.

\section{Instrumental music is heard in church}

Solo singing with instrumental accompaniment had long been practised outside the church. Even as secular solo and ensemble instrumental music for keyboard, string and wind instruments grew in the $1300 \mathrm{~s}$, music accompanied by anything other than the organ was rarely heard in church until the late 1500s. Instruments were associated with secular music, and Trent regulators had clearly stated that music that was "lascivious and impure, whether by instrument or voice" was not tolerated. Previously, introducing instruments into the sanctuary with hopes that the sound they produced would be 
complimentary to the reverential sonorities offered by a trained choir or organist was a gamble at best, since they were heavily dependent on the skill of the player and the quality of the instrument. Usually, neither was high. This probably accounts for the fact that "lascivious and impure" also referred to instrumental music that sounded downright unpleasant - out of tune, rough, inconsistent, clamorous and otherwise animal-like. Council members and church authorities before them were not being prejudicial to instrumentalists, but were simply trying to maintain an ambiance of peace and devotion inside the sanctuary, rather than creating a carnival atmosphere that clearly belonged outdoors, which one could ostensibly walk away from if the sound was offensive. Before 1600 , then, instrumental music remained subordinate to vocal music, and when it was heard, much of its repertoire was derived from, or dependent on, vocal models.

Evidence of the incorporation of instruments into church music was described by the English Catholic Jesuit, Gregory Martin, when he visited Rome: “... a man may goe to so many Churches in one day ... with such musike, such voices, such instrumentes. With the Organs a childes voice shriller and louder then the instrument, tuneable with every pipe. Among the quyre, Cornet or Sagbut ... above all the other voices" (Martin, 1581, in Atlas, 615). There were early references to instrumental music performed in Venice's Church of St. Mark, for example, to honour a visiting delegation of Japanese princes in $1585 .^{75}$ A document from the Cathedral of Seville in 1586 outlining the "Order that must be observed by the instrumentalists in playing" demonstrated that the use of instruments was becoming more commonplace in the late 1500s (in Atlas, 616). Adding instrumental accompaniment to church music also influenced the form of church music. Composers began doubling the voice parts of a cappella polyphonic works to 
provide instrumental accompaniment (colla parte). By the late 1500 s, instruments were used to embellish vocal lines, alternating sections with vocal parts, or taking over entire sections altogether. Another related development was the missa concertata (concert mass) featuring the use of instruments. The inclusion of instruments in church music was also driven by two interconnected developments: technological advances in the craftsmanship of instruments, and the introduction of tempered harmonies.

\section{The sound of music changes: harmony and the standardization of modes}

The Council of Trent signaled a transition from the ancient church music of monophonic chants unadorned by harmony and unaccompanied by instruments, to polyphonic works which included harmony as a result of multiple voice parts heard simultaneously. This ultimately led to the introduction of "new" notes that were not originally part of the modal scales. It is difficult to say exactly when this practice began, since there must have been adjustments made to strict modal composition before it was formally notated (Lawrence, 286). In any case, the introduction of a flattened seventh tone extraneous to the established modes was used to avoid the tritone interval and thus unpleasant dissonance, but it altered the modal system. Resistance to the new note diminished over time and new harmonies were introduced into music using the dominant seventh chord, a feature of early Baroque works. ${ }^{76}$

The harmonic pattern of dissonance and resolution in music signaled the demise of the stile antico of the $16^{\text {th }}$ century, encouraged melody accompanied by chords, and initiated song development without polyphonic influences. Plainsong was adapted by harmonizing the chant melodies and modulating away from the principle key to other 
keys, then returning to the home key. This added even more new notes, disrupting the sequence of whole tones and semitones that had given each mode its distinctive colour.

\section{Technological advancements in light of new harmonies}

By the early 1600 s, craftsmen were producing wind and string instruments that could maintain tuning accurately enough to allow the ability to play in all keys. Additional notes were placed within the octave on keyboard instruments in order to play in tune with other instruments. ${ }^{77}$ These considerations eventually limited the design of keyboards to twelve notes to the octave. A closed system of equal or "even" temperament (known as "regulation") divided the octave into twelve equally tuned semitones, allowing all intervals to sound the same regardless of where they were struck on the keyboard. ${ }^{78}$

Similarly, wind and stringed instruments benefited from enhancements as they were re-engineered and harmonically regulated to accommodate the even-tempered system by adding extra levers, more precisely positioning holes and frets on stringed instruments, and using higher quality materials. Following Trent, the significant improvements in instrument design that were taking place outside of the Church provided composers with opportunities to write music which included instruments that had previously been banned from the sanctuary due to their unrefined sound.

\section{Productive outcomes of regulation on musical forms}

A productive outcome of the new policies emanating from Trent was the liberating effect on what had been a static and backward-looking musical repertoire for the Church. Trent established a need for new compositions that demonstrated conformity to the new standard, providing composers working in and around Rome with new 
creative opportunities. While he was not the only composer involved in this transition, Palestrina held an important role by providing a compositional style that was approved by the church during and after Trent. In the period after the Council, Palestrina's works were regarded by historians as the musical ideal of certain aspects of Catholicism that continued to be emphasized even into the $19^{\text {th }}$ and $20^{\text {th }}$ centuries, and music of this period is still frequently performed today (Grout 1988, 330).

The fusion of music and words was elevated to an increased level of importance, with a focus on music's ability to complement the text and on words adding another layer of meaning to the music. This, in combination with the musical training of clerics, the revision and extensive publishing of music books, the technological advancements to instruments and their inclusion in church worship, the evolution from polyphony to monody, changes in harmonic texture, the decentralization of clerical power and the resulting Venetian and Northern Italian influence on new forms of sacred music, all contributed to a distinct Roman Catholic musical style. By the end of the $16^{\text {th }}$ century, polyphonic had achieved a high degree of perfection. In the early $17^{\text {th }}$ century, monody, based on different textural, structural, formal and expressive principles superseded polyphony, though $16^{\text {th }}$ century stile antico was never abandoned (Phillips 1994, 576).

\section{Conclusion: Guidelines for Change}

This case study provides some important observations about music regulation. First, the Council of Trent's efforts to protect the sacred element provided by music in worship was successful: the dignity that music had lost was restored. This was achieved by conducting a thorough and consultative institutional "hearing" that lasted eighteen years before a decision was rendered. This process allowed participants to fully discuss 
and debate the issues, and gave composers and musicians time to discover, try, test and refine new styles and practices. Thus, the process was negotiated, not dictated. Second, in order to gain buy-in, certain types of music, musical works and styles were held up as examples of music that was considered appropriate. The tribunal struck immediately after the Council by Cardinals Borromeo and Vitelli evaluated the then-current styles of and practices in church music. Once the new standard was established, composers were strongly encouraged to create music that conformed to what was deemed acceptable. Third, there was flexibility in terms of how regulations would be applied outside the centre of control, with a certain amount of leeway tolerated depending on local customs, traditions and practices. All of this contributed to a new church music policy which musicians were well-advised not to contradict, for fear of losing their coveted positions in the steady employ of the church. In short, resistance was futile.

Attali's view that music has the power to signal transformative change in society was demonstrated in this case study with the Tridentine Council's recognition that music was an integral vehicle for communicating the liturgy. Music served a dual purpose: to convey a spiritual message, and to create a mood of meditation and reflection during the worship service. In this example, music signified Attali's "representative power", in that it was inextricably linked to communicating religious doctrine. The action of bringing common "street" music into the sanctuary symbolized the church's loss of power over order and harmony. Dignified and reverential music communicated a message of control; profane, disorderly music represented loss of control. A by-product of the move to regain control through regulation brought about significant changes in music. 
Foucault's theory of governmentality describes the process of increasingly less rigid regulation, of a disciplinary power that results from the transformation of power from a negatively oriented concept towards a positive notion of power centering on the continual reinforcement of regulation through supervision. This example clearly shows the successful effects of governmentality, in terms of providing guidance, rather than forcing strict adherence to regulation through forbidding might. The Council set out guidelines for composers who in turn adapted existing musical styles so that the allimportant meaning of the words could be understood. Singers, organists and instrumentalists also complied by maintaining the sanctity of the service: in short, they "behaved". The regulatory technique used at Trent was ultimately effective by imposing restrictions in a way that did not stifle creativity.

Governmentality as a successful long-term strategy is evident here. Three hundred years passed before the Church felt the need to reiterate that only appropriately dignified music was to be heard in the sanctuary to maintain a measure of reverence. ${ }^{79}$ We were again reminded of the clever and enduring strategies adopted by the Council of Trent when, by a motu proprio of Pope Benedict XVI, the Tridentine Mass was pulled down from the shelf and dusted off in 2007 to be reinstated as an accepted form of the Catholic Church's official worship (CBC, 2007). The continued observance of this ancient regime over many centuries is a testament to its resilience. 


\section{Chapter Three}

"Putting the Sin in Syncopation" "80: New York City Cabaret Laws, 1926 - 1986

"In 1920, the best thing that could have happened for jazz [was the passing of] the most idiotic law in the history of the United States, Prohibition ... [as a result,] at one point in New York City alone, Manhattan had 5,000 speakeasies. Suddenly, there's ... tons of work for jazz musicians. Prohibition is loosening up morals. It's doing exactly the opposite of what it was supposed to do. ... the Jazz Age became a kind of umbrella term to this whole loosening up, this whole lubrication, thanks to Prohibition when everybody was drinking more than they should, just to defy an absolutely unenforceable law."

-- Gary Giddens, in Jazz: A Film by Ken Burns (2001)

An analysis of cabaret laws in New York - the only major city in North America ever to impose such restrictions - provides a rich study of music regulation by illustrating all three modes and regimes described in the analytic framework of regulation (see Appendix 3). This case study is much different from that presented by the Council of Trent, which illustrated aesthetic regulation by an institution. The negotiated process used at Trent lasted eighteen years before an actual "rule" materialized, and when it did, it was merely a guideline. In this case study, authorities mobilized within months to put the clearly worded New York City cabaret law into effect. Originally both a curfew and a licensing restriction, it was expanded with amendments and reinterpretations over the next sixty years to suit changes in political, economic, social and cultural conditions, therefore I consider the cabaret laws as a collection of regulations resulting from this complex layering of events. Jazz in New York City was affected by a co-mingling of the three modes of regulation, first as moral, then institutional, and shortly thereafter, economic. In terms of regimes, initially control of jazz was sought aesthetically. Regulation broadened by adding a spatial regime based on zoning restrictions via the cabaret law. Not long after, jazz was affected by a technological regime that controlled its distribution and duplication, but which also enabled its widespread popularity. 
In examining the actors and techniques used in this example and reviewing the outcomes, we can indeed observe Attali's theory of music as a transformative tool at work. Jazz was a bellwether for social order during a complex period of history which took its name from this music. Jazz Age music exhibited that quality which Attali called "prophetic", possessing ritual power to predict and enact social transformation.

\section{Historical Context}

Nearly four hundred years after the Council of Trent put forward its directives for the reform of music, the Vatican was once more weighing in on lascivious music. In 1924, it felt compelled to comment on the rising popularity of jazz and its effects on youth, and it was not amused. The New York Times reported that the Roman Catholic Church, had "severely condemned" dances such as the "shimmy" and the "camel's step". They were a "cause of flagrant immorality" because they "imitated animal movements", and the "distorted, panting notes of orchestras should be watched [sic] severely". 81 These admonitions, echoed by clergy from numerous religious groups closer to home, went largely unheeded. Influenced by demon drink, shimmying to jazz with wild abandon was all the rage in 1924. A stern warning, even from the Holy Father, would not stop it.

Jazz saw its beginnings at the turn of the twentieth century, starting in the southern United States with Scott Joplin's ragtime piano music and in New Orleans with Dixieland band music. In the early 1900 s, over five million African Americans had migrated from the South to northern cities in the West and Midwest with hopes of finding better jobs and greater equality, bringing their music with them. By 1910, Chicago had become a breeding ground for many young, creative musicians such as Louis Armstrong and Jelly Roll Morton. Saxophones and trumpets played melodies over a dance band 
rhythm section, and stride piano copied this effect, blending ragtime and New Orleans styles to create a new "Chicago Jazz" sound. With the invention of the phonograph, the proliferation of radio, and the constant movement of musicians seeking employment, jazz spread rapidly in popularity throughout the US, from Chicago to New York City's Harlem district, and west to California. This spirited new music was performed mainly in saloons and other drinking establishments by talented black musicians.

Just as polyphonic music became a powerful symbol in the $16^{\text {th }}$ century Catholic Church, jazz emerged as an equally important symbol of the rise of American individualism and the increased emphasis on the pursuit of enjoyment and leisure activities after the misery and destruction experienced during World War I. Many members of society felt there was a little too much spirit, calling for more formal controls over the consumption of alcohol. Groups as diverse as the Women's Christian Temperance Union, the Ku Klux Klan, the Prohibition party, the Anti-Saloon League of New York, and the "Progressives" (mainly pious Protestants from both the Republican and Democratic parties) joined efforts to lobby Congress in passing the 18th Amendment to the United States Constitution. To their relief, Prohibition law came into effect in America in January 1920, banning the sale, manufacture and distribution of alcohol, in order to combat the moral and social ills associated with drinking (Miron, 1991). ${ }^{82}$

Because alcohol was not illegal in nearby countries, distilleries in Canada, Mexico and the Caribbean flourished as their products were either consumed by visiting Americans or illegally imported into the United States. Disobeying Prohibition law was commonplace during this time, and as quickly as law enforcement officials shut down drinking establishments across the country, illegal bars vigorously sprouted up. In New 
York and Chicago, notorious gangsters such as Al Capone made millions of dollars by overseeing the bootlegging business and controlling thousands of speakeasies, named after the need to whisper a password, or to "speak easy", in order to enter them. Once inside these obscure but ubiquitous nightlife venues, there was plenty of alcohol available, and music was supplied by vaudeville acts, cabaret singers and other jazz performers. It was in these establishments of New York City where jazz music became the target of intense regulation through "cabaret laws", first instituted during the 1920s, amended several times over five decades, but continuously enforced until the late 1980s. While Prohibition laws had the reverse effect of actually encouraging jazz, the cabaret laws attempted to counteract the effect of this imbalance, as Gary Giddens notes above.

\section{The Actors and their techniques}

In this case study, actors played roles in all three regulatory modes and took clear sides for and against the regulation of jazz. Initially there were many "publics" that took a stand against jazz, calling for legislation against it. These were disaggregated into several factions, and included the moral public, music traditionalists and commentators.

In the late 1910 s, there was public concern about boisterous dance music that was seen to threaten the preservation of moral standards which could de-stabilize society. Public dancing had gained popularity following WWI, representing not just a celebration but providing a healthy antidote "for overwrought nerves and shellshock ... an agreeable prescription for returning soldiers". ${ }^{83}$ However, fueled by alcohol and "frenzied jazz music", 84 dancing soon took on a form that was thought to be so degrading and evil that it was condemned by the Church. Since it could not possibly have been alcohol that caused the multitude of social ills (after all, it was prohibited), jazz music became "greatly 
responsible for immoral dancing", ${ }^{85}$ and a scapegoat for the real cause of morally reprehensible behaviour: demon drink. Moral outrage inspired numerous appeals for the regulation of dance halls and the censorship of the music heard within. Parents especially were warned to prevent their children from listening to jazz, dancing to it, or frequenting any public place where it could be heard.

By the early 1920s, there were overwhelming calls by certain members of New York society to ban all performances of this new music. The loudest chorus of disapproval came from a vehement group of moral and religious actors who warned that jazz was "degrading, and an agency of the devil", "invented by demons for the torture of imbeciles", 87 "a barbaric pastime and a sensuous menace", 88 "a picture of the world fiddling, while the rest of the world burns up like Rome under Nero", ${ }^{89}$ and furthermore was the cause of many unpleasant afflictions and social states, including madness, ${ }^{90}$ intoxication, ${ }^{91}$ divorce, ${ }^{92}$ and suicide. ${ }^{93}$ This moral public included clergy, educators, parents and social commentators who were fearful of the influence of jazz music on children and youth. As opinion leaders, their urgent appeals were aimed mainly at institutional actors including local politicians, civic leaders, judges, government officials and police. In turn, that group, responsible for upholding civil order and keeping the peace, became vitally interested in controlling the power that jazz possessed to "alter listeners' emotional, physiological and cognitive states" (Appelrouth 2005, 1497).

Jazz challenged pre-meditated musical forms and encouraged concepts of improvisation and individuality that were absent in conventional concepts of western music. The uninhibited qualities of jazz - factors which contributed to its immense popular appeal -- were frowned upon by the guardians of classical music. This actor 
group also supporting jazz regulation included composers, conductors, classical musicians, music educators, music critics and other highbrow cultural elites. These wellestablished music traditionalists were troubled by the possibility that their art could be displaced and felt the need to protect and preserve both their long-standing reputation and their economic livelihood. Their protests were added to the moralists' cries, though for completely different reasons. Jazz was a threat to their belief in upholding certain aesthetic standards, and proceeded to cast doubt on the legitimacy of jazz, questioning its artistic relevance to society.

Actors who resisted or arbitrated against regulation included those who established the physical spaces where jazz could be heard were club and cabaret owners and their lawyers. ${ }^{94}$ Other actors who promoted the performance of jazz were businessmen and impresarios, motivated by opportunities to capitalize on the art form's popularity amongst those who were not offended by it. Obviously jazz musicians themselves had a vested interest in resisting regulation, viewing attempts to control their performances as outright censorship. The musicians' union played a somewhat conflicted dual role of being both for and against certain forms of regulation. The union's primary purpose was to keep its musicians working and to ensure that fair wages were paid, so it resisted any efforts to the contrary. However, the union was also a business insofar as it was equally determined to increase its membership and collect its dues, so it exerted forms of economic regulation which in turn had the effect of aesthetically regulating jazz. Filling out the regulatory roster were audience members who supported jazz, albeit in a relatively passive way, by attending performances and paying fees to listen, dance and drink to it, by enthusiastically purchasing sound recordings of it, and by listening to live 
and recorded performances of jazz via radio broadcasts. Another powerful actor group in this regulatory event were the commentators, whose views were represented in the press.

\section{Moral regulation of jazz through the lens of the press}

The underlying concern over jazz stemmed from the fact that this was music with black origins, highlighting issues of shifting race relations caused by the migration of African-Americans from the South to the North during this time. The moralists and music traditionalists of New York society were alarmed by this popular music with black roots, claiming that it was lewd and dangerous to public morals, could be particularly damaging to youth, and moreover offended the sanctity of Western classical music, but covertly this was purely an indignant reaction to the loss of status (Cohen 2002,166). The press sometimes made passive observations on these views, but the majority of the commentary was anti-jazz, fuelled by writers and journalists who regularly positioned themselves as experts on the moral, psychological, spiritual and physical hazards that they believed jazz produced (Anderson 2004, 141). Racial innuendoes about jazz appeared in stories attempting to initiate a discussion the authors believed would disenfranchise jazz by stigmatizing jazz musicians. Often this was done by portraying the black race as savage. Newspapers and magazines carried articles with titles such as, "Primitive, Savage Animalism -- Preacher's Analysis of Jazz", 95 "Why Jazz Sends Us Back to the Jungle", 96 "The Appeal of Primitive Jazz", ${ }^{97}$ and even "The Jazz Problem", 98 a thinly veiled critique of jazz music focusing on the racial elements of various concert performances of jazz.

The press also reported on events where these views were expressed in public. Respected members of society such as professors and clergymen spoke at public 
meetings and preached to congregations, warning that "Jazz music ... [is] turning modern men, women and children back to the stages of barbarism", and that "Jazz is retrogression. It is going to the African jungle for our music. It is a savage crash and bang. It makes you clatter on all fours and whisk your tail around a tree". ${ }^{100}$ Stern reminders recalling the warnings of the ancients were invoked: "Plato said that whenever modes of music change, morals change. Music has changed greatly ... we have had storms of all kinds - international and inter-racial. Jazz ... clos[es] our ideals, even our humaneness". 101 Jazz musicians were characterized as "contemporary savages", violent animals who "bang on barrels" and played music that "invokes savage instincts". 102 This discourse instilled a culture of fear by suggesting that listening to jazz could make white people just as savage as they allegedly believed blacks could be.

Stories in the press also appealed to the sensibilities of the music traditionalists. Reports warned that jazz insulted the sensitivities of an audience accustomed to the western classical music aesthetic through the frequent use of the still-problematic "devilish" tritone in jazz that created dissonant harmonies, and improvisational performance that disrupted European-influenced compositional styles. Moreover, one of jazz's most powerful stylistic characteristics was the use of syncopation and other unusual rhythms based on African influences. Music critic M.B. Levice warned that in the past, drums had led to savagery, and rhythm had been known to intoxicate adults and children. In a full-page New York Times article, Levice denounced the saxophone as an "esthetically immoral" musical instrument, able to "produce indecent tones". ${ }^{103}$ In their efforts to contain this threat, the musical traditionalists attempted to influence public opinion by articulating their concerns in a manner similar to the moralists' strategy. Both 
groups identified jazz as a symbol of disorder in society, suggesting that jazz could undermine behavioural standards and challenge aesthetic values. To these actors, jazz was intrinsically "bad" music because it represented something morally reprehensible.

Moral panic in New York City: jazz as a "folk devil"

The war on jazz was a textbook case of Stanley Cohen's concept of a "moral panic", which notionally assumes that the reactions triggered by certain episodes are disproportionate to the actual threat they pose to the community (Cohen, 2002) ${ }^{104}$ This concept is underlined in the related work on moral panics by Erich Goode and Nachman Ben-Yehuda, who note that while interest groups may have different moral and economic motivations, they are often connected. "Advancing a moral cause ... almost inevitably entails advancing the status and material interests of the group who believes in it; likewise, advancing the status and material interests of a group may simultaneously advance its morality" (Goode and Ben-Yehuda 1994, 166).

The infiltration of jazz music throughout New York City and its characterization as a "folk devil" 105 follows precisely Cohen's depiction of the various stages of a moral panic: first, a warning (concern that the current tranquility could be upset); then, a threat (communication is disseminated about the approaching disaster); then, the impact (the folk devil emerges); followed by an the inventory of reports (those exposed to the devil describe what has happened and report it to the media); next, the rescue and remedy take place (formal activities are undertaken to relieve those affected); and the final stage, recovery (a return to the former equilibrium, or else achievement of stable adaptation to the changes the devil has invoked) (Cohen 2002, 12). 
Moral panics necessarily involve the media, and there were plenty of newspaper and magazine articles from the late 1910 s to 1930 expounding on the troubles with jazz. This inventory by the popular press provided a platform for communicating the moral and artistic issues and the press became the primary theatre for the war on jazz. Many news stories from the early 1920s warned of the problems of jazz: its destructiveness, its potential for proclivity towards immorality, its negative impact on youth, and its representation as a style of low-brow music. From 1920 to 1926, the New York Times alone ran nearly 400 stories about jazz, the majority focusing on moralist anxieties over its growing popularity. Headlines such as "Wants Legislation to Stop Jazz as an Intoxicant"106 and "Judge Rails at Jazz and Dance Madness"107, served to equate jazz with alcohol addiction and madness. The report of a lawsuit initiated by the Salvation Army over fears that music from a theatre planned to be built near an unwed mothers' shelter "would implant jazz emotions in babies born in the home"108 would have caused further alarm to Prohibitionist sensibilities. An article in The Etude magazine attacked jazz's future, stating that "Jazz will eventually fade and be replaced by 'high-brow' classical music". The author continued by mocking jazz fans, claiming that "in ten to twenty years, jazz will be liked, [but] little do they know the public!" (Fink 1924, 528).

Articles against jazz appeared in other publications that upheld middle-class morals, such as the Ladies' Home Journal. In the August 1921 issue, the national chairwoman of the General Federation of Women's Clubs warned that jazz's "demoralizing effect on the human brain have been demonstrated by many scientists"; that jazz was "the expression of protest against law and order" and that "jazz disorganizes all regular laws and order; it stimulates extreme deeds, to a breaking away from all rules 
and conventions; it is harmful and dangerous, and its influence is wholly bad" (Faulkner 1921, 16). Later that year, the same publication ran a story entitled, "Unspeakable Jazz Must Go" offering the following opinion on music:

Those moaning saxophones and the rest of the instruments with their broken, jerky rhythm make a purely sensual appeal. They call out the low and rowdy instinct. ...We have seen the effect of jazz music on our young pupils. It makes them act in a restless and rowdy manner. ...They can be calmed down and restored to normal conduct only by playing good, legitimate music. (McMahon, 1921, p. 34)

The inventory of stories was not always negative, however. As the moral panic shifted to the "rescue and remedy" stage, away from the threat of inevitable societal doom propagated by the jazz nay-sayers, there were countervailing efforts by prominent white musicians who worked to legitimize jazz music in New York City. These included conductor Paul Whiteman, band leader and pianist Vincent Lopez, band leader and composer Roger Kahn, composer Irving Berlin, and composer and pianist, George Gershwin. Whiteman, dubbed the "King of Jazz" in the press, was one of the first to help de-stigmatize jazz for dubious members of the New York public by concert-izing the music heard in nightclubs with performances of his orchestra in concert halls, and by making sound recordings of jazz on the Victor and Columbia labels. In an historic February 12, 1924 concert advertised as "An Experiment in Modern Music" at the Aeolian Hall, Whiteman presented a variety of jazz styles. The concert was designed to educate the audience, curious about this new music, by helping them gain a better understanding about how jazz had progressed from its "crude" origins to the refined heights of popular music. Whiteman hoped to win over the censors by eradicating concerns that jazz was low-brow by making it more symphonic and less improvised. Bringing it into the concert hall made it a more respectable art form. The evening 
culminated in a premiere of George Gershwin's concerto Rhapsody in Blue which mixed European styles with African American influenced jazz. There was "tumultuous applause for Gershwin's composition" and the composition was declared a triumphant success. ${ }^{109}$

Towards the end of the 1920 s, news articles began to shift in focus away from the evil influences of jazz on society to debates about whether jazz was a legitimate art form compared to classical music. In 1927 the Times published a full-page article by eminent British music critic Ernest Newman entitled "Summing Up Music's Case Against Jazz", ${ }^{110}$ a well-argued case that jazz was nothing more than "a bundle of tricks which restricts the serious composer's power of imagination". The article provoked a full-page rebuttal the following week by Paul Whiteman, entitled "In Defense of Jazz and Its Makers", 111 calling jazz a "new art" and "the folk music of the machine age". For the rest of 1927 these two musical authorities volleyed back and forth in the press and others joined in the debates for and against the artistic merits of classical music, jazz and “pseudo-jazz".

During the next decade, the press continued as the major site for public debates over artistic regulation. White jazz critics such as John Hammond, who favoured Billy Holiday's unique vocal sound and Count Basie's swing, and Roger Pryor Dodge, who preferred the New Orleans style rather than the classicism of Paul Whiteman, debated jazz's authenticity in their writings. Dodge, who coined the term "pseudo-jazz" after attending Whiteman's experimental Rhapsody in Blue concert, favoured the purity of Harlem jazz, improvisation, and Ellington's long-form development, suggesting that "the golden age of jazz [i.e., the small-ensemble, hot jazz of the 1920s] preceded a profound aesthetic decline into symphonic jazz, commercial swing music, and the modern jazz of 
the 1940s" (Dodge, in Anderson 2001, 11). This intellectual discourse did not interest the moralists, however. The "inventory" of persistent media reports that described the ill effects of jazz continued to fuel the moral panic.

Economic regulation of jazz begins, while moral regulation continues

Considerable concern had been raised over fears that the wild qualities invoked by jazz could cause a shift in behaviour patterns and an infiltration of lower class standards of decency. There was a call for regulations that would limit performances to specific areas of the city in order to minimize community disturbances and lessen the impact jazz purportedly had on class structure. These worries continued despite the efforts by businessmen such as Otto Kahn whose actions leant credibility to jazz. A society man, Kahn was a wealthy New York banker, an arts patron ${ }^{112}$, and father of Roger Kahn, a gifted sax player who led a jazz orchestra. Kahn Sr. purchased Ciro's night club to showcase his son's band and financed a deal allowing Roger to assemble a series of jazz orchestras for the Statler Hotel chain. ${ }^{113}$ Through these actions, Kahn not only demonstrated that jazz was an art form worthy of respect, but he also represented a group of actors with completely different motives than those of the moral regulators. These businessmen controlled jazz under a mode of economic regulation.

While jazz gave dignity and pride to blacks since it was music for and about them, it became an extremely popular form of music for whites, some of whom sought to take advantage of its popularity, and looked for ways of capitalizing on it. As a result, there were attempts to commodify the growing popularity of jazz by producing and selling a "whiter" flavour of jazz, characterized by the highly orchestrated style performed by the orchestras of Whiteman and Lopez. In 1925, Lopez saw the economic benefits of 
popularizing jazz, and, similar to Kahn, proposed selling shares in an enterprise that would offer jazz orchestras to be hired by large hotel chains. His idea was to "train orchestras so that if you ordered one from us anywhere in the United States, you will always get the same thing and know what you are getting". ${ }^{114}$ Lopez also planned to establish an innovative jazz school that would broadcast jazz lessons over the radio, thus acting as a source of properly trained players with which to feed the hotel orchestras. While the details of Lopez's financing were a little hazy (the Kahns eventually landed the contract with Statler Hotels), Lopez insisted that his were orchestras, not jazz bands, and he boasted about their use of "the best arrangements [and] the richest harmonic effects", noting that "any good jazz orchestra is entitled to serious consideration from the musical standpoint". 115 This polished form of jazz was decidedly different from the raw, improvised, "authentic" jazz heard in the cabarets of Harlem. ${ }^{116}$ The efforts by Kahn and Lopez characterized a movement to commodify jazz by distinguishing a form of it that would presumably appeal to white tastes. This concertized version was viewed as higherclass and more acceptable to white society, especially since it was performed in high-end hotels and concert halls. Jazz performed in these spaces would also serve to exclude black audience members, most of whom could not afford to attend.

This enterprising spirit was echoed in Whiteman's successful attempts to appease the curiousity of New Yorkers who had never ventured into a night club or cabaret by bringing jazz to concert halls and theatres. Whiteman was a dedicated musician who spent considerable energy upholding the legitimacy of jazz with his frequent public comments in defense of jazz against traditional views of music ${ }^{117}$. He was also a shrewd businessman and impresario who saw an opportunity to capitalize on jazz's growing 
popularity. Conforming to union regulations that black musicians could not join white unions (Kraft 1995, 519), up until the late 1930s Whiteman hired only white musicians to perform publicly with his orchestra, though he frequently hired black musicians to play in the recording studio. ${ }^{118}$ His aim, first and foremost, was "to make a lady out of jazz" (Welburn 1987, 43), and it was his music that was identified with the notion of jazz emerging in the average white American's consciousness. Aware that this flavour of jazz was not just more palatable but highly marketable to a larger, well-heeled audience, the performances served up by Whiteman, Lopez, Kahn and others resulted in taste-shaping that grew out of a desire to profit from commercializing the jazz product. This mode of economic regulation through commercial control of music was enacted under an aesthetic regime that altered the artistic features of the music to increase its acceptance by a wider audience. Even this economic-artistic regulation did not reduce the large numbers of New Yorkers who enthusiastically made the trek uptown to Harlem to see, hear and dance to the real thing at The Cotton Club, which had become the premier "black and tan club", providing black entertainment exclusively for white audiences. While New York society was slowly getting used to the kind of jazz mediated by the "white man's" music machine, there were others that preferred their jazz aesthetic "hot".

Yet another actor that exerted a form of economic regulation over jazz was the union that represented musicians themselves, the American Federation of Musicians (AFM). In an effort to curb the importation of "cheap jazz players" 119 from European countries who were effectively displacing American musicians, the AFM sought to categorize all musicians as labourers rather than artists, eliminating any special treatment of aliens. Many foreign jazz players were imported by night club owners and hotels under 
a professional artist exemption, rather than using contract labour laws that prohibited the importation of regular workers on promises of employment. While the effort to provide economic protection was applauded by American musicians, it had a reverse effect on artistic creativity. By limiting the influx of non-American musicians, encouraging new aesthetic influences and explore interpretive possibilities for jazz was restricted.

None of these economic forms of regulation were powerful or prominent enough to overtake the moral panic seething forth over jazz, however. Starting with Prohibition, fueled by the influx of different races to the city, deeply-held beliefs involving racial discrimination and class stratification boiled to the surface and churned the consciousness of a powerful segment of New York society. The moralists grabbed hold of the jazz folk devil, and they would not let it go. Although frequenting cabarets, dance halls and night clubs to listen, drink and dance to jazz appealed to many citizens as a leisure activity, middle- and upper-class reformers continued to insist on the need for increased regulation of these spaces to curb the excesses promoted by these establishments. A well-oiled Temperance machine was already in place, and although moralists believed, albeit naively, that the issue of drinking had been settled by establishing social dominance through political means - even though it was virtually unenforceable - Prohibition was at least a triumph of respectability over its opposite: indecency and disorder.

\section{Institutional regulation of jazz venues}

The reformers felt compelled to uphold the moral high ground and they could see that cabarets were sites of disorder that encouraged unruly behaviour. By 1926, the

moralists had had enough, so numerous urgent calls were made for the civic regulation of cabarets by various interest groups, religious leaders and individual citizens, demanding 
that at a minimum, curfew restrictions and licensing requirements should be placed on clubs where jazz was performed. This public outcry demonstrated a reconfirmation of the need to maintain decency by regaining control over the production and consumption of jazz, and to prevent further any destruction this music had wrought over the individual, New York society, and even against civilization itself! The well-publicized and regular public debates and forums kept the reformers' concerns in front of civic leaders, pressuring them to step up and take charge of the situation. All politicians appreciate the opportunity to involve themselves in high-profile issues, and since a new Mayor had just been elected, late 1926 was the perfect time to institute some new statutes. If nothing else, doing so would keep him high in the popularity polls.

Thus began the "rescue and remedy" stage of the moral panic. The call for civic action could not be ignored by politicians, especially the new Mayor, James J. Walker. After holding three public hearings attended by licensees, cabaret owners, their lawyers, and by representatives of musical organizations, the city aldermen passed the cabaret laws by a vote of fifty-eight to two on December 7, 1926. Private clubs and larger hotels with cabarets where food was served were exempted from the bill, which some aldermen felt was "discriminatory legislation", but in the end the majority was won over as "its adoption was urged by the Police and License Commissioner, by clergymen of various religious denominations and by citizens interested in social and recreational work". ${ }^{120}$ Mayor Walker made the curfew bill effective January 1, 1927, declaring that all night clubs and cabarets in New York City were to close by three o'clock each morning. In a move that also controlled the ownership of night clubs and cabarets, the city council included in the legislation that a cabaret license was required for 
... any room, place or space in the city in which any musical entertainment, singing, dancing or other similar amusement is permitted in connection with the restaurant business or the business of directly or indirectly selling the public food or drink (Proceedings of the Board of Aldermen, New York City, 7 December 1926, p. 573, in Chevigny 1991, 56).

The council reported that the new legislation was primarily based on concerns that "when strangers came to New York City, they wanted to run wild", and declared that such "wild people should not be tumbling out of these resorts at six or seven o'clock in the morning to the scandal and annoyance of decent residents on their way to daily employment" (in Chevigny 1991, 56). The statutes, then, were based on "regulation as denigration" (Chevigny 1991, 54), by attempting to regulate sites that were considered to be degenerate entertainment, controlling the "wild" tourists from the hinterlands, and by discouraging the racial mixing in Harlem clubs due to jazz's growing popularity.

Although the 1926 cabaret laws (which were both curfew and licensing statutes) were justified in terms of enforcing Prohibition and combating the criminal activities of gangsters who owned many of the speakeasies, they were a clear example of the use of city ordinances to regulate the moral and artistic standards of the community. These regulations effectively made legislators into moral gatekeepers, turned nightclub owners into suspicious entrepreneurs (who were committing a criminal offence if found operating without a license and were fined), ${ }^{121}$ intimated that musicians playing in the clubs were degenerates, cast doubt on the morals of audience members who frequented these establishments, and served to reconfirm the beliefs of those whose feet were firmly planted in the moral, religious and music critique camps.

Heaping on the regulations: carding and zoning

The original cabaret laws were followed by a series of amendments that, taken together, had an enormous impact on music and musicians in New York City for the next 
sixty years. In 1931, the police took over the licensing function which was separated from zoning and safety issues, effectively turning the law into an instrument of control over cabaret employees (Chevigny 1991, 57). Beginning in 1940, all cabaret employees including waiters and musicians were required to register for a cabaret card and be fingerprinted by the police. Cards were issued only to those deemed to be of good character. Anyone with a prior arrest record, regardless of whether or not their offense was related to the specific cabaret, could be denied a card. The city's approach prevented jazz musicians with any criminal offense - from more serious narcotics charges (as was the case for Billie Holiday, Charlie "Bird" Parker and Thelonious Monk) to a failure to pay parking tickets - from making their livelihood in New York clubs, effectively equating nightclub entertainers without a card to criminals. Now musicians themselves were regulated, their personal reputation in question - they were "guilty" if they attempted to play in a nightclub without a card. This oppressive control only added to the musicians' feelings about the subversive nature of jazz and it affected their mood and demeanor. There was never a specific reason given for the identity card regulation, but Chevigny has suggested that perhaps it was enacted as an anti-radical measure, since many unions were dominated by Communists $(1991,58)$. In the twenty-seven years following the amended legislation, each time the carding regulation was fought in court, no matter who appealed it, $^{122}$ the justification given was always that identity cards were meant to curb corrupting influences on the patrons by preventing the employment of criminals and undesirables. The racist impulse to control allegedly immoral black music morphed into a more indistinct purpose: to shield patrons from "undesirable" influences (Chevigny 1991, 59). 
Perhaps it was the patrons themselves who should have been carded. The musicians were only trying to make an honest living playing in clubs - it was not their behaviour that was under scrutiny. As if the indignity of the requirement for artist identification cards was not enough, the regulatory scheme was magnified when combined with the original zoning restrictions from 1926 that limited cabarets to certain neighbourhoods in the city. Not surprisingly, these were centred around Harlem. Zoning was a way of hiding or excluding business or pleasure use of venues that civic governments found dangerous or controversial (Chevigny 1991, 56-7). Since the law stated that "places of large entertainment" such as hotels were exempt from these regulations, it seemed to be targeting mainly the numerous smaller clubs in Harlem where jazz was performed. It was in these more intimate venues that jazz thrived, promoting lively interaction amongst performers, and between performers and the audience who could experience the dynamic interaction of artists at work. Jazz musicians viewed the smaller speakeasies, dance halls and nightclubs as nurturing environments where their improvisational skills could be honed in front of a live audience (Erenberg 1981,123).

By the early 1950s, it was not enough simply to have an identity card to be permitted to play music, or a license that allowed music to be played in a club. The venue itself also had to comply with zoning regulations which included conformance to rigorous safety standards. ${ }^{123}$ This prevented many restaurants and clubs that were not located in the permitted zones from offering live music. Initially, challenges to these rules by club owners were fought based on zoning by-laws that were recommended by police for city planning interests. For police, the regulations became a way of controlling "unruly elements" that were supposedly associated with jazz. For city planners, zoning 
regulations created an environment free of crowds and congestion that live performances might allegedly provoke. Restricting jazz clubs to designated entertainment zones indicated an ongoing distrust of street life, social diversity and racial integration.

To mitigate these spatial regulations, in 1955, Local 802 of the AFM proposed an amendment to the cabaret laws to change the definition of what a cabaret was, which would then at least allow the performance of "incidental musical entertainment". This provision allowed a maximum of three musicians to perform in zones where cabarets had previously been forbidden, but they were limited to playing only piano, organ, accordion, guitar, or any stringed instrument. Recorded music was the only other alternative. This proposal relegated music to being part of the background ambience rather than the centre of attention. The union felt that this was an acceptable concession by providing musicians with increased opportunities to perform in some of the more upscale restaurants and nightclubs that were not located in designated zones where music was allowed. After considerable legislative wrangling, the change became effective in 1961.

Unfortunately, although proposed by the union for the benefit of musicians, the amendment was a disaster. In addition to the existing modes of institutional, economic, moral and an aesthetic regime, now the "incidental musical entertainment" amendment to the cabaret laws set out limitations that controlled the performance of jazz. The 1961 amendment was also problematic because entertainment tastes were changing during this period. Nightclubs were declining in popularity but coffee houses began to flourish. Jazz musicians saw an opportunity to offer their services in these new, trendy venues; however, once again, sites of production for jazz fell under regulatory scrutiny. Many of these establishments were located in Greenwich Village which was mainly a residential 
area. Residents began to complain about the increased traffic and noise in their neighbourhood, so police began to issue summons to the café owners claiming that they were operating as unlicensed cabarets. ${ }^{124}$ In addition to difficulties imposed by complying with cabaret licenses, owners of night clubs, restaurants and cabarets operating in one of the most expensive cities in the world had to deal with expensive rents, sky-high real estate costs, burdensome city taxes and a construction contracting business run by the mob. All of this resulted in the closure of many clubs within a few years of opening. ${ }^{125}$

The cabaret laws were not the only cause of club closures. Well before the 1960s, New York's once-vital $52^{\text {nd }}$ Street music scene suffered what was reported as “a total collapse" in the 1940 s. ${ }^{126}$ Other factors that contributed to the decreasing number of night clubs offering live music included competing forms of popular entertainment (such as phonographs and film); the economic and societal effects of war; and the emergence of new forms of music (big band) and entertainment (such as larger format variety shows) that did not fit the intimate club atmosphere. These troubles added to owners' frustration as another amendment was added to the last, creating a patchwork quilt of regulations that blanketed what had been a burgeoning cabaret scene. It took patience, an altruistic dedication to jazz, and significant financial means to own a jazz club in New York City.

\section{The Musicians' Union: hurtful, not helpful}

The musicians' union played a unique role as an actor in this study in that it was both a regulator and a resistor, sometimes at odds with itself by frenetically playing both roles at once. As early as 1890 , musicians in New York City had legally organized themselves, and later joined the New York-based national AFM organization when it was 
formed in 1896. Similar in many ways to the musicians' confraternities that had formed after the Council of Trent, the AFM had its origins in the "guild" tradition, requiring members to adhere to their own regulations and to stick together against outsiders, thus imposing tight discipline that helped unite members, allowing the organization to remain effective and powerful. The AFM maintained its power through internal discipline extended to employers through the union's virtual monopoly of the supply of music. Therefore it was difficult for a musician to work outside the union or for any venue to hire a band unless it was a union band (Chevigny 1991, 26). The union's most stringent rule was that members were forbidden to play with non- members. In New York City this regulation was strictly enforced with its concentration of jazz musicians and clubs.

The union rose to prominence in New York in the early 1920s when Local 310 successfully negotiated a 40 percent wage increase for its members in vaudeville houses (Countreyman 1948, 65). While this appeared to be a triumph, it was short-lived. For the most part, jazz musicians were left on their own to scrounge for a living, constantly facing both musical and economic challenges. Players were forced to work in an oppressive environment within the confines created by the early cabaret laws. They were restricted by where, how, with whom and on which instruments they could play their music. For many years, the union paid little attention to these issues. The organization was complacent, speaking up in hearings against the 1926 cabaret laws but resigning itself to the ruling, realizing over the next decade that the majority of its paying members were the increasingly expanding number of relatively well-paid (mainly white) musicians who played in the larger licensed establishments and hotels. The union was racist, forcing black musicians to start their own unions, and preventing blacks from joining white 
unions. It was dismissive, doing little more than mildly protesting the carding of musicians, since the problem was viewed as one between venue owners and the City, and was only an issue in New York City (Chevigny 1991, 6). Finally, the union was meddlesome, if not short-sighted, pushing for the incidental music amendment which in turn created a multitude of problems for musicians and club owners.

The incidental music amendment proposed by the union was meant to open up the market for musicians and venue owners by encouraging the performance of background music in restaurants, but there were concessions tied to expanding these new performance opportunities. Outwardly, constraints were imposed so that music contributed only pleasant enhancements to these venues. Covertly, the restrictions prevented "undesirable elements" (the sound of "lower class" music) from creeping into posh restaurants, confirming the existence of an undercurrent of racism and general discrimination against "wild" jazz that lay behind the exception. The amendment resulted in severe restrictions in the way jazz was performed.

Musicians were barred from playing wind (including sax, trumpet, clarinet and flute) and percussion instruments in venues that lacked a cabaret license. ${ }^{127}$ These limitations eliminated traditional elements of jazz itself (saxes and drums). Looking back at the restrictions, it is incredible that the union allowed this to happen. Was it because the music produced in these venues was considered too loud? Any musician knows that an entire orchestra can play at a decibel level just barely over a whisper. It could not have been an issue of noise, since amplification of permitted instruments (piano, voice, and strings) was allowed, as were juke boxes, so music could be performed at ear-splitting volumes without contravening the regulations. I suggest that the union was acquiescing to 
the earlier intolerance towards the prohibited instruments. There was still a stigma attached to saxes (they were immoral) and drums (they were intoxicating) carried over from the 1920s. Such preconceived notions were not easily shaken.

Musicians did not want to appear confrontational because they needed the income from playing in the smaller venues since these were the only places in which lesserknown musicians were hired to play. Even the union felt uncomfortable intervening by negotiating directly with the clubs, since it was the union that had proposed the amendment in the first place. Many clubs were financially fragile and the union did not wish to upset that balance any more than it had already done.

The AFM's New York chapter finally began to consider these issues in the 1960s and seriously take up the cause for jazz musicians against the mounting regulations, though only after the club scene had greatly diminished from its peak in the 1920s and 30s. With the City's technique of digging a deep regulatory trench by piling on new exceptions, amendments and additional zoning and licensing restrictions, it seemed to be capable of resisting change indefinitely. The union, musicians, and remaining music venue owners had been lulled into a mindset of complacency. The rules were what they were - they came with the territory, and for musicians, complying with regulations was a compromise they had to make for the privilege of performing in New York City.

Union leaders and frustrated musicians who were not allowed to perform tried to find ways of resisting what became known as the "three player" rule throughout the 1970 s and early 80 s, but to no avail. That changed when New York law professor and jazz aficionado Paul Chevigny became aware of the dilemma and offered to intervene. Argued on the basis that the laws were discriminatory and restricted freedom of 
expression, the incidental music entertainment amendment was disputed via a lawsuit spearheaded by Chevigny. It was filed in May 1986 by Local 802 of the AFM on behalf of Warren Chiasson, a Canadian vibraphonist working in New York who had been repeatedly denied the ability to perform in clubs because of the instrument he played. In January 1988, a Supreme Court judge declared the entire exception unconstitutional and struck down the law (Chiasson v. NYC Dept. Consumer Affairs, 1988). He later privately commented that the City had gone "much too far" (Chevigny 1991, 130). Two more years of protracted bureaucratic wrangling ensued before the City finally rewrote the zoning rules which would allow any number of musicians to play any instrument they wished, anywhere bars and restaurants were permitted. Musicians were finally free from the stultifying regulations that, ironically, had been instigated by their own union.

\section{The dissolution of institutional regulation}

In contrast to this triumphant though sluggish victory, one of the more repressive aspects of music regulation facing jazz musicians earlier in the century literally disappeared overnight, and it happened through no effort on the part of any musician, union, club owner, or lawyer. In 1967, Mayor John Lindsay decided to remove the rule about the necessity of identification cards to identify musicians. Prior to this decision, his administration was working to encourage tourism and loosen some of the more restrictive entertainment laws such as allowing sidewalk cafés to open. The elimination of artist fingerprinting in $1966^{128}$ and the entire system of cabaret identity cards ${ }^{129}$ was done seemingly on a whim, through an administrative order similar to a Papal motu proprio. After trying unsuccessfully to pass a bill through City Council abolishing the fingerprinting aspect of the ID cards, the administration realized that no bill passing was 
needed. Because the fingerprinting and carding regulation had begun as an administrative decision in 1940 , it could be terminated in the same way, so the Mayor simply ordered it to be ended. The abolition of identity cards was the result of a change in social attitudes and administrative practice, and not based on any legal reason. While the cards had grudgingly become acknowledged as a necessary part of a New York City jazz player's life, musicians were grateful that this humiliating regulation had finally ended, relieved that the City had finally seen its way to ending such an oppressive practice. ${ }^{130}$

Mayor Lindsay's decisive act demonstrates how quickly institutional regulations can be enacted or dissolved when a single entity holds omnipotent power. In 1940, Mayor LaGuardia had made a decision to impose his power by introducing carding to ensure that undesirable people, including musicians who might play the wrong kind of music, would not be in contact with citizens. In order to demonstrate how important jazz was to the city, in 1967, Mayor Lindsay decided that the carding rule no longer made any sense, so he simply ordered it to be nullified. The 1926 Mayor-elect used the opportunity to curry favour with his constituents and Aldermen ${ }^{131}$ by responding to the moralists (undoubtedly many of whom had voted him into office). He also took decisive action by reigning down on the speakeasies where jazz was being played with "wild abandon", urging his Aldermen to pass the city's first cabaret law, which they did, by a large majority. It was the centralized power that existed in the office of the 1990 Mayor which enabled the coordination of various factions of power throughout the city to change the complex system of zoning laws so that even the spatial regulation of music could finally be abolished. As Barbara Fife, the deputy mayor responsible for managing the implementation of the 1990 zoning changes stated, "New York has a special relation to live music. Jazz is a signature 
of the city. It is something that the mayor is proud of and enjoys ... The city needs a reasonable number of jobs for musicians. This is part of our general commitment to new economic development" (in Chevigny 1991, 152). Six decades after the jazz folk devil had raised its menacing head, there was a "recovery", a return to the city's former equilibrium, where music in clubs was concerned. The changes that the devil had wrought in this moral panic went beyond a state of "stable adaptation" and were viewed as positive achievements, necessary to the city's future.

This view of jazz was a far cry from being an object of intense scrutiny by the moralists and critics who had engaged in what some would argue was narrow-minded cultural warfare. Politicians, civic administrators and law enforcers realized there was a fundamental connection between their political objectives and their commitment to support or discourage the performance of jazz in their city. The technique of continually amending legislation created a labyrinth of bureaucracy that perpetually thwarted venue owners and musicians, and kept the cabaret law viable. Beyond New York, jazz thrived as a result of economic control through commodification: it was packaged and reproduced by businessmen, impresarios and recording companies that capitalized on its popularity. With the conflict brought on by the effects of not one but all three major modes of regulation in play, jazz seemed to be in a state of permanent crisis.

\section{Outcomes: The Effects of New York City Cabaret Laws on Jazz Music}

As restrictions were introduced in waves, since there was not just one but an entire system of cabaret regulations that had accumulated over six decades, so too were the results of specific outcomes affected musicians, listening practices, and the fundamental nature of the music itself. On one hand, jazz had the power to endanger an 
entire social and cultural fabric; on the other, it was viewed as a unique art form that challenged classical music aesthetic conventions and created an entirely new musical language. Limitations on the place of performance of jazz allowed a distinct style to evolve that was unique to New York City's Harlem area, preserving some of the folkrooted authenticity that had traveled there from the Deep South. Regulations forbidding certain instrumental formations allowed variations of styles to emerge that otherwise would never have flourished. Technology mitigated the effects of the cabaret laws through radio and sound recording devices, since jazz could be consumed and enjoyed away from public performance sites, eliminating the need to ghettoize jazz, as was the case in early 1920 s Harlem.

Harlem Renaissance and the diversification of jazz: effects of regulating the place of jazz By containing the geographic space of jazz performance in New York City, the original cabaret laws helped to foster a cultural movement known as the Harlem Renaissance. The name represented the containment of black culture within city's black middle-class neighbourhood. The movement later spread to other cities through wider distribution of sound recordings and literary publications, and included African American music, visual art, theatre and various forms of literature. It was supported by black patrons, black-owned businesses including book and magazine publishers and black-run record labels that produced "race records". It was also supported by a number of white Americans ${ }^{132}$ who provided forms of assistance through financial backing, encouragement, patronage or publication, opening doors that otherwise would have remained closed to the promotion of black Americans' work outside their community. 
Many commentators of the Harlem Renaissance agreed that promoting black culture could lead to racial equality and artistic freedom. As Arthur Schomburg wrote in 1925, "The American Negro must remake his past in order to make his future" (in Anderson 2001, 2). African American spirituals, folk songs, blues, jazz heard in Harlem nightclubs, the early swing music of band leader Fletcher Henderson, and African American concert music such as Duke Ellington's jazz suites comprised the main musical idioms of this Renaissance aesthetic. Issues of authenticity versus the progressive development of jazz forms were debated by black writers such as W.E.B. Du Bois, Alain Locke and Langston Hughes. Their arguments centred around whether emerging forms of jazz and its concertization were destructive to the preservation of vernacular AfricanAmerican music, mainly spirituals, gospel and folk music. Just as white musicians were working hard to make jazz sound palatable to white middle-class audiences, black musicians establishing their Harlem Renaissance roots were equally determined to preserve the sanctity of their people's sound. There are similarities between this Renaissance movement, where the black community was fixed on maintaining purity, and the one four hundred years previously, when the Roman Catholic church encouraged the preservation of Gregorian chant - the "spirituals" of Tridentine times - by restoring the ancient tunes in the new editions of missals and breviaries after the Council of Trent, providing composers with additional thematic material for religious works.

While the web of cabaret regulations became increasingly tangled between 1926 and 1986, regulation was unsuccessful in repressing jazz. Instead, it helped to encourage its diversification. Jazz heard in New York evolved along different paths, starting from ragtime, blues, Dixieland, New Orleans and Chicago styles. As jazz gained in popularity, 
a New York sound developed, leading to swing and bebop styles. Rather than replacing earlier forms, each of the previous genres continued to evolve, and each exists today along with other jazz genres. This complex evolutionary development was due to factors as diverse as the "whitening" of jazz; the influence of new artists, both black and white, whose unique styles created new forms; the crossover of genres as artists learned to play in multiple styles; the evolution of improvisational techniques; distribution and reproduction technologies such as radio and sound recordings which opened up consumption of jazz to all races; and the commodification and mass production of jazz.

\section{The benefits of economic regulation}

Economic regulation motivated by capitalistic exploitation played a beneficial role for many musicians in the 1920 s due to the increased number of performance sites and larger performance venues, and the regularity of work. While some of jazz's popularity could be categorized as exploitative through the desire to capitalize on the fad and fascination of the African American persona, Paul Whiteman and others employed economic-aesthetic forms of control to promote their style of jazz. Interest in "primitive" cultures grew, much to the moralists' chagrin, as regulation fueled the desire to observe black American culture by whites who were curious to see this primitivism emerging from Harlem. This attraction to the African-American "other" extended to Broadway with Gershwin's opera Porgy and Bess (1935), and into concert halls where white band leaders defied racist attitude - and union rules - by including talented and innovative the African American jazz artists. As attitudes to racial prejudice changed, hiring policies in bands began to change, and integration became acceptable, at least when musicians performed together. This tokenism worked both ways: Duke Ellington's jazz orchestra 
was originally made up strictly of black musicians, but as time went on, white musicians were also hired. Racial integration of musicians became a by-product of the united struggle against attempts to control jazz. The argument that jazz was exclusively black could not be upheld considering that "of all areas in American life, the one in which the long-standing and fiercely defended barriers between black and white races first began to break down was jazz" (Collier 1993, 183).

\section{Productive outcomes of regulation on musicians, formats, and musical venues}

As time passed, nightclub owners found it expensive to present jazz because of zoning and licensing restrictions, and many clubs were forced to close, unable to strictly comply with the regulations and still draw an audience large enough to make ends meet. Clubs that were able to acquire a license often did so only after waiting for many years and then paying exorbitant fees. Many owners felt they could not afford to hire any but the most prominent names in jazz and remain in business. As a result, these restrictions prevented hundreds of musicians from performing their music and influenced both the nature and amount of jazz performed. Most jazz musicians remained underemployed, underpaid, or both, many agreeing to be paid under the table. Younger players, traditionally the main source for innovation in this music, found it difficult to find a place where their music could be heard, even if they were able to get a cabaret card (Shaw, 54).

The requirement for nightclub performers to hold artist identification cards was an act of oppression, and jazz music reflected this. Through carding, performers were individually regulated as artists, their personal reputation in question - they were "guilty" if they attempted to play in a nightclub without a card. This regulation degraded the status of working in a club by making performers feel rejected based on the kind of music they 
played. This only added to their feelings about the subversive nature of jazz. As Chevigny notes,

to play jazz was to be a musical outsider, even sometimes a revolutionary, to cut against the grain of ordinary musical tastes. The City's rules governing the lives of musicians, together with the nature of the places where the music was played, only exemplified, indeed legislated, that status $(1991,61)$.

Prior to the removal of the "incidental musical entertainment" amendments in 1986 , anyone playing a horn, wind or percussion instrument was prohibited from playing in any venue that did not have a cabaret license, preventing performers from playing with the musicians they desired. Carding, combined with the three-musician rule, compounded problems for band leaders, who were frequently unable to assemble the necessary type or number of musicians to give a sense of fullness to the sound. Music arrangements were often re-jigged in order to ensure that music at least minimally resembled the way the composer or arranger had envisioned, since the sound that an individual or group of players produces is dependant on the type or number of instruments used. Restricting the number of live musicians to three effectively hampered the improvisational atmosphere that jazz needed to flourish. Artistic frustration and compromise was the outcome when a different arrangement was needed to achieve the proper voicing in order to present the performers' musical ideas. Musicians commented that "the limitations had ruined their arrangements", and that they had "a difficult time expressing [their] ideas in a trio without a drummer" (Chevigny 1991, 119). Jazz musician and composer David Amram summed it up: "The emotional impression that [jazz]... makes depends on what instruments are used. ...It is difficult for me as a composer ... to be restricted to creating only for strings and keyboards" (in Chevigny, 1991, 108-110). Dixieland jazz, which required a minimum of six instruments (sax, trombone, trumpet, clarinet, drums and 
piano), was not heard in the City's clubs for many years due to these limitations. Without drums, Brazilian, Latin and African music styles were also impossible to perform.

The incidental music amendment seemed directed at precisely the combination of instruments that were typical of jazz, even though its purpose, at least overtly, was not to deter jazz. Pianists could not play in a trio with a drummer, and singers were barred from working with any combo that included more than a guitar or a piano. Restricting the instrument type was frustrating not just for musicians who were forced to perform on alternative instruments (if they could), ${ }^{133}$ but also for the audience, who may have wanted to hear specific performers, only to discover that they could only play a certain instrument for a few numbers and then had to sit out for part of each set. ${ }^{134}$

As musicians adapted to the new laws, they overcame these problems by creating innovative musical arrangements. Jazz musicians who made their name in New York including pianists Art Tatum, Nat King Cole and Oscar Peterson, as well as guitarists Wes Montgomery, Jim Hall and Charlie Christian, became so attached to the trio configuration that their preferred ensemble was piano, double bass and guitar, and the format became an accepted ensemble arrangement for jazz performances in both small clubs and larger performance venues. "You have no idea how much satisfaction I got from the acceptance of the trio, because we opened the way for countless other small groups, units that before were strictly for cocktail lounges" (Nat King Cole, 1957). ${ }^{135}$

\section{Outcome of the Union's regulatory actions on jazz}

The national arm of the musician's union never attempted to overturn the New York City cabaret laws but instead left the problem to the AFM's local New York chapter to sort out. Furthermore, the incidental music amendment proposed by the local chapter 
and accepted by the City was not the only regulation that affected the configuration of musical instruments in an ensemble. Earlier national union action in the 1920s limited the engagement of non-American musicians to ensure that jobs were filled by Americans, keeping the sound of jazz pure from "fusion" influences that might have crept in from other musical traditions. For nearly two decades, that insularity prevented opportunities for musicians to experiment with new aesthetic influences and to explore new interpretive possibilities. While the use of "alien" musicians in the US was discouraged by the union, exporting jazz to international destinations was welcomed enthusiastically in other jurisdictions, especially in continental Europe, where jazz was rarely subjected to the restrictive practices occurring in New York City. ${ }^{136}$ A bohemian lifestyle was more accepted in Europe: drinking, dancing and jazz were less offensive to continental mores.

The popularity of live performances offshore was further bolstered by a healthy trade of jazz sound recordings, which intensified interest in the music and bestow celebrity status on both black and white American artists. The AFM maintained a stiff regulatory stance on integrating black and white performers and on immigrant artists, but the latter restrictions eventually dissipated when immigration and visa-granting policies for artists were eased after WWII, allowing in foreign musicians who introduced nontraditional instruments to jazz ensembles. ${ }^{137}$ The union realized that African American jazz players were often the "soul" of an ensemble, contributing techniques and traditions that produced sounds the audience most wanted to hear. It eventually eased off on its former restrictions due to the overwhelming success of the burgeoning sound recording industry that made the colour of an artist's skin invisible to a listener's ears. 
Indeed, as much as the cabaret laws were attempting to contain jazz, control musicians and limit instrumentation, those localized laws had no jurisdiction over suppressing the steady increase of jazz music broadcast over the radio or played on phonographs. By the 1940s, the restrictive effect of the cabaret laws in New York was inversely proportional to the accessibility recording and broadcasting technologies provided by promoting the popularity and growth of jazz throughout North America. The effects of commercialization through mass production and distribution via new phonograph and radio technologies caused improvised jazz in recorded performances to become more formulaic. While the element of spontaneity was removed, many more people could now listen and dance to jazz whenever it wished without the need to venture out to nightclubs. This flew in the face of any barriers that had been created by the City's regulation of licensed establishments. Jazz was broadcast live from New York nightclubs such as Roseland, the Savoy and the Cotton Club, reaching larger audiences in an evening than what would have taken months to reach through live performance (Burns, 2001). Listening to recorded music allowed all races to hear and enjoy each others' music. Technology thus acted as an enabler, rather than a regulator of jazz.

However, the AFM viewed technology as a disruptive force that took jobs away from musicians playing live performances, and in the 1940s it ordered a boycott of all recording sessions by union members. When the union's demands were finally met, there was an overhaul of the royalty/residual system involving record labels, distributors, publishers and creators. ${ }^{138}$ While the AFM's drastic actions on a national level benefited all musicians, the local New York chapter was slow in responding to the particular battles that jazz musicians were faced with in the City between 1926 and 1986. It was only when 
the local chapter realized that it might be able to overturn the jumble of civic laws urged along by a jazz-loving lawyer who was clever enough to unravel the muddle of regulations created and maintained by City Hall over sixty years - that the entire mess was overturned. As Chevigny notes, it was finally on December 19, 1986 that "the City Council passed a resolution declaring jazz to be a City and a national treasure" (1991, 177). The cabaret law still exists in New York City statutes, but it is a zoning restriction only, and its regulatory purpose is strictly to control noise levels and rowdy dancing.

\section{Conclusion: Regulation transformed jazz, and jazz transformed society}

Because of music's ability to elicit a wide range of audience responses, individuals and institutions charged with protecting social order have often sought to regulate both the content and form of musical composition and performance. In the $1920 \mathrm{~s}$, jazz produced reactions in moral reformers that condemned this new music, inducing responses that revealed the power music had to change moral codes and disrupt social order. Other actors attempted to regulate jazz by critiquing it on the basis of taste, elevating traditional, classical forms of music as "good" or "better" over jazz, which was considered by some to be low class or primitive. The attempts by music traditionalists to influence public opinion were amplified by the press, an actor that produced, in Cohen's terms, an extensive inventory of public sentiment that mainly served to fuel the moral panic over jazz. Similar to Palestrina's role in Tridentine times, many influential musicians who had already achieved notoriety in the music community acted as pioneers, demonstrating that jazz could be accepted by the Establishment, blessing it as palatable, fashionable, and therefore highly marketable to large segments of the public. These actors both validated and capitalized on the new art form through intellectual discourse and by 
demonstration. They were successful at doing so, although their attempts produced a commercialized form of jazz that some critics and black jazz musicians argued was inauthentic. This act of commodification was a form of economic regulation, in that musical tastes were being controlled and manipulated to yield a financial profit from the production of this "whitenized" music.

The actions of these trailblazers served to diffuse the moral indignation expressed by reformers who claimed that because jazz was ruining society, it needed to be institutionally regulated in order to control its immoral influences. Despite civic regulation that was enacted in 1926 by the Mayor, jazz continued to be heard in clubs in and beyond Harlem. The cabaret laws were meant to curtail jazz by containing it within isolated areas of the City, but confinement caused an inverse reaction. Annexing jazz increased demand for this new, racy, exotic music that symbolized freedom and individualism and encouraged the development of African American culture. Although the regulatory system tried to squeeze it out of existence, jazz leaked out everywhere, appearing in new forms and appealing to new audiences.

Institutional actors sought to regulate music heard in cabarets on the basis of what was convenient for them to administer and what the influential moral majority (read: the voting public) demanded. Zoning, licensing, imposing curfews, and carding artists were not just forms of control, but also sources of revenue for the civic coffers, and the City saw no reason to curb such regulations even when they had outlived their usefulness. Whenever the laws were questioned by club owners and musicians, the civic response was to uphold them as a necessity for maintaining order and curtailing criminal activity. However, even as by-laws and amendments kept the original 1926 New York City 
cabaret laws alive for six decades, neither civic nor moral regulation could wipe out what was becoming a cultural symbol.

Regulation produced a range of effects on musicians that elevated jazz musicmakers into heroes. While black musicians were initially allowed to perform only in segregated ensembles, their skills and talents eventually elevated them to iconic status and they became sought-after artists in multi-racial groups. Jazz musicians suffered the indignity of being fingerprinted and carded, but at the same time, this also identified them as a unique, select class of creators. The musicians' own union was unwilling to interfere with the City's relentless pursuits against jazz, and even imposed its own regulations to prevent racial and immigrant integration from occurring. As technology enabled wider accessibility to all music, the union realized its power to protect musicians' livelihoods was diminishing, so it invoked its own regulatory bans, barring musicians from any sound recording activities over fears that technology would replace live performance.

Neither moral nor institutional regulation could curb the tide of jazz's commercial popularity, which spread beyond New York due to new distribution and duplication systems. Technology caused the aesthetic and spatial regimes of regulation against jazz to become obsolete, rendering the cabaret laws inconsequential. As jazz rose in popularity, audience demand for access increased. Sound recording technology and radio broadcasting allowed consumers to listen to jazz whenever they wanted to without having to attend live performances. It was a double-edged sword: the more popular jazz became, the more technology enabled the distribution and consumption of jazz. This resulted, for a time, in less live performances, less clubs, less improvisation and ultimately, fewer musicians. Unfortunately, it represented a further loss of income in a city where it was 
already difficult to find work. Musicians left the City to find work elsewhere, allowing their various styles of jazz to spread throughout the country and beyond.

As cultural and societal norms changed over the decades, the cabaret laws were amended on the local AFM chapter's recommendation, with changes eventually implemented by the City in the early 1960s. Although the union action was an attempt to create more work opportunities for musicians, it actually presented severe difficulties for jazz performers, limiting both the types and numbers of instruments that could play in clubs. To comply with the regulation, artists adapted by inventing new forms of jazz and developing innovative performance approaches. Jazz music's ability to flourish despite encountering a complex regulatory system resulted in its elevation as an iconic symbol of New York City, a unique cultural emblem of innovation, pride and triumph over struggle, and the Mecca for jazz musicians.

The study of the cabaret laws illustrates that jazz music embodies all three states of power as identified by Attali. Jazz possessed "ritual" power by entertaining people, allowing them to forget their troubles albeit momentarily and let their hair down, even in the face of restrictive practices such as zoning, noise by-laws, carding, and limiting the types and numbers of instruments that could be used to create it. Furthermore, jazz demonstrated "representative" power, providing its creators a sense of pride and ownership by giving them an opportunity to offer new forms of musical order and harmony. Jazz also illustrated "bureaucratic" power as it grew in popularity, patiently enduring its opponents and silencing its critics as it continued to be performed, morphing into different styles and adapting to audience tastes. 


\section{Chapter Four}

Observations and Lessons Learned from Policing Music

"I believe that the introduction of computers to the world of music ... will change nothing that is fundamental to music as an art form. What changes music is ideas, not tools."

-- Music composer David Rosenboom (in Roads 1986, 52)

A simplified version of my thesis statement is that rather than having a chilling effect, regulation is a catalyst for producing changes in music. Based on the analysis of the two examples here, I believe there is a compelling case for the accuracy of this statement. Throughout the history of music, there have been numerous instances where modes and regimes of regulation have produced all manner of disruptive problems that, fortunately, musicians have been able to build their creative solutions around. I have located a few of these in the chart in Appendix 4. Unfortunately there is not enough space in a project of this scope to provide an exhaustive inventory of all the productive results, but some of the more obvious include the shifting and morphing of genres and styles, the development of new forms and sounds of music, the promotion of national styles and iconic artists, the emergence or suppression of creators, changes to musical tastes, the nurturing of audiences, audiences reception (both good and bad), and the creation of new business models for music distribution and access. It should be obvious that regulation, as the quote from Rosenboom above suggests, has been, if nothing else, quite an ideagenerator for music.

And, regulation is unquestionably involved in today's music scene. The music copyright conundrum epitomizes the most familiar form of regulation we encounter today. The ability to encapsulate music in digital format and move it virtually instantaneously anywhere in the world using the Internet has increased both the ways 
music can be experienced and regulated. Peer-to-peer (P2P) networking systems allow consumers to share virtually any digitally encoded music available. At the same time, $\mathrm{P} 2 \mathrm{P}$ has enabled consumers to access music by circumventing control mechanisms that content owners have tried to impose. Devices smaller than a deck of playing cards have the capacity to digitally store thousands of hours of music, ${ }^{139}$ allowing consumers to organize their own "personal programming" by assembling and repackaging the music they want to hear, by-passing any notion of governmental "quota" regulations. Others are gathering and scheduling music using personalized Internet streaming that offers a form of customized Internet radio, with the result that the use of traditional radio to disseminate new content is becoming obsolescent. Creators are excited by opportunities to reconfigure music by sampling it, remixing and mashing it up, but are frustrated having to deal with the regulatory regime of complex rights clearances when their goal is to turn out a commercial product. While it is possible to argue that the aesthetic properties of music are not directly affected by many of these new forms of technology regulation, no one can refute the profound changes occurring in the way music is delivered from creators to be experienced by consumers.

When fans are restricted from accessing a musician's work, there can be financial impacts to the creator. Musicians are ambivalent on this point as they realize that there are negative effects of technology regulation on their fans, and do not necessarily want to be used by the labels as decoys to garner sympathy over accusations that fans who "steal" music are taking money directly out of creators' pockets. For this reason, many musicians have aggressively and publicly stated that they are not the ones seeking regulatory measures. For example, the Canadian Music Creators Coalition (CMCC) has lobbied 
against governmental legislative proposals that slap lawsuits against their fans and increase the labels' control over music. Their point is that these efforts are not made in the name of musicians, but on behalf of the labels' foreign parent companies. ${ }^{140}$ Some creators are trying out new business models, bypassing the middlemen in the distribution supply chain to reach the market directly. Likewise, as record labels sue consumers and urge governments into revising copyright laws, music fans are lobbying in favour of filesharing and against the heavy-handed regulatory tactics of the labels. Public interest actors such as the Electronic Frontier Foundation (EFF), ${ }^{141}$ the Future of Music Coalition, ${ }^{142}$ FreeCulture, ${ }^{143}$ and numerous individual commentators such as Lawrence Lessig $^{144}$ in the U.S. and Michael Geist ${ }^{145}$ in Canada are also speaking out against technology regulation.

\section{Music is not just content}

Music is one of the oldest forms of human expression. From earliest times it has been a medium for communication, whether in its purest form, or when coupled with words. Because of music's power to create and communicate social meaning, those who lead or influence societies have sought to regulate it throughout much of history. From Plato's discourse in the Republic, to religious leaders in the $1500 \mathrm{~s}$, from moralists in the Prohibition era to dictatorships and hegemonic corporations in more recent times, regulators have been aware of music's capacity to appeal to human intellect, to emotions, and to the pocketbook, and have therefore sought to control the actions of musical creators, compositional styles, performances and access to music, arguably for the benefit of society. Reaction against that control often produces some surprising innovation. 
By analyzing only two instances of music regulation from the multitude that exist using my proposed framework, it is not possible to detect and predict all the patterns and trends that emerge from the regulatory system. However, using the framework as a tool helps to understand the mechanics of regulation, and can help broaden our understanding of some of the issues faced by regulators and creators today. History demonstrates that Western society has considered music's social, cultural and economic roles, and the roles of those who create and perform music, in different ways over time. Put in today's context, instead of assuming that music is "content" and therefore that the only concern is protecting it as "property" against the threat of "stealing" it, there are benefits to considering alternative means of encouraging musical creativity that were successful in previous times, in different environments and under varying socio-cultural circumstances. By using the analytic framework, it is possible to make some observations about music regulation by considering findings in the case studies. For example, the analysis of the Council of Trent shows that a collaborative, negotiated style of policy-making works well when lasting results are the goal. The success of the Council's strategy shows the importance of consistent, long-term regulations that offer guidance rather than harsh directives. Musicians who successfully adapt to changes can serve as an example to others involved in the creative process, even while adjusting to restrictions. Local interpretation of regulations and directives assists in the development of best practices and also stimulates new styles, techniques and forms to emerge. This example also shows that musicians who gather to organize their business affairs accumulate negotiating power, which allows them to improve their position and increase their worth. 
Likewise, from analysis of the New York City cabaret laws, it is possible to observe that ill-conceived government-imposed institutional regulation can produce negative long-term effects on music and musicians. This example shows that taste-based regulation of music is subjective and although moral panics can lead to stigmatization of certain music styles, this can dissipate as times and fashions change. We also find that musicians are capable and willing to adapt to unpleasant, even oppressive situations in their desire to create music, and that commercial regulation can be successfully utilized to promote or protect music and musicians. Mass media can be used to produce an inventory of incontrovertible evidence about the regulatory event which can sway public opinion - sometimes for music's benefit, and sometimes, not. At least it gets people talking about music in new ways. Confining or hiding music is not necessarily a successful regulatory device if the goal is to relegate or suppress a particular style of music. We also see that a few respected actors (musicians, impresarios, even musicloving lawyers!) can successfully champion a resistance movement against regulation, or otherwise re-focus regulation in a way that does not negatively impact music production. Using the regulatory framework to analyze outcomes or by-products of regulation on music creation, production and consumption allows me to highlight some prominent general trends. These are apparent from the case studies analyzed here, as well as from reviewing other examples while researching this project. Regulation has acted as a catalyst for change in terms of creating new styles of music; galvanizing musicians to organize themselves in order to improve their ability to negotiate with regulators; influencing the globalization of music; changing the methods of musical production, 
distribution and consumption; and diminishing state involvement in institutional regulation of music.

I believe the most exciting by-product of regulation involves the development of new business models that benefit performers and their fans. For example, some artists are experimenting with pay-what-you-can or pay-what-you-want-to pricing models on their websites, where listeners are invited to download music and pay what they feel is appropriate. Jane Siberry offers an example. ${ }^{146}$ Another example of tremendous innovation is the Artistshare model, an Internet-enabled service for musicians that compensates creators using a centuries-old model of securing funding through patronage whereby audiences can actively participate in the creative process. ${ }^{147}$ These concepts demonstrate to me that regulation can act to inspire those who wish to seek innovative ways of extricating themselves and others from the regulatory chaos that has threatened to become an endless loop of non-productive debate.

By analyzing the actors involved in regulating music, it is possible to see how one entity or group rather than another is in a position to impose its truth by seeking out regulatory action. I suggest that it is because at a given moment in time, a specific actor elects to name and own that power, or otherwise be perceived as the holder of power. Those actors upon which the power is exerted will either accept or reject this truth. Thus, certain actors wield power over music through regulation - controlling when and where it can be consumed, deciding what sort of music is created or produced, or choosing how music will be distributed and received - or "communicated" - and other actors either resist, adapt, or conform to that power. Manuel Castells offers one view of actors and power in a regulatory environment: 
I understand power to be the structural capacity of a social actor to impose its will over other social actor(s). All institutional systems reflect power relations, as well as the limits to these power relations as negotiated by a historical process of domination and counter-domination. ... I ... analyze the process of formation of counter-power, which I understand to be the capacity of a social actor to resist and challenge power relations that are institutionalized. Indeed, power relations are by nature conflictive [sic] (Castells 2007, 239).

While Castell's view of the power of social actors does apply to some examples of music regulation, I suggest that it is a narrow view. Foucault's view of power suggests that there are other forms of regulation than those imposed by an institution, the government or a legislative body. In the case of New York City's cabaret laws, moral and economic regulation came well before institutional regulations were invoked. Foucault suggests that the opportunity to exert influence by imposing control through negotiation demonstrates the possibility of movement from strong to weak regulation, and that effective regulatory regimes evolve to a state of de-regulation that in turn produces knowledge, truth, subjects and objects. Foucault also suggests that a traceable course of development often exists from institutional or economic power towards self-regulation and self-discipline as society assumes the responsibility to uphold certain moral/ethical values $(1991,102)$. This is precisely what the Council of Trent music regulations set out to do, and its efforts were productive, influential, far-reaching and long-serving.

However, this is the reverse of what happened with the cabaret laws in New York City, where moral regulation appeared first and forced the imposition of institutional regulation, which lasted for many decades, while economic regulatory forces were in play throughout almost the entirety of the event. Attali's view that music transforms society suggests the music-power dynamic in the reverse: rather than music being regulated, music itself becomes the regulator. This is the case today, where music more often than 
not manages to escape attempts at regulation, and as a product has had profound effects on society by altering long-established paradigms in the entertainment industry.

This is not so surprising when we consider that throughout history, music has possessed power, depending on its dominant, residual, or emergent value at any given time (Williams 1997, 121-2). This suggests to me that rather than moving in one direction, from strong to weak regulation as Foucault has indicated, in many cases there is oscillation between different forms of control - one mode of regulation dominates more than another as the value of music changes and actors adapt, finding new ways to create, access, consume and distribute music.

Today's music audiences are also increasingly resistant to technological regulation by supporting creators who choose to distribute their music without the encumbrance of record labels, publishers and other middlemen. We can now enjoy new supply channels, are afforded choice in the ways we can access and receive music, and we have power over what prices they choose to pay. In short, the audience is now able to dictate market power resulting in control being wrested from economic regulators. In our desire to change the way we experience music, consumers are regulating the regulators. The cycle of control has begun to shift towards increased institutional regulation as economic players lobby for governmental legislation ${ }^{148}$ to help protect what they consider to be their property. Audiences are countering with equally vigorous lobbying. At this time, the tipping point is unclear.

The music regulation framework provides a way of pointing out similarities between actors in terms of their motivations, strategies and their success or failure in maintaining regulatory power. For example, there are parallels between groups of like- 
minded creators that together have impacted regulation by resisting, conforming or adapting to unwanted or new regulation, such as the actions of the musicians' union in New York City and the musicians' confraternities in the sixteenth century - actions that speak to bonding and fraternizing in response to regulation.

There are also parallels with examples of powerful individuals who initiate regulatory action through their prerogative power, such as the Papal motu proprio requiring all musicians in the Vatican be unmarried and of holy orders, causing the immediate dismissal of certain musicians from the Church's employ. We see a mirror of this authoritarian behaviour in the actions of the mayor of New York City in the 1940s when he suddenly imposed legislation without explanation requiring all musicians to be carded. Later, a mayor from a later decade overturned that previous law, admitting that it made no sense. The lesson here is that leaders come and go - they can be voted out of power - so if regulation threatens musical creativity, the situation will likely improve when the power shifts. Rulers operating in a similar dictatorial fashion may think they are deciding what is right or wrong about music or particular musicians, but these regulators do not always stay around for long. In their time, Goebbel's Nazi culture police banned all jazz and other popular music, Stalin censored formalism and denounced Shostakovich, and Taliban extremists have tried to prohibit all music, everywhere. None of their strategies has been effective in the long run. In each of these cases, it appears that acting out of one's accord without public consultation is not a strategy that seems to have any lasting power in a regulatory environment.

Analyzing these strategies more closely helps to illustrate, as Foucault has suggested, the interconnections and relationships between the actors, and likewise the 
interplay between the modes and regimes of regulation. These examples and others show that regulation is frequently present as a productive force during disruptive moments of musical history. Foucault's concept of governmentality indicates that forms of regulation imposed more as guidance than control may meet with greater long-term success in circumstances where far-reaching, wide-scale reform is needed. A regulatory policy that balances political, economic and social interests and considers the impacts on creators themselves is an effective way to impose regulation, when it is necessary.

Another lesson from history is that alternative methods for fostering creativity are possible. Today most of the music industry works under the principle that a copyright regime is the only way to handle ownership, distribution and authorship issues even though it is questionable as to whether music copyright is serving the purpose that it was originally designed to do. Copyright began as a method of protecting the rights of the creator but today it seems to mainly benefit content owners who are frequently not the original creators. Nascent alternative compensation systems like Noank Media ${ }^{149}$ are not based on a royalty model, yet provide a possible way forward for funding music creation, protecting creators' intellectual property and still allowing musicians their creative freedom. I suggest that the efficacy of these systems should be closely examined for their ability to simultaneously reward creators while providing the audience with easy access.

It would also be useful to review and analyze how creative production in art forms of other cultural industries are affected by regulatory challenges including copyright. In my opinion the situation would greatly improve if governments were to develop policies that focused on encouraging new artistic forms, spaces and places of music performance, or on developing new methods of accessing music that everyone can enjoy and that artists 
can financially benefit from, perhaps in the form of blanket taxation or via the award of tax credits. Failing that, encouraging less political (government and legislative) intervention over time would allow market forces to prevail.

Attali's argument is that music has the power to invoke social transformation and acts as a beacon for impending social change, so that rather than being an object of regulation, music itself possesses the power to regulate society. Foucault has suggested that power can be both punitive and productive at the same time $(1995,104)$. Likewise, the dynamic flux of resistance and counter-resistance to regulation is continuous (1980, 56). Foucault's ideas therefore suggest that within power relationships, there is always the possibility for resistance and disruption of power. Foucault observes that, "when one speaks of power, people immediately think of a political structure, a government, a dominant social class, the master and the slave, and so on" $(1984,291-2)$. I suggest that Attali has simply taken Foucault's idea one step further by applying this notion of power to music, suggesting that music itself is a disruptive force in society because it has accumulated power through its long political, economic, and socio-cultural history.

Throughout the ages, music has not only threatened to disrupt social order, but in some cases, it has disrupted society, and in doing so has provoked calls for regulatory action. In each case, whatever music's role was in that disturbance, it was harnessed, controlled or restricted for a time, but it did manage to survive, sometimes in a different form, and at other times, it remained relatively unchanged.

\section{Conclusion: Has regulation had a productive effect on musical creativity?}

The two case studies show that regulation had a profound creative effect on music. The decrees issued by the Council of Trent produced differences in regional 
interpretations that led to local "scenes", helped influence changes to harmonic structures, encouraged new musical forms, and even resulted in changes to instrument design. The cabaret laws in New York City forced jazz to be centralized in Harlem, but the music acted as an anchor to foster the development of an entire culture. The "threemusician rule" affected jazz ensembles, forcing musicians to develop innovative solutions to overcome this obstacle. Using the analytic framework to assess effects of regulation on other musical examples could provide further opportunities to assess regulation's effect on creativity.

Music as an art form is an expression of humanity and shared experiences. It provides a voice with which to express fear, anxiety, hope and dreams, all of which are affected by specific social and historical circumstances. As I have studied the circumstances under which music was created, presented, received, valued, and controlled in the past, I have learned more about its power to shape the ideals of society. In pondering music's presence during the time of the Renaissance, the Roaring Twenties, or in the present day, whether it is heard in the church, in a cabaret, a concert hall, or as a discrete recorded performance artifact played on a phonograph, over the radio, from a tape machine, CD player or digitally downloaded from the Internet onto a tiny hard drive, music offers not just a creative cultural experience to be enjoyed, but also provides a unique window through which to examine it as a regulator of society. Music has the capacity to resist constraints, and in doing so, morphs into new forms. Attali's "dream of music" is a collection of possibilities, inventions and creations, not an array of struggles, orders or rules. Even when regulation silences the music, it is momentary. When it resumes, almost always, music has changed. 


\section{Endnotes}

\section{Chapter One}

${ }^{1}$ For example, in ancient Greece, Rome and China, music represented order, the law, and stability.

${ }^{2}$ From 1981 to 1991, Attali was a Presidential advisor to France's socialist government. In April 1991 he became the first President of the London-based European Bank for Reconstruction and Development, the financial institution established by western governments to assist the countries in eastern and central Europe and the former Soviet Union in a transition to democratic market economies.

${ }^{3}$ From an introduction to Noise: The political economy of music (1977). This comment, dated April 2000, does not appear in the book, but is found on his website (http://www.attali.com/eng/index.htm) as an introduction to the book.

${ }^{4}$ From the Oxford English Dictionary, online edition, see: http://dictionary.oed.com.proxy.library.carleton.ca/cgi/entry/50201385

${ }^{5}$ As Ustad Mash'al, the famous Afghanistan artist asks, "Can someone actually stop birds from singing?" (in Baily 2001, 42).

${ }^{6}$ Tony Bennett notes that Foucault distinguishes between government and governmentality, government being "that of the state", versus governmentality being a "much broader sphere of practices in which claims to particular forms of knowledge and authority ... direct the "conduct of conduct' " $(2003,61)$.

Interestingly, while Foucault frequently discussed this notion, especially in his last lecture series on the government of one's self and of others entitled "Subject and Power" (Foucault, Michel. (1994). Dits et écrits IV (Paris: Gallimard) p.237), he never used this exact phrase, although "conduire des conduites» became "the conduct of conduct" when it was translated to English. Colin Gordon uses the phrase in his explanation of Foucault's concept of governmentality ("Governmental rationality: an introduction") in The Foucault Effect (p.2).

${ }^{7}$ Canadian Radio-television and Telecommunications Commission

${ }^{8}$ Similar quota systems exist in Australia, Belgium, France and Germany.

${ }^{9}$ Freemuse (free musical expression), with its extensive body of research and commentary at www.Freemuse.org), is an international organization, established in 1999 and chaired by Martin Cloonan, which documents and publicizes cases of global music censorship affecting performers, composers and their audiences. Much of the research analyzes the messages of violence or unrest carried by music that can equally influence the attitudes of governments or emotions of an audience, resulting in stirring hatred within groups or inciting harmful acts towards musicians.

${ }^{10}$ Ten days before the 2003 invasion of Iraq, lead vocalist of the Dixie Chicks, Natalie Maines, publicly criticized President Bush. The ensuing controversy cost the group their popularity amongst audiences in the United States, as chronicled in the 2006 documentary film, Dixie Chicks: Shut Up and Sing.

${ }^{11}$ The Chicks won five Grammy Awards in 2007 including one for their song, "Not Ready to Make Nice", about being censored.

${ }^{12}$ In his Republic, Plato suggested that soldiers should listen to music in Dorian or Phrygian modes to help make them stronger, but avoid music in Lydian, Mixolydian or Ionian modes, for fear of weakening their resolve before battle (Plato $360 \mathrm{BC}$, Book 3). Aristotle made similar comments about which modes of music were preferable in his Politics (Aristotle $350 \mathrm{BC}$, Book 8).

${ }^{13}$ Consider the rather odd noise restriction which strikes at the heart of regulation of music performance / place: imagine living in Burbank, California, where there are severely restrictive by-laws involving the teaching of music lessons out of one's home: when, for how long, at what decibel level the music will be tolerated, how many students and lessons can be taught per day, etc. The by-law section cites twelve unique regulations relating specifically to music lessons (City of Burbank, 2006).

${ }^{14}$ Society of Composers, Authors and Music Publishers of Canada (See: www.socan.ca)

${ }^{15}$ These theories are appropriated from an economic orientation to regulation, but I find that they are easily adapted to the regulation of cultural forms.

${ }^{16}$ The French Regulation School's main contributors are Alain Lipietz (1987a and b), Michel Aglietta (1979), Bob Jessop (1990) and Robert Boyer (1985).

${ }^{17}$ The French School of Regulation offers Gramsci's "Fordism" as an example of an ROA, situating economic policies around mass production. 
${ }^{18}$ Digital Millennium Copyright Act

${ }^{19}$ Bill C-61 (2008). An Act to Amend the Copyright Act (12 June). Government of Canada. Available at http://www2.parl.gc.ca/HousePublications/Publication .aspx?DocId=3570473\&Language=e\&Mode=1\&File $=27$

${ }^{20}$ World Intellectual Property Organization

${ }^{21}$ American Society of Composers, Authors and Publishers (ASCAP) monitors broadcast or live performances created by ASCAP members' music, compensates them by collecting licensing fees from users, and distributes these back to its members as royalties. See: www.ascap.com.

${ }^{22}$ Broadcast Music Inc. (BMI) is a performing right organization that collects license fees on behalf of its songwriters, composers and music publishers and distributes them as royalties to members whose works have been performed. See: www.bmi.com.

23 "Formalism" in music refers to works created by the Soviet composers during Stalin's reign. Borrowed from literary criticism, it described works that were condemned by the Soviet party Central Committee as lacking appeal for the masses. A "formalist" work focused too much on aspects of form, at the expense of accessible music which glorified the Soviet state. Shostakovich was accused of formalism by Stalin and as a result, he lived a frenetic life, at first condemned but then later celebrated as the most talented Soviet composer of his generation (Grove Online, Shostakovich).

\section{Chapter Two}

${ }^{24}$ KISS $=\underline{\text { Keep }} \underline{\text { It }}$ Short and $\underline{\text { Sweet }}$ (or, $\underline{\text { Keep }}$ It $\underline{\text { Simple, }}$ Stupid!)

${ }^{25} \mathrm{~A}$ bull is a special charter issued by the Pope, named after the seal (bulla) applied at the end of the document to authenticate it. Originally issued to communicate a variety of public messages, after the fifteenth century, Papal bulls were used to convey only very formal or solemn messages.

${ }^{26}$ From the Greek, polyphonos, polyphony means "many" (poly) "voices" (phonos). It describes music with more than one part, a style where all or several of the musical parts move independently.

${ }^{27}$ Cardinals are very important and influential bishops appointed by the Pope.

${ }^{28}$ The first was caused by the threat of plague; the second, due to civil conflict in Northern Italy.

${ }^{29}$ Monson's work deserves to be singled out. In "The Council of Trent Revisited" (2002), he reconstructs texts of drafts and final versions of Council documents, carefully translating them from Latin (which are included as an appendix so those who read Latin can consult them directly). From his interpretations, one gains a clear understanding of the Council's musical decrees that is much different from commonly-held views relayed in musical historiography about how Trent nearly abolished polyphony and how Palestrina "saved" polyphony from the clutches of an over-zealous papacy. We know now that these are misunderstandings, and Monson supplies the proof. Much of my analysis is indebted to his thorough reading of the situation at Trent.

${ }^{30}$ A frequently cited account is that Palestrina and his Pope Marcellus Mass (Missa Papae Marcelli) saved church music from the Council's attacks. This was first suggested by composer Agostino Agazzari in 1607 and was elaborately repeated by Palestrina's biographer Giuseppe Baini in 1828. Later, German composer Hans Pfitzner wrote an opera, Palestrina (1917) which served to propagate the myth. Historian Lewis Lockwood dissects several versions of the legend, from Agazzari onwards (1975, 28-36).

${ }^{31}$ Tridentinus was the Latin form of the name, hence the reference to "Tridentine" in later discussions about the Council.

${ }^{32}$ A series of twelve notes, each being an interval of a fifth higher in pitch than the one previous to it

${ }^{33}$ The reference to "modes" of regulation here pertains to the musical term, "mode", as a specific combination of a series of musical tones (such as Dorian, Phrygian, Lydian, Aeolian modes, and so on). In the early 16th century there were eight, later expanded to twelve, medieval modes used in opening thematic statements of Gregorian chant (Lawrence 1987, 281; Grove Online at:

http://www.grovemusic.com.proxy.library.carleton.ca/shared/views/article.html?section=music.43718.1).

${ }^{34}$ Besides the acoustic use of the terms "consonance" and "dissonance", there is a further psychological use that denotes aesthetic preferences, i.e., "pleasant" or "unpleasant" (Palisca: 'Consonance', Grove Music Online, ed. L. Macy, http://www.grovemusic.com.proxy.library.carleton.ca) 
${ }^{35}$ In music, this was the era from c. 1430 to 1600 (Lockwood, "Renaissance": Grove Music Online, http://www.grovemusic.com.proxy.library.carleton.ca)

${ }^{36}$ Synods are short meetings convened to discuss local ecclesiastical business on a regular basis; councils are assemblies called by the Pope and last for months or years to deal with larger issues that concern the whole church. Cardinals are expected to attend Councils, but synods involve only parish priests, deacons and bishops. Before Trent, there were 18 Councils held over fifteen hundred years.

${ }^{37}$ The tritone, or augmented fourth, is the interval heard when the first and fourth degrees of the Lydian or Hypolydian modes are sung or played. The tritone is regarded as an "unstable" interval, sounding dissonant and unpleasant to most listeners.

${ }^{38}$ Besides Josquin des Prez, other composers who wrote parody masses include Orlando di Lasso and Palestrina, who occasionally used source material from his own motets.

${ }^{39}$ This is the case, despite the fact that nearly every musicology text seems to suggest otherwise.

${ }^{40}$ In addition to the linguistic barrier, there was often a physical one created by large opaque choir-screens of wood, wrought iron or stone. These transverse walls blocked the entire altar and clergy from the view of those standing in the nave. The officiating priest would say the Mass with his back to the congregation, facing the altar. Clearly, the shepherds were failing to communicate with their sheep.

${ }^{41}$ As a composer himself, Luther recognized the value of participatory congregational singing in the vernacular, suggesting his own ideas for a reformed style of music by writing a German Mass (1526) and many chorale tunes with simple melodies that the congregation could join in singing (Grout, 311-312). 42 This opposition was not surprising: the Church had finally recovered from the "Great Schism" (13781417) when there were two popes, one at Rome and one in Avignon, both of whom claimed to be the rightful head of the Church. Finally it was decided that one pope would be elected (Martin V) and based in Rome to "hold primacy over the whole world" (Schatz 1996, 188).

${ }^{43}$ This included aspects of doctrine previously raised by the Protestants; interpretation of scriptures; original sin; holy sacraments of baptism, confirmation, marriage and penance; episcopal duties, residency, jurisdiction and benefices (compensation); issues of the Mass; communion; purgatory; veneration of saints, relics and images; holy orders; clerical education; service books, and music (Bulman, 2006).

${ }^{44}$ Throughout the Council, musical advisors attended as guests of certain Bishops. There were also musicians specifically hired to perform at certain times during the sessions, mainly at session openings and closings (Sherr 1994, 613).

${ }^{45}$ These were two popular songs of the time: "The chase" and "The battle" (Monson 2002, 8).

${ }^{46}$ In Latin, "Ab ecclesis vero musicas eas, ubi sive organo sive cantu lascivum aut impurum aliquid miscetur" (Council of Trent, Canon 8 (final), paragraph 963).

${ }^{47}$ Many modern musicologists are unaware that this short directive was the actual decree. This has caused confusion about what the actual Council of Trent statements were concerning church music. Monson notes that both the preliminary draft and the final approved passages are usually combined by music historians to present a single Tridentine pronouncement on music (Monson 2002, 11). Such quotations appear in Reese $(1954,449)$; Grout $(1988,320)$; Grout $(1996,250)$ and Atlas $(1998,58)$ and it is the draft version that is also regularly quoted in popular accounts of the Council of Trent.

${ }^{48}$ One exception concerned female religious orders (Kendrick 1996, 58-59). In the twenty-fifth session of the Council, polyphonic music in convents was seriously close to being banned, though in the end this decree was not ratified at Trent and matters such as this were instead left to the heads of their orders to decide. This was an instance of regulation of music based on gender, and is discussed later.

${ }^{49}$ In 1563, Emperor Ferdinand of Spain strongly endorsed the retention of polyphonic music, presumably to support the works of Spanish composers Cristóbal de Morales (1500-1553) and Tomás Luís de Victoria (1548-1611), writing, "If ... polyphony [is] ... removed from churches altogether, we are not going to approve it, for we consider that such a divine gift as music, which often kindles the souls of men (especially those skilled or zealous in that art) to heightened devotion, ought [not] to be driven out of church" (in Monson 2002, 16).

${ }^{50}$ The Council of Trent had barely adjourned when Cardinal Paleotti attempted to re-institute music regulations in the convents of Bologna, the diocese over which he presided. In 1580, he successfully restricted convent music by setting out several cloistering rules that effectively made the singing nuns invisible (Monson 1992, 192). If nothing else, Paleotti was a determined regulator.

51 "Excommunication to all heretics". 
52 This may have been the basis for the "proof" by historians that Palestrina had saved polyphony from the clutches of the fathers of Trent by arranging to have the Pope Marcellus Mass "judged" by this panel of cardinals. Whether Palestrina's Missa Papae Marcelli was performed on that occasion is unknown, but it is certainly possible. While the Mass may have been written ten years earlier during Marcellus's short-lived papacy in 1555, there is also evidence that it was written later, in 1562, based on a copy found in a choirbook at the church of St. Maria Maggiore where Palestrina was chapel master (Lockwood 1975, 31).

${ }^{53}$ De Kerle was originally from Flanders, but he held musical posts at many cathedrals throughout Europe during his lifetime.

${ }^{54}$ The Church showed mercy to those who were involuntarily retired by arranging to provide them with life-long pensions.

${ }^{55}$ Venice became the main printing centre in Europe with press runs of 500 to 1,000 copies per title, producing two to three million copies of music books in the 1500 s alone (Bernstein 1996, 21).

${ }^{56}$ A madrigal is a song for two or more voices using secular text, often in Italian.

${ }^{57} \mathrm{~A}$ motet is a short polyphonic song similar to a madrigal, but using sacred texts; or for ceremonial purposes, praising a monarch

${ }^{58}$ After the Council, there was legislation introduced in provincial councils such as that of Milan, convened by Cardinal Borromeo in 1565, to "have all church musicians in the clerical state" (O'Regan 1994, 553).

${ }^{59}$ Most organists were professionally trained in France or Belgium where the organ originated, and were also hired as choirmasters, responsible for directing the music and training chapel singers. Palestrina was the first home-grown contender to fill the post of maestro di cappella in Rome (O'Regan 1994, 554).

${ }^{60}$ Lockwood has painstakingly researched the controversy over the dating and purpose of the Missae Papae Marcelli. Marcellus was interested in the regulations surrounding church music with respect to word intelligibility, but he died after only three weeks in office. If a Mass had been written during his pontificate, then it must have been dated at 1555 . If instead the Mass had been composed in his memory or in accordance with his principles, it would have been written at a later date. The work was likely heard as one of several "test pieces" during Vitelli and Borromeo's musical Commission in 1565. It was first published in 1567 in Palestrina's second Book of Masses. (Lockwood 1975, 6-9 and 10-36).

${ }^{61}$ While it was true that Palestrina's music combined polyphony with textual clarity and was likely influenced by events at Trent, Lockwood suggests that "it is equally beyond doubt that the legends surrounding his role in these developments, particularly those concerning the Missa Papae Marcelli, have distorted the known reliable evidence beyond the limits of credibility" (Lockwood 1975, 28).

${ }^{62}$ Venice had 120 confraternities in the early 1500 s, and nearly 400 at the end of the century; almost 20 percent of the population of mid-seventeenth century Antwerp belonged to a brotherhood, a proportion found in most European cities.

${ }^{63}$ Benefits of membership included the guarantee of a decent burial; providing social support to widows and orphans of a departed member; and caring for poor or sick members (Black 2004, 91-2).

${ }^{64}$ One of Sixtus V's first acts after becoming Pope in 1585 was to recognize the Congregazione dei Signori Musici di Roma as both a confraternity and guild for the city's musicians (Sherr 1984, 76). O'Regan has suggested that Palestrina helped to found this confraternity (O'Regan 1994, 566).

${ }^{65}$ Many of the revisions were specific to plainchant: tonal formulas were to adhere to the established patterns for each of the eight Gregorian modes; only proper texts based on Scripture or the approved lives of the saints were permitted; and melodies were retained from the large medieval repertoires of the chants (Atlas 1998, 605).

${ }^{66}$ We do not know why Paleotti went about enthusiastically publishing such rigid rules as cloistering the nuns while they sang, walling up the convents' organs, allowing only one sister's voice to be heard singing plainchant at a time, and banning all polyphonic singing in convents. However, his decrees were written in such a way that they continued to be enforced for the next 150 years. Following Paleotti was "a succession of archbishops [in Bologna who were] deeply suspicious of the 'music of the sisters"' (Monson 1992, 192).

${ }^{67}$ Borromeo forbade external music teachers to visit convents and also banned polyphonic music in convent churches (Monson 2002, 27).

${ }^{68}$ For example, by a motu proprio of Pope Pius V in 1571, an exemption for countries under Spanish rule was granted, allowing them to follow the rites of the Church in Toledo, the Primal See for Spain (Hayburn, 34).

${ }^{69}$ The clergy and musicians of St. Mark's were independent from Rome, reporting to the Venetian Doge (a state official) rather than the Pope. 
${ }^{70}$ Both Willaert and Giovanni Gabrieli (1557-1612) expanded Palestrina's technique of using multiple choirs stationed in separate locations in the church. The polychoral style, or cori spezzati, grew in popularity across Europe and flourished especially in Britain at the hand of the English composer, Thomas Tallis (1505-1585).

${ }^{71}$ The singing of psalms alternating with readings from the Bible.

${ }^{72}$ Alternating chants sung by the priest, congregation and choir during the Mass.

${ }^{73}$ Anerio and Soriano revisions were influenced by the polyphonic music of Palestrina and his contemporaries. They made extensive changes to the plainchant melodies by adding rhythmic note values, removing long passages of music that were sung over a single syllable (melismas). They also reorganized the way music was sung based on a more natural pronunciation of the Latin text (Hayburn, 33).

${ }^{74}$ Influenced by Palestrina's later works in this style, composers such as Claudio Monteverdi (1567-1643), Orlando di Lassus (1532-1594), and the Venetian composers Adrien Willaert and Cipriano de Rore produced madrigal collections.

75 "The Church was so full of people that one could not move. A new platform was built so that together with the two famous [church organs] and other musical instruments, the best singers and players that [could] be found ... took part, and so the mass began" (Sansovino, 1585, in Atlas, 616).

${ }^{76}$ The first use of the dominant seventh chord is attributed to Monteverdi, though Palestrina had already used it in some of his compositions, probably without understanding its harmonic importance (Saint-Saens 1915/1997, 32).

${ }^{77}$ The $16^{\text {th }}$ century Italian music composer and theorist Gioseffo Zarlino wrote music for harpsichords with keyboards that had nineteen notes to the octave. In the same period, the composer Nicola Vicentino invented a harpsichord with 31 notes to the octave (Lawrence, 287).

${ }^{78}$ This is why all keys sound similar to the undiscerning ear, and are more or less equally in tune.

${ }^{79}$ It was felt that a reminder was needed partly due to the growing influence of opera and the popularity of theatre, which the Church felt was a site of licentious behaviour. Thus in 1903 by motu proprio, Pius X cautioned against the use of theatrical music in church, encouraged the singing of Gregorian chant and use of classic polyphony, and re-stated the warnings against lascivious and worldly music (Hayburn, 222-225).

\section{Chapter Three}

${ }^{80}$ Annie Faulkner Shaw's famous article in Ladies' Home Journal attacking jazz 1921 was entitled "Does Jazz Put the Sin in Syncopation?"

${ }^{81}$ NYT, "Vatican Organ Condemns Jazz Dances as Immoral", Feb. 25, 1924, p. 1.

${ }^{82}$ In Canada, prohibition laws were passed by several provinces in the years prior to 1920 , but were quickly repealed when the governments realized that the regulations were simply unenforceable.

${ }^{83}$ NYT, "On with the Dance in Gotham ... the Exit of Bacchus will not Silence the Jazz", March 2, 1919, p. 76

${ }^{84}$ NYT, "Warns College Girls on Extreme Dances ... Jazz Music is to Blame for Present Social Ills", January 12, 1921, page 13.

${ }^{85}$ NYT, "Dancing Masters Urge Censorship to Prevent Undesired Novelties -- Want Music Regulated", August 14, 1921, page 25.

${ }^{86}$ NYT, "Stratton Says Jazz is 'Agency of the Devil' ", May 7, 1926, page 10

${ }^{87}$ NYT, "Attach Immoral Art. Dr. Van Dyke Also Tells Educators that the Demon Invented Jazz", February 28, 1921, page 10

${ }^{88}$ NYT, "Welsh Invoke Curfew as one way to Stop Jazz", March 7, 1926, page X12

${ }^{89}$ NYT, "Rector Calls Jazz National Anthem, Says it is Retrogression and Harks Back to African Jungle", January 30, 1922, page 9

${ }^{90}$ NYT, "Judge Rails at Jazz and Dance Madness", April 14, 1926, page 15

${ }^{91}$ NYT, "Wants Legislation to Stop Jazz as an Intoxicant" February 12, 1922, page 1

${ }^{92}$ NYT, "Sees American Morale in a State of 'Jazz' ", May 20, 1923, page 22

${ }^{93}$ NYT, "Rector Calls Jazz National Anthem, Says it is Retrogression and Harks Back to African Jungle", January 30, 1922, page 9 
${ }^{94}$ Besides New York Times articles, a primary source for this research is the fascinating account told by Paul Chevigny in Gigs: Jazz and the Cabaret Laws in New York City (1991). Chevigny is not only a jazz aficionado, but the lawyer who represented musicians and the musicians' union in the lawsuit that eventually overturned the cabaret laws that had been established sixty years before (Chiasson $v$. NYC Department of Consumer Affairs, 1986). He was chiefly concerned with asserting musicians' rights and argued for legal change against shifting hegemonic power based on freedom of rights. Chevigny succeeded by understanding that "the challenge to the cabaret laws was a matter of using existing concepts to get new, practical results, rather than one of a sea change in the law" (Chevigny 1991, 3).

${ }_{95}$ NYT, March 3, 1922, page 13

${ }^{96}$ Current Opinion, September 1918, page 165

${ }^{97}$ Literary Digest, August 1917, pages 26-29, in Koenig (2002).

${ }^{98}$ Wilson, E. The New Republic, January 1926, pages $217-9$.

${ }^{99}$ NYT, "Condemns Age of Jazz", quoting Professor H.A. Smith, Head of Fine Arts in Religion at Boston University, January 27, 1925, page 12

${ }^{100}$ NYT, "Rector Calls Jazz National Anthem", quoting Reverend Dr. Percy Grant, Rector of the Episcopal Church of the Ascension on Fifth Avenue, January 30, 1922, page 9.

${ }^{101}$ Ibid.

${ }^{102}$ Literary Digest, August 1917, page 26, reprinted in Koenig (2002).

${ }^{103}$ NYT, "Our Moaning Saxophone is now called Immoral", September 13, 1925, page SM2.

${ }^{104}$ Cohen defines a moral panic as follows: "A condition, episode, person or group of persons emerges to become defined as a threat to societal values and interests; its nature is presented in a stylized and stereotypical fashion by the mass media; the moral barricades are manned by editors, bishops, politicians and other right-thinking people; socially accredited experts pronounce their diagnoses and solutions; ways of coping are evolved or ... resorted to; the condition then disappears, submerges or deteriorates and becomes invisible" (Cohen 2002, 1).

${ }^{105}$ A folk devil is the "personification of evil", an "unambiguously unfavourable symbol" (Cohen, in Goode and Ben-Yehuda, 1994, 28).

${ }^{106}$ NYT, "Wants Legislation to Stop Jazz as an Intoxicant", February 12, 1922, page 1.

${ }^{107}$ NYT, "Judge Rails at Jazz and Dance Madness, April 14, 1926, page 15.

${ }^{108}$ NYT, “Enjoin 'Jazz' Palace to protect New-Born; Salvation Army Fears Effect on Babies", February 4, 1926 , page 4.

${ }^{109}$ Downes, Olin. (1924). “A Concert of Jazz", The New York Times (13 February), p. 16.

${ }^{110}$ Newman, Ernest. (1927). "Summing Up Music's Case Against Jazz", New York Times (Mar. 6), p. SM3. ${ }^{111}$ Whiteman, Paul. (1927). "In Defense of Jazz and its Makers", New York Times (Mar 13), p. SM4.

${ }^{112}$ While Kahn chaired the Board of the Metropolitan Opera Company, he called for proposals from composers for a jazz opera to be commissioned for the Met (NYT, "Jazz Opera in View for Metropolitan, November 18, 1924, p. 23). In 1926, John Alden Carpenter's jazz composition, Skyscrapers, was mounted as a ballet there, and in 1935, Kahn commissioned Gershwin's opera Porgy and Bess which premiered not at the Met, but at Carnegie Hall.

${ }^{113}$ NYT, "Roger Kahn Plans Orchestra Chain - offers to provide Jazz for all Statler Hotels for $\$ 1,000,000$ a year", 20 March 1927, p. B4.

${ }^{114}$ NYT, "Lopez to put Jazz into Stock Market", January 10, 1925, p. 8.

${ }^{115}$ Ibid.

${ }^{116}$ Frequently in historiographies of jazz music, this period of time is known as the "Harlem Renaissance", referring the emergence of African American literature, art and music during the 1920s and 1930s.

${ }^{117}$ In addition to numerous guest columns in the New York Times explaining aspects of jazz, and the very public debate carried on between Whiteman and Ernest Newman in the same paper, Whiteman wrote a book entitled "Jazz", (New York: J. H. Sears, 1926), written with Mary McBride (an American radio host), to explain the history and practice of jazz. Whiteman never denied jazz's origins or the debt to black musicians: he began the book by writing, "Jazz came to America 300 years ago in chains".

${ }^{118}$ Although Whiteman hired black musicians to play in recording sessions that produced phonographs which were then widely available to consumers and were also played on the radio, he conformed to the rule that a mixed-race orchestra could not be seen in public. However he felt it made no difference who was performing in sound recordings, adopting an out of sight, out of mind attitude. Whiteman was ahead of his 
time, hiring black musicians and fiercely defending them when it was not politically correct to do so (Berrett, 2004).

${ }_{119}$ NYT, "Says Jazz Players are not Artists", August 1, 1927, page 21.

${ }^{120}$ NYT, "Night Club Curfew passes Aldermen - Wild Visitors to City Assailed in Report", December 2, 1926, p. 1

${ }^{121}$ The first offence under the new law was given out to a white club owner, a John T. Baine, who was fined $\$ 50$ for operating a cabaret without a license when police found couples dancing to live music in his establishment (NYT, “Lacks Cabaret License, Fined \$50”, December 20, 1927, p. 25).

${ }_{122}$ There are reports of hundreds of challenges to carding, including many high-profile musicians such as

Billie Holiday, Sonny Stitt, Charlie Parker, Bud Powell and Thelonius Monk. One musician who somehow managed to perform at the Copacabana Club without a card numerous times in the 1950s was Frank Sinatra (Chevigny 1991, 63).

${ }^{123}$ Whether the venue was a café, a nightclub that offered dancing, a restaurant, or a cabaret, owners were required to submit an application for an expensive license if they wanted to hire more than three musicians. The city also required cabarets with occupancy over 75 to have expensive sprinkler systems, special fire alarms and other safety precautions installed. The cost to retrofit existing venues was exorbitant -estimated to range from $\$ 25,000$ to $\$ 50,000$ or higher (NYT, "Musicians Taking City Cabaret Law to Court", June 4, 1986, p.1). If a club was found to be in violation, the fine was $\$ 100$ per day, and under certain circumstances the premises could be padlocked (NYT, "Jazz combo sounds protest note on cabaret law", March 5, 1985, p. C15).

${ }^{124}$ In May 1961, there were sixty complaints against coffee houses (NYT, "City is Criticized on Café Licensing", May 10, 1961, p. 32), and by 1964, fifteen of these venues offering music were ordered closed (NYT, “15 'Village' Shops ordered to Close”, March 25, 1964, p.43).

${ }^{125}$ Examples of club closures in the 1970s included Seventh Avenue South; Eddie Condon's; Lush Life; The Burgundy; and Discover (Chevigny 1991, p. 85). In 1960, there were between eleven and twelve hundred cabaret licenses issued to venues in New York City and its boroughs, but by 1986, less than two hundred had been issued (Chevigny 1991, 89). See also NYT, "In New York, the Jazz Life is Mostly the Blues", April 25, 1986, p. A34.

${ }^{126}$ Downbeat Magazine, 29 January 1947. Author unknown.

${ }^{127}$ In 1985, ten per cent of all nightclubs and discos in New York City possessed cabaret licenses which allowed the use of any number or type of instrumentalists (NYT, "Panel hears tuneful protest of limits on music in clubs", June 29, 1985, page 27, and NYT, "New York Cabaret Law an Anachronism", May 9, 1986, page A34).

${ }_{128}$ Zion, S. (1966). "Mayor Backs end to Cabaret Law", New York Times (January 20), p. 24.

${ }^{129}$ Callahan, John. (1967). "Doom of Cabaret Identification Law Is Foreseen", New York Times, (September 8), p. 31.

${ }^{130}$ Perlmutter, Emanuel. (1967). "Identity Cards for Performers Exit to Applause", New York Times, (September 26), p.53.

${ }_{131}$ One of the Aldermen was reported to have said before the bill was taken to a vote that "a vote for the bill would be a vote in support of Mayor Walker and the Democratic City Administration" (NYT, "Night Club Curfew passes Aldermen - Wild Visitors to City Assailed in Report", December 2, 1926, p. 1).

${ }^{132}$ For example, agent-publisher Irving Mills helped Duke Ellington get his start at the Cotton Club in New York City and arranged recording sessions on the Brunswick, Victor, and Columbia labels which gave Ellington popular recognition. Although his fee was $45 \%$ of Ellington's performance rights, Mills took on all of Ellington's management duties, allowing the musician to focus on his band's sound, and composing. ${ }^{133}$ In the 1960s, Warren Chiasson, the vibraphonist named in the cabaret law lawsuit, was prevented from playing his instrument with his group in a club when "police came to the club and said that the vibraphone could not be used because it was a percussion instrument" (Chiasson, in Chevigny 1991, 19). He was prevented from playing with an ensemble that he himself had organized. In the 1970s, he had the opportunity to play in another bar, but was informed by the owner that he could not play his instrument because it was not legal (Chevigny 1991, 20). In order to be paid, he had to switch to playing piano - which is, arguably, a percussion instrument as well.

${ }^{134}$ This was exactly the situation that inspired Paul Chevigny to investigate the nature of cabaret laws in the early 1980s, and what motivated him to initiate legal action against the City on behalf of the Union. 
${ }^{135}$ Downbeat Magazine, 1957, issue unknown. Available at: http://www.gale.cengage.com/free resources/bhm/bio/cole n.htm

${ }^{136}$ One exception was the ban on all jazz music in Germany in the 1930 s and 40s. Jazz was considered to be "alien music ... as composed by or originated from Jews and Negroes" by the Propaganda Ministry of the Third Reich (Ellis 1975, 234). However, this did not prevent jazz from being heard in Germany's underground clubs or in private residences.

${ }^{137}$ Ironically, these included African-influenced instruments such as mbiras (thumb pianos), cowbells and gourds.

${ }_{138}$ NYT, “Petrillo Bans Recordings 'Once and for All' on Dec. 31”, October 19, 1947, p. 1.

\section{Chapter Four}

${ }^{139}$ The amount of music an MP3 player can hold depends on the compression rate of the music. For example, at $128 \mathrm{kbit} / \mathrm{s}$ (the most common compression rate used for MP3 players), $20 \mathrm{~GB}$ is equivalent to over 5000 four-minute songs, or $500 \mathrm{CDs}$. At $80 \mathrm{~GB}$ of storage, an iPod Classic could hold 2,000 CDs.

${ }^{140}$ Besides the CMCC (www.musiccreators.ca), another example of a coalition is the Songwriters Association of Canada (www.songwriters.ca), which in December 2007 proposed to the Canadian government that a compulsory $\$ 5 / \mathrm{mo}$. music license fee be levied for all Internet subscriptions, which would then be distributed to artists through a digital collective.

${ }^{141}$ See: http://www.eff.org/

${ }^{142}$ See: http://www.futureofmusic.org/

${ }^{143}$ See: http://freeculture.org/

${ }^{144}$ See: http://www.lessig.org/

${ }^{145}$ See: http://www.michaelgeist.ca/index.php?option=com topics\&lask=view\&id=10055\&Itemid=273

${ }^{146}$ Siberry (now known as "Issa") calls this "self-determined pricing" (www.sheeba.ca/store/help.php\#sdp)

${ }^{147}$ ArtistShare (www.artistshare.com), established in 2001 by entrepreneur and musician Brian Camelio, allows fans to show appreciation for their favourite artists by funding recording projects in exchange for access to the creative process, limited edition recordings, access to recording sessions (either through live sessions or via video- or audio-conferencing) and through credit listing on the CD. Artistshare is, in effect, an Internet-age patronage system.

${ }^{148}$ As proposed in Canada under Bill C-61, introduced into Parliament in July 2008. However, this Bill will die on the order paper due to the September 2008 election call and the dissolution of Parliament.

${ }^{149}$ Alternative Compensation Systems (ACS) described by detail in Fisher, 2004, impose levies or taxes on users through surcharges or optional payments on internet connections, blank CDs, digital media players. These are then distributed based on frequency of downloading by consumers, usage measurements or voting systems (Liebowitz 2003, 18-21). Noank Media Inc., established by Harvard-based law professors Terry Fisher and Paul Hoffert (presented at McGill conferences in 2006 and 2007), is an ACS currently working in China and Hong Kong (www.noankmedia.com). 
Appendices 


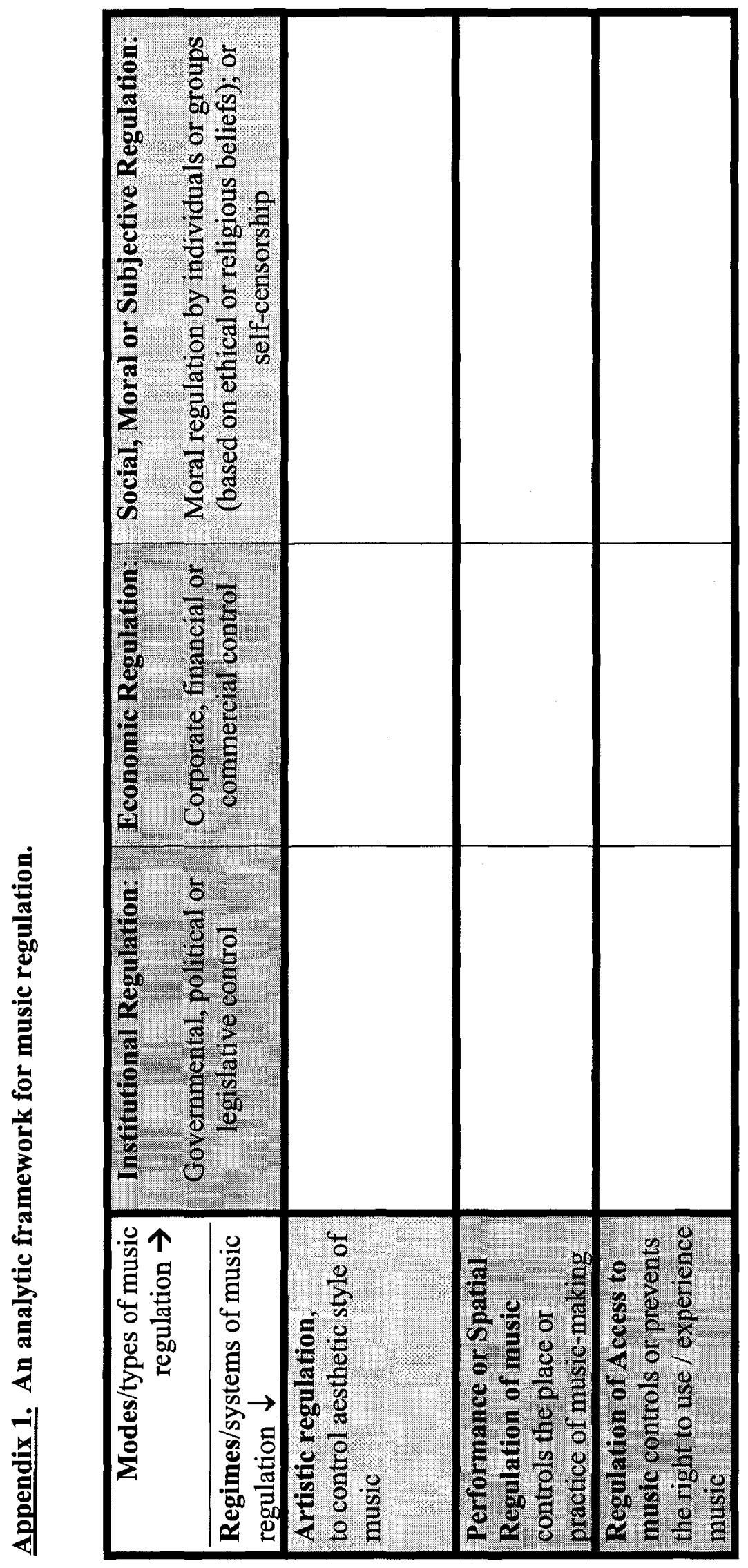




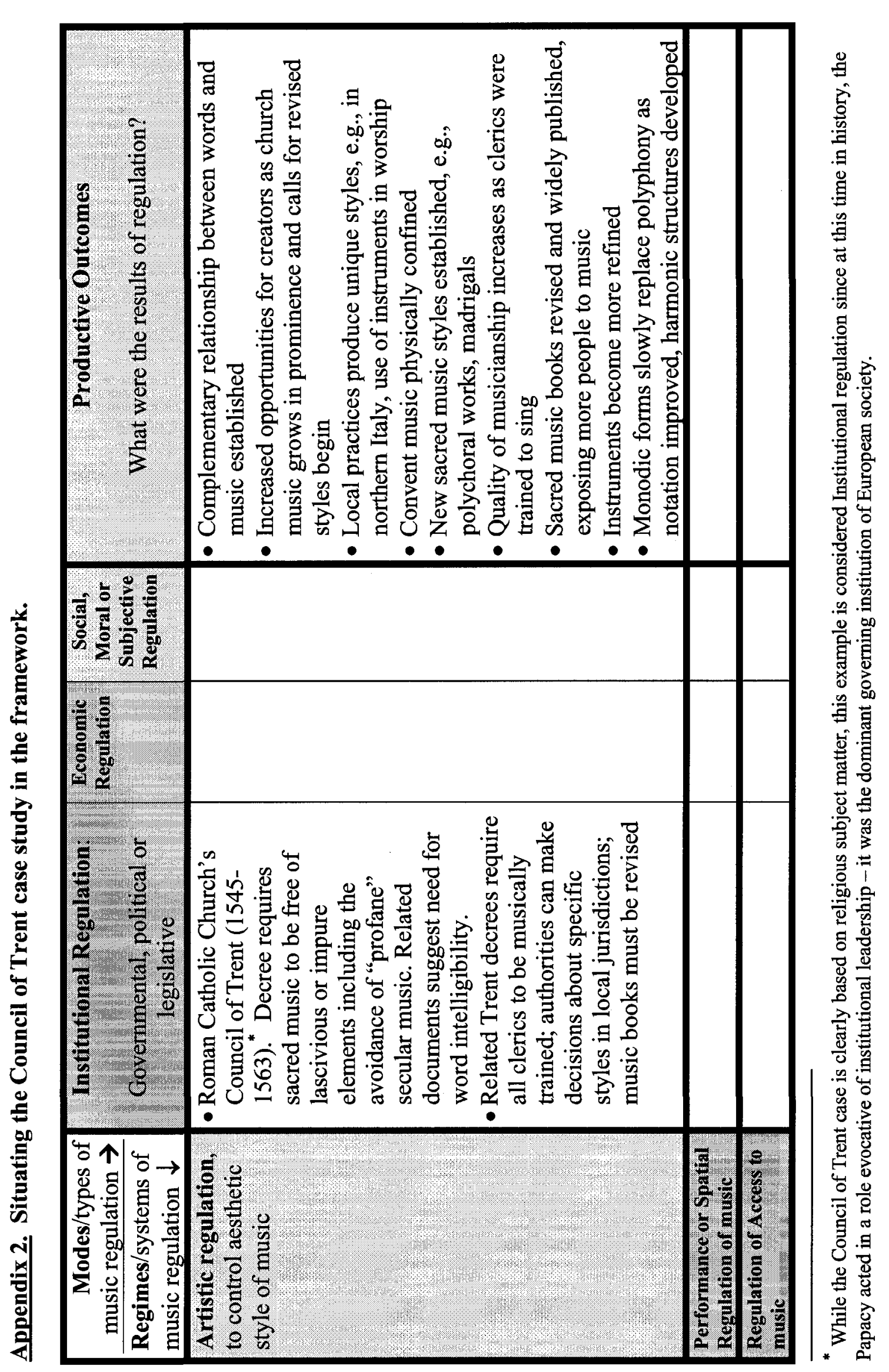




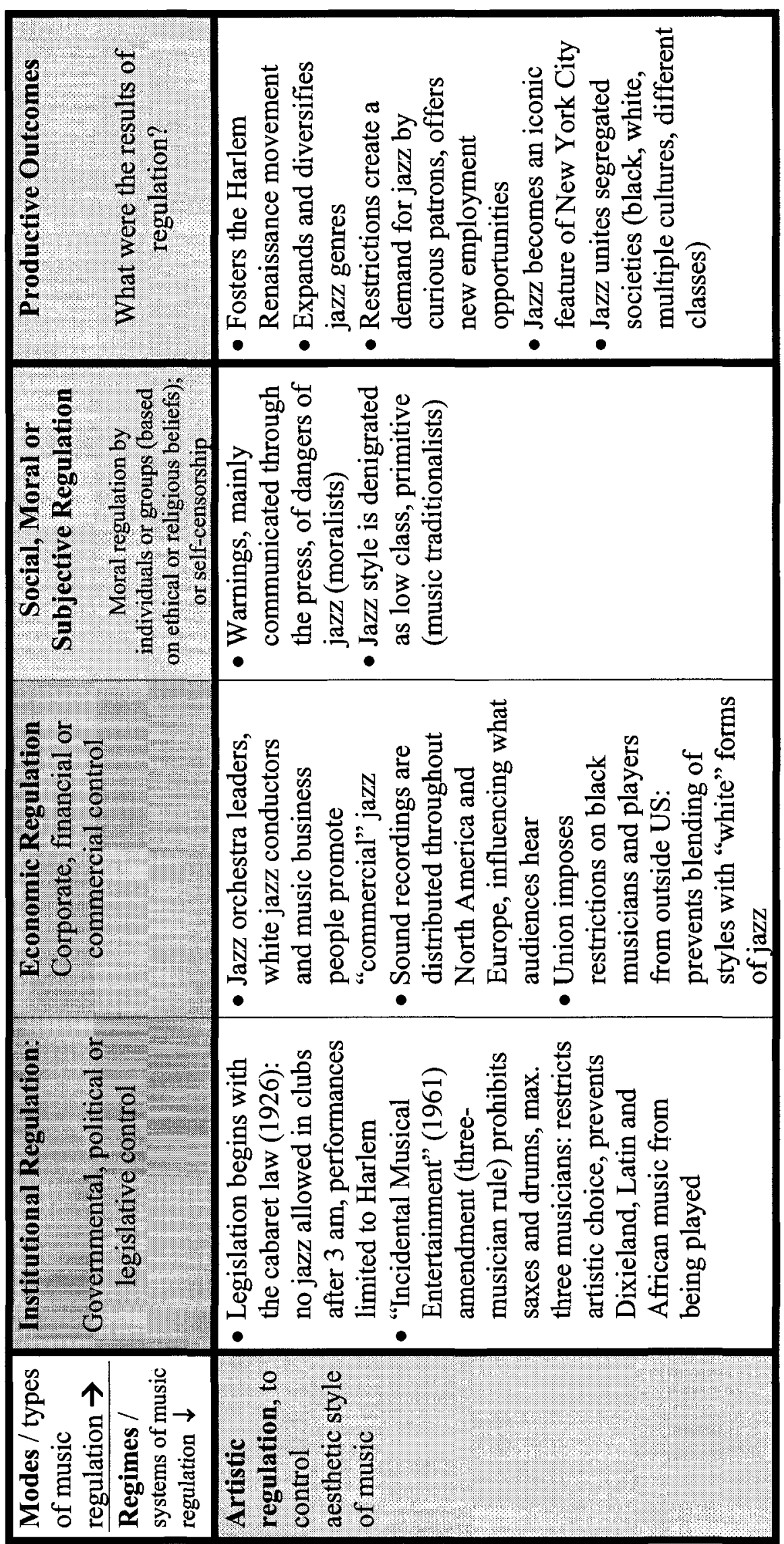




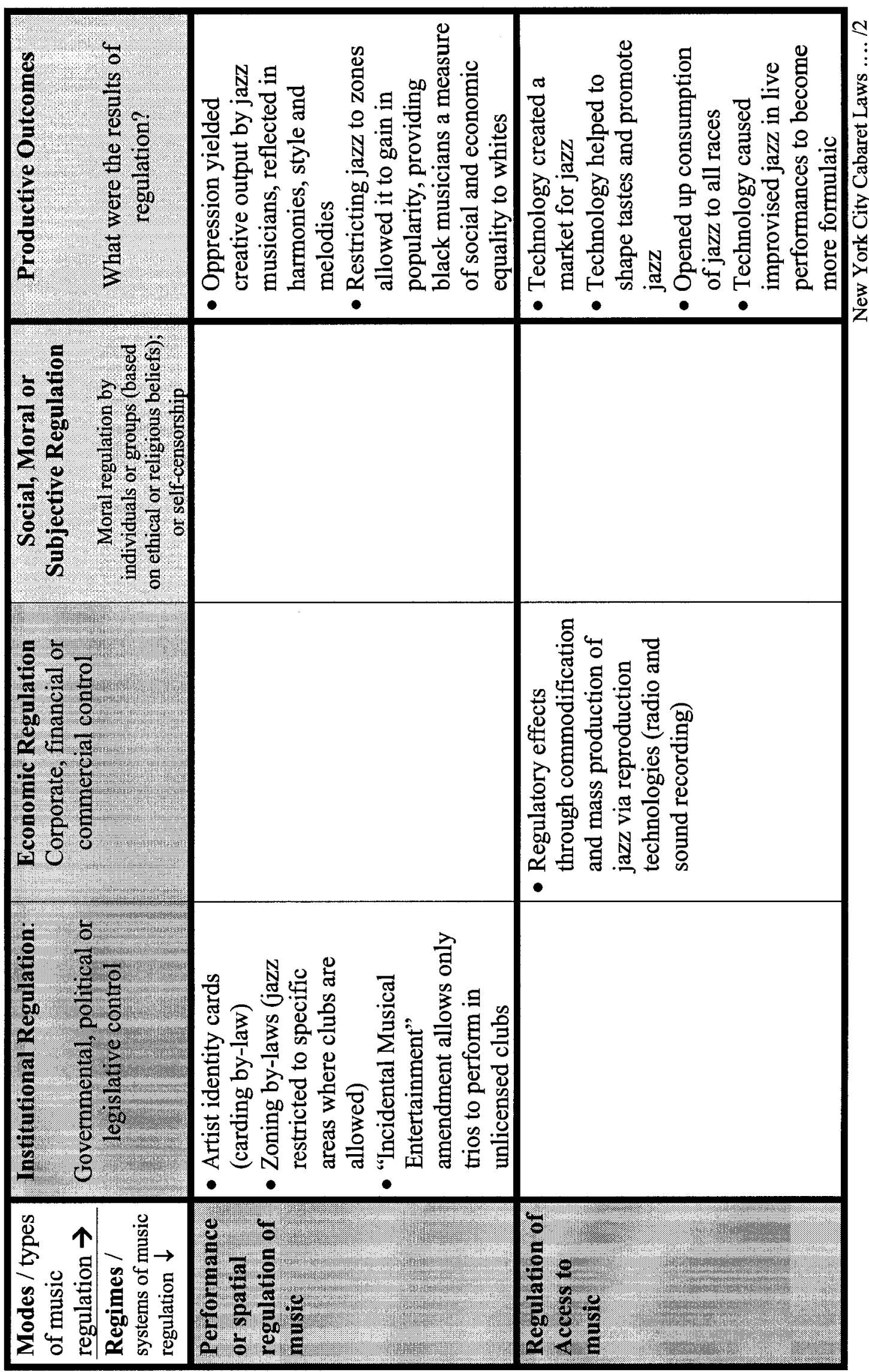




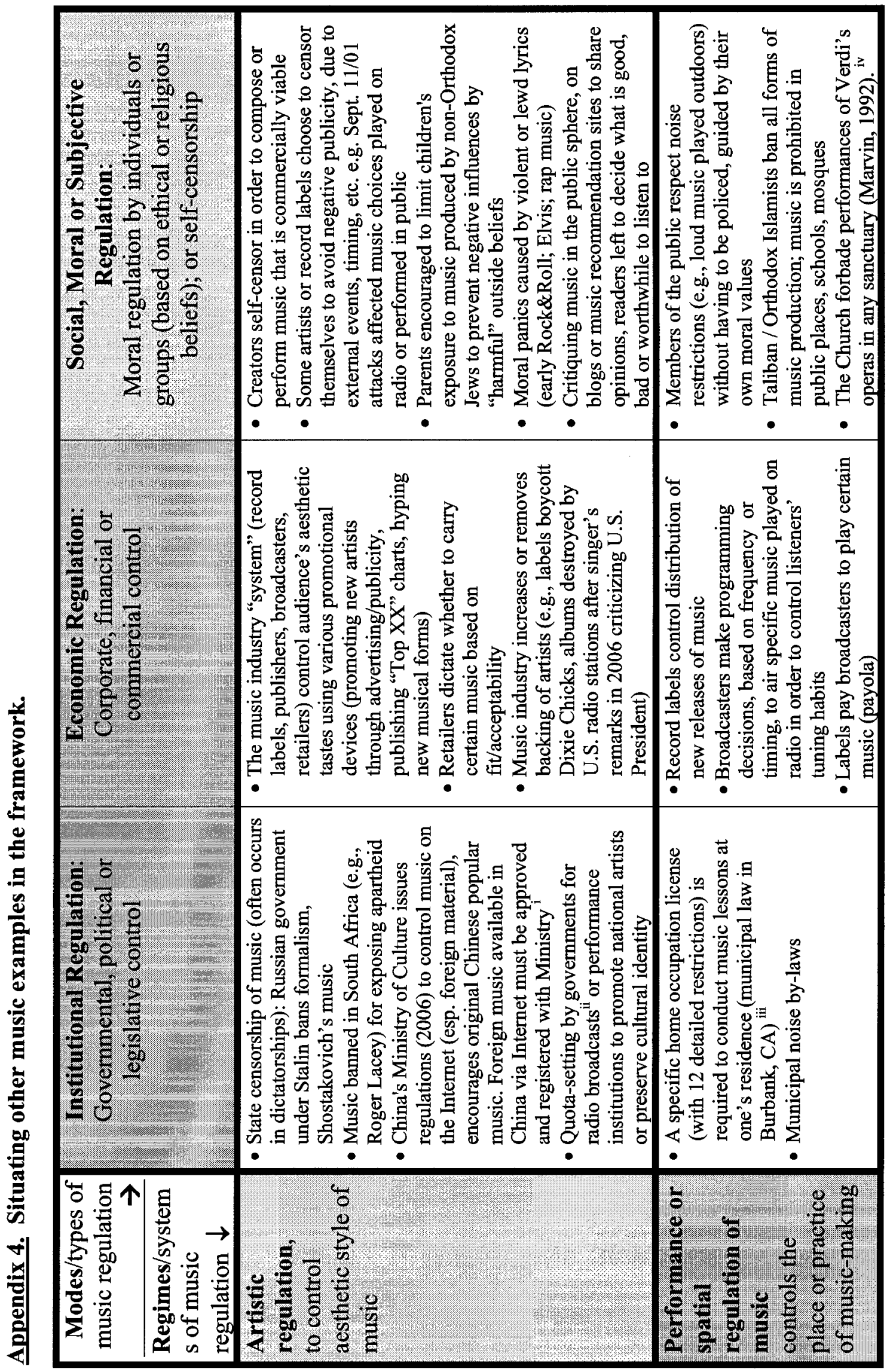



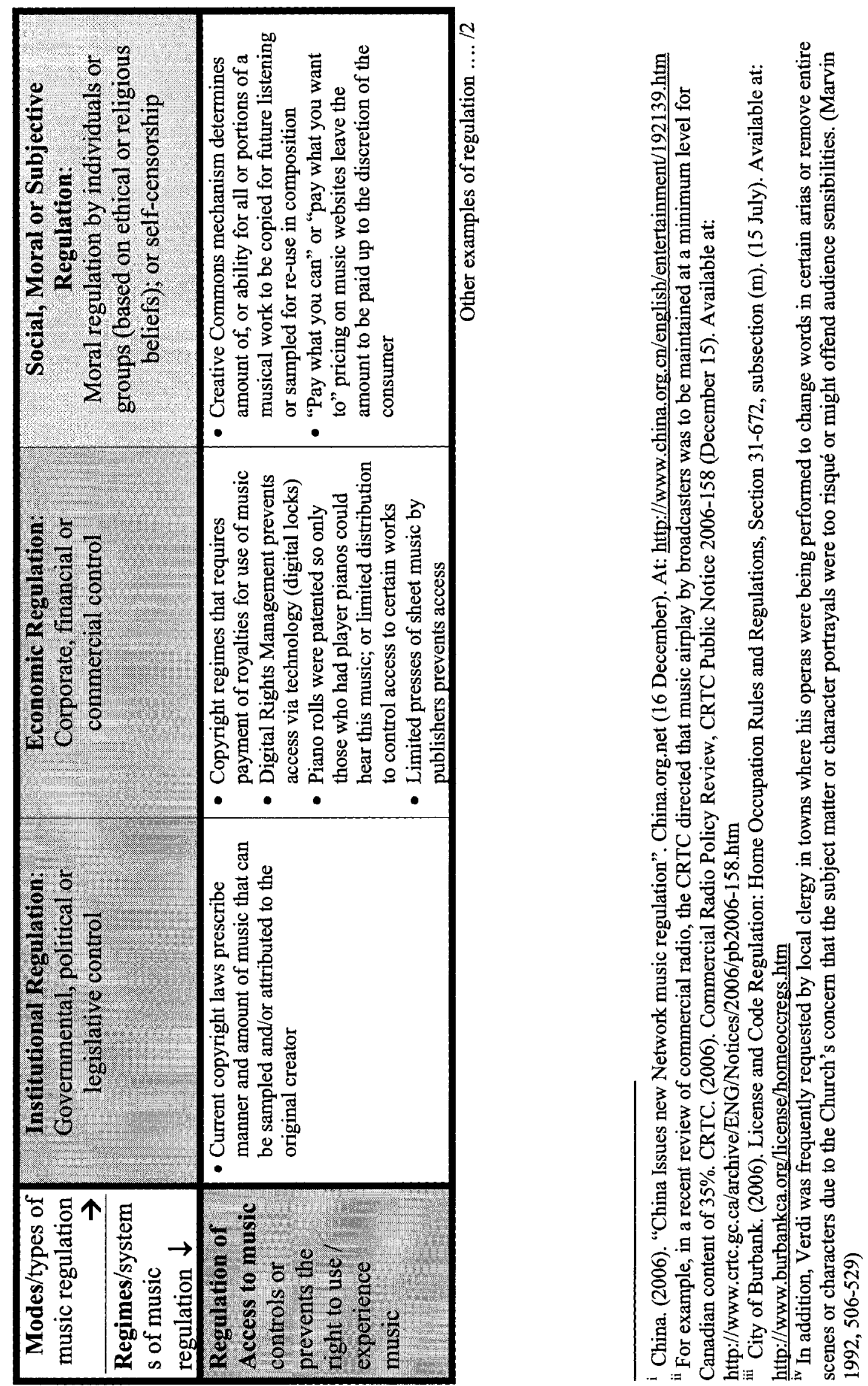


\section{Bibliography}

All websites checked on 15 August 2008.

Acheson, Keith and Christopher Maule. (1999). Much ado about culture: North American trade disputes. Ann Arbor: University of Michigan Press.

Adorno, Theodor and Max Horkheimer. (1944, 1972). "The Culture Industry", in The Dialectic of Enlightenment, trans. John Cumming, p. 120-167. New York: Continuum.

Adorno, Theodor. (1941/2002). "On Popular Music", (with the assistance and collaboration of George Simpson), in Essays on Music, Selected essays with an introduction, commentary, and notes by Richard Leppert. New translations by Susan $\mathrm{H}$. Gillespie, p. 437-469. Los Angeles: University of California Press.

Aglietta, Michel. (1979). A Theory of Capitalist Regulation. London: New Left Books.

Anderson, Maureen. (2004). "The White Reception of Jazz in America", African American Review (Spring), Vol. 38, No. 1, p. 135-145.

Anderson, Paul Allen. (2001). Deep River: Music and Memory in Harlem Renaissance Thought. Durham: Duke University Press.

Andersson, Muff. (1981) Music in the Mix: The Story of South African Popular Music, Johannesburg, Ravan Press.

Applerouth, Scott. (2005). "Body and Soul: Jazz in the 1920s", American Behavioral Scientist, Vol. 48, No. 11 (July), p. 1496-1509.

Arnold, Denis. (1965). 'Music at a Venetian Confraternity in the Renaissance', Acta Musicologica, Vol. 37, No. 1/2. (January-June), p. 62-72.

Aristotle. (350 BC). Politics. Translated by Benjamin Jowett. Available at: http://classics.mit.edu/Aristotle/politics.8.eight.html

Atlas, Allan W. (1998). Renaissance Music. New York: Norton.

Attali, Jacques. (1977). Noise: The Political Economy of Music. Translated by Brian Massumi (1985), with a foreword by Frederic Jameson and afterward by Susan McClary. Minneapolis: University of Minnesota Press.

Baily, John (2001). "Can You Stop the Birds Singing?": The censorship of music in Afghanistan. Copenhagen: Freemuse.

Bennett, Tony. (2003). "Culture and Governmentality", in Foucault, Cultural Studies and Governmentality, ed. Jack Bratich et al, p. 47-66. Albany: State University of New York. 
(1992). "Putting policy into cultural studies", in Cultural Studies, L.

Grossberg, ed. et al, p. 23-37. New York: Routledge.

Berg, Wilbur. (date unknown). "Should Artistic Creativity Have Restraints?", research paper for the Worldwide Church, edited by Wheeler, John (2003). Available at:

http://www.friendsofsabbath.org/ surfer/Miscellaneous/Should_artistic_creativity have Restraints.pdf

Berland, Jody. (1998). "Locating Listening: Technological Space, Popular Music, and Canadian Mediations", in The Place of Music, ed. Andrew Leyshon, p. 129-150. New York: Guilford.

Bernstein, Jane. (1996). "Buyers and Collectors of Music Publications: Two SixteenthCentury Music Libraries Recovered", in Music in Renaissance cities and courts; studies in honor of Lewis Lockwood, p. 21-33. Warren, Michigan: Harmonie Park Press.

Berrett, Joshua. (2004). Louis Armstrong and Paul Whiteman: Two Kings of Jazz. New Haven, CT: Yale University Press.

Bettig, Ronald V. (2003b). "Copyright and the commodification of culture", Media Development 1. Available at: http://www.wacc.org.uk/wacc/content/pdf/629 . (1996). Copyrighting Culture: The Political Economy of Intellectual Property. Boulder: Westview Press.

Binder, A. (1993). "Constructing Racial Rhetoric: Media Depictions of Harm in Heavy Metal and Rap Music." American Sociological Review Vol. 5, p. 753-767.

Black, Christopher. (2004). "The Public Face of Post-Tridentine Italian Confraternities", The Journal of Religious History, Vol. 28, No. 1 (February), p. 87-101.

Boethius, Anicius (505 AD), ed. by Claude V. Palisca. (1989). Fundamentals of Music: Anicius Manlius Severinus Boethius, trans. Calvin M. Bower. New Haven: Yale University Press.

Bokina, John. (1988). "Resignation, Retreat, and Impotence: The Aesthetics and Politics of the Modern German Artist-Opera", Cultural Critique, No. 9 (Spring), p. 157-195.

Bourdieu, Pierre. (1984). Distinction: A social critique of the judgement of taste (trans. R. Nice). London: Routledge.

Bossy, John. (1985). Christianity in the West, 1400-1700. Oxford: Oxford University Press.

Boyer, Robert. (1985). La Theorie de la Régulation: une analyse critique. Paris: la Decouverte. 
Boyle, James. (1997). "Foucault in Cyberspace: Surveillance, Sovereignty, and HardWired Censors", University of Cincinnati Law Review, Vol. 66, p. 177-205. Also available at: http://www.law.duke.edu/boylesite/foucault.htm.

Bratich, Jack et al, ed. (2003). Foucault, Cultural Studies and Governmentality. Albany: State University of New York.

Breen, Martin. (1992) "Copyright, Regulation and Power in the Australian Recorded Music Industry: A Model”, Occasional Paper 13, Brisbane: Institute for Cultural Policy Studies, Griffith University. Available via JSTOR.

Brooke, Carolyn. (2002). "Soviet Musicians and the Great Terror", in Europe-Asia Studies, Vol. 54, No. 3 (May), p. 397-413.

Bulman, Raymond F. (ed.), and Frederick J. Parrella (ed.). (2006). From Trent to Vatican II - Historical and Theological Investigations. New York: Oxford University Press.

Burbank, City of. (2006). License and Code Regulation: Home Occupation Rules and Regulations, Section 31-672, subsection (m). (updated 15 July). Available at:

http://www.burbankca.org/license/homeoccregs.htm

Capes, J. M. (1847). "Life of Palestrina", The Musical Times and Singing Class Circular, Vol. 2, No. 40. (September 1), p. 121-122.

Carlsson, Ulla. (2006). Regulation, awareness, empowerment: young people and harmful media content in the digital age. Göteborg: Nordicom (Nordic Information Centre for Media and Communication Research (Sweden). Available at: http://unesdoc.unesco.org/images/0014/001469/146955e.pdf

Castells, Manuel. (2007). "Communication, Power and Counter-power in the Network Society", in International Journal of Communication, Vol. 1, p. 238-266. Available at http://ijoc.org/ojs/index.php/ijoc/article/view/46/35

CBC News. (2007). "Pope to issue decree authorizing broader use of old Latin mass, Vatican says". CBC News Online. (7 July). Available at:

http://www.cbc.ca/cp/Home+Family/070705/U070517AU.html

Chevigny, Paul. (1991). Gigs: Jazz and cabaret laws in New York City. New York: Routledge.

Chiasson (1988). Chiasson v. NYC Department of Consumer Affairs, 524 NYS 2d 649, 651, 652 (Supreme Court New York County, 1988).

China. (2006). "China Issues new Network music regulation". China.org.net (16 December), at: http://www.china.org.cn/english/entertainment/192139.htm 
Cloonan, Martin. (2004). "What is music censorship? Towards a better understanding of the terms", in Shoot the Singer! Music Censorship Today, p. 3-5. London: Zed Books.

Cockayne, Emily (2002). "Cacophony, or vile scrapers on vile instruments: bad music in early modern English towns”, Urban History. Vol. 29, p. 35-47.

Cohen, Stanley. (2002). Folk Devils and Moral Panics, $3^{\text {rd }}$ ed. Abingdon: Routledge

Cohen, Stanley. (1972). Folk Devils and Moral Panics. Harmondsworth: Penguin.

Collier, James Lincoln. (1993). Jazz: The American Theme Song. New York: Oxford University Press.

Collins, Douglas. (1985) "Ritual Sacrifice and the Political Economy of Music", Perspectives of New Music, Vol. 24, No. 1 (Autumn-Winter), p. 14-23.

Coombe, Rosemary. (1998). The Cultural Life of Intellectual Properties: Authorship, Appropriation, and the Law. Durham: Duke University Press.

Countryman, Vern. (1948). The Organized Musicians: I. The University of Chicago Law Review, (Autumn), Vol. 16, No. 1, p. 56-85.

CRTC. (2006). Commercial Radio Policy Review, CRTC Public Notice 2006-158 (December 15). Available at: http://www.crtc.gc.ca/archive/ENG/Notices/2006/pb2006$\underline{158 . h t m}$

Dahlhaus, Carl. (1967/2004). "Preface to Trivialmusick" and "Trivial Music and Aesthetic Judgment", in Bad Music: The Music We Love to Hate. New York: Routledge, p. 333-362 (originally published in German in 1967).

Dean, Mitchell. (1999). "Basic Concepts and Themes" in Governmentality: Power and Rule in Modern Society. London: Sage, p. 9-39.

Demers, Joanna. (2006). Steal This Music: How Intellectual Property Law Affects Musical Creativity. Athens: University of Georgia Press.

Dorland, Michael. (2000). "Policying Culture: Canada, State Rationality, and the Governmentalization of Communication", in Capital Culture: a reader on Modernist Legacies, State Institutions, and the Value of Art, p. 142-151. Montreal: McGill University Press.

Dotter, D. (1994). "Rock and Roll Is Here to Stray: Youth Subculture, Deviance, and Social Typing in Rock's Early Years", in Adolescents and Their Music: If It's Too Loud, You're Too Old, edited by J. S. Epstein, p. 87-114. Hamden, CT: Garland. 
Dowler, Kevin. (1996). "The Cultural Industries Policy Analysis", in The Culture Industries in Canada: problems, policies and prospects, p. 329-346. Toronto: Lorimer.

Ellis, Donald W. (1975). "The Propaganda Ministry and Centralized Regulation of Music in the Third Reich: The 'Biological Aesthetic' as policy", Journal of European Studies. Vol. 5, p. 223-238.

Erenberg, Lewis. (1981). Steppin' Out: New York Nightlife and the Transformation of American Culture. Chicago: University of Chicago.

Faulkner, Anne Shaw. (1921). "Does Jazz Put the Sin in Syncopation?" Ladies' Home Journal (August), pg. 16-40. Available at:

http://faculty.pittstate.edu/ knichols/syncopate.html

Fay, Laurel. (2000). Shostakovich: A Life. London: Oxford University Press.

Fellerer, K. G. and Moses Hadas. (1953). "Church Music and the Council of Trent", The Musical Quarterly, Vol. 39, No. 4 (October), p. 576-594.

Fenlon, Iain. (1980). Music and patronage in sixteenth-century Mantua. Cambridge: Cambridge University Press, 1980.

Fink, Henry T. (1924). "Jazz: Lowbrow and Highbrow", The Etude (August), p. 527-28.

Fisher, William (Terry). (2004). Promises to Keep, Technology, Law, and the Future of Entertainment. Stanford: Stanford University Press.

Foucault, M. (1995). Discipline and Punish: The Birth of the Prison, 2nd ed. New York: Vintage Books, Random House.

(1991). "Governmentality," in The Foucault Effect: Studies in Governmentality, Graham Burchell, ed., p. 87-104. Chicago: University of Chicago Press.

Books. . (1984). The Foucault Reader, ed. Paul Rabinow. New York: Pantheon (1980). "Two Lectures", in Michael Foucault, Power/Knowledge: Selected Interviews and Other Writings, 1972-1977, ed. and trans. by Colin Gordon. p. 78-104. Brighton: Harvester Press.

. (1977). Discipline and Punish. The Birth of the Prison, ed. and trans. by Alan Sheridan. New York: Pantheon Books. . (1970). "Classifying", in The order of things: an archaeology of the human sciences, p. 137-179. London: Routledge. 
Fox, Aaron. (2004). "White Trash Alchemies of the Abject Sublime: Country as "Bad" Music", in Bad Music: The Music We Love to Hate, p. 39-61. New York: Routledge.

Freeman, R. Edward and Laurie Alkire. (2006) "The Record-Rating Wrangle (A)". Social Science Research Network. Available at: http://ssrn.com/abstract $=908118$

Frith, Simon and Lee Marshall, eds. (2004a). Music and Copyright, $2^{\text {nd }}$ ed. Edinburgh: Edinburgh University Press.

Frith, Simon. (2004b). "What is Bad Music?", in Bad music: the Music we Love to Hate, ed. Chris Washburne and Maiken Derno, p. 15-36. New York: Routledge.

. (2002). "Illegality and the Music Industry," in Michael Talbot, ed., The Business of Music, p. 195-216. Liverpool University Press.

(1996). "Popular music policy and the articulation of regional identities: The case of Scotland and Ireland", in Paul Rutten (ed.), Music, culture and society in Europe, p. 98-103. Part II of European Music Office, Music in Europe. Brussels. Available at:

http://www.icce.rug.nl/ soundscapes/DATABASES/MIE/Part2_chapter04.shtml

. (1993) "Popular music and the state", in Rock and Popular Music: Politics, Policies, Institutions, eds T. Bennett, S. Frith, L. Grossberg, J. Shepherd \& G. Turner, p. 14-24. London: Routledge.

Pantheon. (1981). Youth, Leisure, and the Politics of Rock 'N Roll. New York:

Goode, Erich and Nachman Ben-Yehuda. (1994). "Moral Panics: Culture, Politics and Social Construction", Annual Review of Sociology, Vol. 20, p. 149-171.

Gordon, Colin. (1991). "Governmental rationality: an introduction" in The Foucault Effect, p. 1-52. Chicago: University of Chicago Press.

Gramsci, Antonio. (1929/1971). "American and Fordism", in Selections from the Prison Notebooks. London: Lawrence and Wishart. (originally trans. 1933).

Grout, Donald and Claude Pasilica. (1988). A History of Western Music, $4^{\text {th }} \mathrm{ed}$. New York: W.W. Norton \& Company. Also $1996,5^{\text {th }}$ edition.

Grove Music Online, ed. L. Macy (accessed 18 October 2006), grovemusic.com (subscription access). 
Hanslick, Eduard. (1891/1986). On the musically beautiful: a contribution towards the revision of the aesthetics of music. Translation of the 1891 edition, ed. Geoffrey Payzant. Indianapolis: Hackett Publishing Company.

Hayburn, Robert F. (1979). Papal legislation on sacred music, 95 A.D. to 1977 A.D. Collegeville, Minnesota: Liturgical Press.

Hebdige, Dick. (1987). Cut ' $n$ ' mix: cultural identity and Caribbean music. London: Comedia.

Hemmungs Wirtén, Eva. (2006). "Out of sight and out of mind: On the cultural hegemony of intellectual property (critique)", Cultural Studies, Vol. 20, No. 2/3 (March/May), p. 282-291.

. (2004). No Trespassing: Authorship, Intellectual Property Rights, and the Boundaries of Globalization. Toronto: University of Toronto Press.

Ho, Allan and Dmitry Feofanov. (1998) Shostakovich Reconsidered. London: Toccata Press.

Hunter, Ian. (1991). "Aesthetics and cultural studies", in L. Grossberg, ed., et al. Cultural Studies. New York: Routledge.

Jaeger, Johannes, and Werner Raza. (2001). "French Regulation Theory and Political Ecology: a proposed framework for integration with an illustration in urban studies", at euroecolecon.org (draft). Available at:

http://www.euroecolecon.org/frontiers/Frontiers1/F1Contributions/F1papers/129paper.pdf . Subsequently published by Jaeger as: "Eine regulationstheoretische Konceptualisierung der Theorie der Bodenrente. Politokonomischer Entwicklungsprozess und urbane Raumstruktur im Vien und Montevideo. Service Fachverlag, Vienna, 2002.

Jessop, Bob. (1990). "Regulation Theories in Retrospect and Prospect", Economy and Society, Vol. 19, No. 2, p. 153-216.

Johnson, David and David Post. (1996). "Law and Borders - The Rise of Law in Cyberspace", Stanford Law Review, Vol. 48, p.1367. Available at: http://www.cli.org/X0025 LBFIN.html\#4.

Jones, Steve. (2002). "Music that moves: popular music, distribution and network technologies", in Cultural Studies, Vol. 16, No. 2, p. 213-232.

. (1991). "Ban(ned) in the USA: Popular Music and Censorship", Journal of Communication Inquiry, Vol. 15, p. 73-87.

Kater, Michael. (1992). Different Drummers: Jazz in the Culture of Nazi Germany. New York: Oxford Univeristy Press. 
Katz, Mark. (2004). Capturing sound: how technology has changed music. Berkeley: University of California Press.

Kendrick, Robert. (1996). Celestial Sirens: Nuns and Their Music in Early Modern Milan. Oxford: Oxford University Press.

Koenig, Karl, ed. (2002). Jazz in Print (1856-1929): An Anthology of Selected Early Readings in Jazz History. Hillsdale, New York: Pendragon Press.

Korpe, Marie, ed. (2004). Shoot the Singer! Music censorship today. London: Zed Books.

Kraft, James P. (1995). "Artists as Workers: Musicians and Trade Unionism in America, 1880-1917”, The Musical Quarterly, Vol. 79, No. 3 (Autumn), p. 512-543.

Krebs, Stanley. (1970). Soviet Composers and the Development of Soviet Music. London: George Allen and Unwin.

Kretschmer, Martin, et al. (2001). "Music in Electronic Markets: An Empirical Study", New Media Society, Vol. 3, p. 417-441.

Lawrence, John S. (1987). "The Diatonic Scale: More Than Meets the Ear", The Journal of Aesthetics and Art Criticism, Vol. 46, No. 2 (Winter), pg. 281-291.

Liebowitz, Stanley. (2003). "Alternative Copyright Systems: The Problems with a Compulsory License". Conference talk delivered to the Progress and Freedom Foundation, School Of Management, University of Texas at Dallas (10 June). Available at: http://www.utdallas.edu/ liebowit/intprop/complpff.pdf

Leichtentritt, Hugo. (1944). "The Reform of Trent and Its Effect on Music", The Musical Quarterly, Vol. 30, No. 3 (July), p. 319-328.

Lessig, Lawrence. (2006). "Foreword", Podcasting Legal Guide, version 1.0, in CreativeCommons.org. Available at: http://mirrors.creativecommons.org/Podcasting_Legal_Guide.pdf . (2004). Free Culture: How Big Media Uses Technology and the Law to Lock Down Culture and Control Creativity. New York: Penguin Press. . (1999). Code: and other laws of cyberspace. New York: Basic Books. Levi, Erik. (2004). "The Censorship of Musical Modernism in Germany, 1918-1945”, in Censorship and cultural regulation in the modern age, ed. Beate Müller, p. 63-85. New York: Rodopi. 
Leyshon, Andrew, and Peter Webb, Shaun French, Nigel Thrift, Louise Crewe. (2005). "On the reproduction of the musical economy after the Internet", Media, Culture \& Society, Vol. 27, 177-209.

Leyshon, Andrew, et al. (1998). "Music, Space and the Production of Place", in The Place of Music, ed. Leyshon, Andrew et al, p. 1-30. New York: Guilford.

Lipietz, Alain. (1987a). Mirages and Miracles. London: Verso.

. (1987b). "Rebel Sons: the Regulation School", interview conducted by Jane Jenson, in French Politics and Society, Vol. 5, No. 4 (September).

Litman, Jessica. (2001). Digital copyright: protecting intellectual property on the Internet. Amherst, NY: Prometheus Books.

Lockwood, Lewis. (1975). Palestrina: Pope Marcellus Mass. New York: Norton. . (1966). "Some Observations on the Commission of Cardinals and the Reform of Sacred Music (1565)," Quadrivium, Vol. 7, p. 41-44. . (1957). "Vincenzo Ruffo and Musical Reform after the Council of Trent”, The Musical Quarterly, Vol. 43, No. 3 (July), p. 342-371.

Lovering, John. (1998). "The Global Music Industry: Contradictions in the Commodification of the Sublime", in The Place of Music, ed. Leyshon, Andrew et al, p. 31-56. New York: Guilford.

Lynxwiler, John and David Gay. (2000). "Moral boundaries and deviant music: public attitudes toward heavy metal and rap", Deviant Behavior: An Interdisciplinary Journal, Vol. 21, p.63-85.

Marvin, Roberta Montemorra. (1992). Verdi's I Masnadieri: Its Genesis and Early Reception. (Ph. D. dissertation). Boston: Brandeis University.

Marx, Karl. (1859/1973). "A contribution to the critique of political economy", in Karl Marx: selected writings in sociology and social philosophy, trans. by Martin Nicolaus. Harmondsworth: Penguin.

McDonald, J. (1988). "Censoring Rock Lyrics: A Historical Analysis of the Debate”, Youth and Society, Vol. 19, p. 294-313.

McGuire, Mike and Derek Slater. (2005). "Consumer Taste Sharing Is Driving the Online Music Business and Democratizing Culture". Report for The Berkman Center for Internet \& Society, Harvard Law School. (13 December). Available at: http://cyber.law.harvard.edu/home/uploads/511/11-ConsumerTasteSharing.pdf 
McLeod, Kembrew. (2001). "Owning culture: authorship, ownership, and intellectual property law", in Popular culture \& everyday life, Vol. 1, New York: P. Lang.

McMahon, J. R. (1921). “Unspeakable jazz must go", Ladies' Home Journal, (December), p. 34, 115-116.

Meisel, John and Timothy Sullivan. (2002). "The impact of the Internet on the law and economics of the music industry", Info - The Journal of Policy, Regulation and Strategy for Telecommunications, Vol. 4, No. 2 (1 April), p.16-22.

Miron, Jeffrey A. and Jeffrey Zwiebel. (1991). "Alcohol Consumption During Prohibition." American Economic Review, Vol. 81, No. 2, p. 242-247.

Mitchell, Rebecca. (2004). Music and Politics in the Soviet Union: From Revolution to reaction (1917 - 1936). M.A. Thesis. Ottawa: Carleton University.

Monson, Craig A. (2003). "The Composer as 'Spy': The Ferraboscos, Gabriele Paleotti, and the Inquisition", Music and Letters, Vol. 84, No. 1, (February), p. 1-18.

(2002). "The Council of Trent Revisited", Journal of the American Musicological Society, Vol. 55, No. 1 (Spring), p. 1-37.

(1992). "Disembodied Voices: Music in the Nunneries of Bologna in the midst of the Counter-Reformation", in The Crannied Wall: Women, Religion, and the Arts in Early Modern Europe. Studies in Medieval and Early Modern Civilization, p. 191-209. Ann Arbor: University of Michigan Press.

Mosco, Vincent. (1996). The political economy of communication rething and renewal. Thousand Oaks: Sage Publications.

Murray, Andrew and Colin Scott. (2002). "Controlling New media: Hybrid Responses to New Forms of Power”, Modern Law Review, Vol. 65, No. 4 (July), p. 491-516.

Norris, Chris. (1982). Shostakovich: The Man and His Music. London: Faber.

Nuzum, Eric. (2004). "Crash into me, baby: America's implicit music censorship since 11 September", in Shoot the Singer! Music censorship today, ed. Marie Korpe, p. 149159. London: Zed Books.

O'Regan, Noel. (1994). "Palestrina, a Musician and Composer in the Market-Place", Early Music, Vol. 22, No. 4 (Palestrina Quatercentenary, November), p. 551-571.

Phillips, Peter. (1994). "Reconsidering Palestrina", Early Music, Vol. 22, No. 4 (November), p. 574-585. 
Plato (360 B.C.). Republic, Book IV. Translated by Benjamin Jowett, 1871. Available at: http://reactor-core.org/republic.html

Raboy, Marc. (2006). "Making Media: Creating the Conditions for Communication in the Common Good", in Canadian Journal of Communication, Vol. 31, p. 289-306.

Reese, Gustave. (1954). Music in the Renaissance. New York: Norton.

Roads, Curtis. (1986). "Symposium on Computer Music Composition: Introduction", in Computer Music Journal, Vol. 10, No. 1, (Spring), p. 40-63...

Rodman, Gilbert B. and Cheyanne Vanderdonckt. (2006). "Music for nothing or, I want my MP3: The regulation and recirculation of affect", Cultural Studies, Vol. 20, No. 2/3 (March/May), p. 245-261.

Saint-Saëns, Camille. (1915/1997). "From the Archive: Now and Then", The Musical Times, Vol. 138, No. 1856. (October; reprinted from 1915), p. 31-35.

*Schatz, Klaus. (1996). Papal primacy: from its origins to the present, translated by J.A. Otto. Collegeville, MN: Liturgical press.

Scherzinger, Martin. (2005). "Music, Corporate Power, and Unending War", Cultural Critique, Vol. 60 (Spring), p. 23-67.

Shaw, Arnold. (1977). 52 ${ }^{\text {nd }}$ Street: The Street of Jazz. New York: DaCapo.

Sherr, Richard. (1994). "Competence and Incompetence in the Papal Choir in the Age of Palestrina”, Early Music, Vol. 22, No. 4 (Palestrina Quatercentenary, November), p. 606629.

. (1984). "A Letter from Paolo Animuccia: A Composer's Response to the Council of Trent”, Early Music, Vol. 12, No. 1 (February), p. 74-78.

Society of St. Gregory. (1928). The White List: With a Selection of Papal documents and other information pertaining to Catholic Church Music. Glen Rock, N.J.: Society of St. Gregory of America.

Starr, S. Frederick. (1983). Red \& Hot: The Fate of Jazz in the Soviet Union, Oxford, Oxford University Press.

Steinmetz, George. (1994). "Regulation Theory, Post-Marxism, and the New Social Movements" in Comparative Studies in Society and History, Vol. 36, No. 1 (January).

Sterne, Jonathan. (2003). "Bureaumentality", in Foucault, Cultural Studies, and Governmentality. p. 101-133. Chicago: University of Chicago Press. 
Stravinsky, Igor (1947). Poetics of Music. New York: Alfred A. Knopf. (Lectures delivered in 1939-1940)

Straw, Will. (1996). "Sound Recording", in The Cultural Industries in Canada. Toronto: Lorimer, p. 95-117.

Street, John. (2003). "Fight the Power': The Politics of Music and the Music of Politics", in Government and Opposition Ltd., p. 113-130. London: Blackwell.

Tanner, Norman P., ed. (1990). Decrees of the Ecumenical Councils, Vol. 2, Trent to Vatican II. Washington, D.C.: Georgetown University Press.

Taylor, Brian, et al. (2002). "New Media and the Circuit of Cyber-Culture: Conceptualizing Napster", Journal of Broadcasting and Electronic Media, (December), p. 607-629.

Terpstra, Nicholas, ed. (2000). The politics of ritual kinship: confraternities and social order in early modern Italy. Cambridge: Cambridge University Press.

Théberge, Paul. (2004). "Technology, Creative Practice and Copyright", in Frith and Marshall, ed., Music and Copyright, $2^{\text {nd }}$ ed., p. 139-156. Edinburgh: Edinburgh University Press.

. (1997). Any sound you can imagine: making music/consuming

technology. Hanover, NH: Wesleyan University Press.

Thompson, Kenneth and Anita Sharma. (1998). "Secularization, Moral Regulation and the Mass Media”, The British Journal of Sociology, Vol. 49, No. 3 (September), p. 434455.

Thompson, Kenneth (ed). (1997). "Regulation, De-regulation and re-regulation", in Media and Cultural Regulation, p. 10-52. London: Sage Publications.

Trosow, Samuel E. (2003). "The Illusive Search for Justificatory Theories: Copyright, Commodification and Capital", Canadian Journal of Law and Jurisprudence, Vol. 16, p. 217-241.

Vaidhyanathan, Sida. (2004). The Anarchist in the Library. New York: Basic Books. . (2001). Copyrights and copywrongs: the rise of intellectual property and how it threatens creativity. New York: New York University Press.

Washburne, Christopher. (2004). "Does Kenny G Play Bad Jazz? A Case Study”, in Bad Music: The Music We Love to Hate. p. 123-147. New York: Routledge. 
Welburn, Ron. (1987) "James Reese Europe and the Infancy of Jazz Criticism", Black Music Research Journal, Vol. 7, p. 35-44.

Williams, Raymond. (1977). "Dominant, Residual and Emergent", in Marxism and Literature, p. 121-127. Oxford: Oxford University Press,

Wilson, Elizabeth. (1994). Shostakovich: A Life Remembered. London: Faber.

\section{Other resources:}

Burns, Ken. (2001). Jazz: A Film By Ken Burns. Episode Two: The Gift. New York: PBS Home Video (10 video set).

CBC. (2007). Censor this! Radio series (taped) from CBC Radio One and Two, week of 18 - 24 February 2007. Programs included Choral Concert, 18 February 2007, 8:00 am 10:00 am (Radio Two); Global Village, 22 February 2007, 8:00 pm - 9:00 pm (Radio One); In Performance, $20^{\text {th }}$ and $22^{\text {nd }}$ February $2007,8: 00 \mathrm{pm}-10: 00 \mathrm{pm}$ (Radio Two); Definitely Not the Opera, 24 February 2007, 1:00 pm - 3:00 pm (Radio One).

McGill. (2007). Talk from "Musical Myopia, Digital Dystopia: New media and Copyright Reform", conference on Copyright Challenges in the Digital era, on 23 March 2007 at McGill Centre for Intellectual Property Policy and Schulich School of Music. Panelists: Professor Terry Fisher from Harvard (founder of Noank Media), Bruce Lehman (drafted the US DMCA), Professor Michael Geist (University of Ottawa), Sandy Pearlman (sound producer, guest lecturer at McGill). Webcast available at: http://mediasite.campus.mcgill.ca/mediasite2/viewer/Viewer.aspx?layoutPrefix=LayoutT opLeft\&layoutOffset $=$ Skins/Clean\&width $=800 \&$ height $=631$ \&peid $=6 \mathrm{e} 197 \mathrm{c} 68-0 \mathrm{~b} 63-$ 4474-ac3b-f770e220de0e\&pid=2276b8bb-0299-4f9e-9be8d83d3539f313\&pvid=501\&mode=Default\&shouldResize $=$ false\&playerType=WM7\#

McGill. (2006). Presentation from the Sixth Annual Future of Music Policy Summit conference, October 5-7, 2006, at McGill University, Schulich School of Music, Montreal. Speaker: Professor William Fisher (Harvard) on NOANK, and panel discussing NOANK model and other online business models.

\section{Websites:}

www.Artistshare.com

Website for Artistshare, a service for musicians using a "fan-based" funding model that allow audiences to directly finance creators' projects without involvement by the record labels.

www.Attali.com (Jacques Attali's website)

Reference/introduction to his book Noise: the political economy of music, in his blog, dated April 2000. 
www.Freemuse.org

Website focusing on global music censorship issues. Freemuse stands for "freedom of musical expression".

www.NoankMedia.com

Website for Noank Media Inc., an example of a working Alternative Compensation System.

www.Sheeba.ca/store/help.php\#sdp (Music website for Sheeba, formerly Jane Sibbery) Explanation of "Self-determined Pricing" 